Eduardo Sylvestre Lopes de Oliveira

\title{
Sistemas Inteligentes Aplicados no Controle e na Obtenção de Indutância de Um Gerador a Relutância Chaveado
}

Tese de Doutorado apresentada à Escola de Engenharia de São Carlos da Universidade de São Paulo, sendo parte dos requisitos para obtenção do título de Doutor em Ciências, Programa de Engenharia Elétrica.

Área de Concentração: Sistemas Dinâmicos Orientador: Prof. Dr. Ivan Nunes da Silva

\section{São Carlos}

2015 
AUTORIZO A REPRODUÇÃO TOTAL OU PARCIAL DESTE TRABALHO, POR QUALQUER MEIO CONVENCIONAL OU ELETRÔNICO, PARA FINS DE ESTUDO E PESQUISA, DESDE QUE CITADA A FONTE.

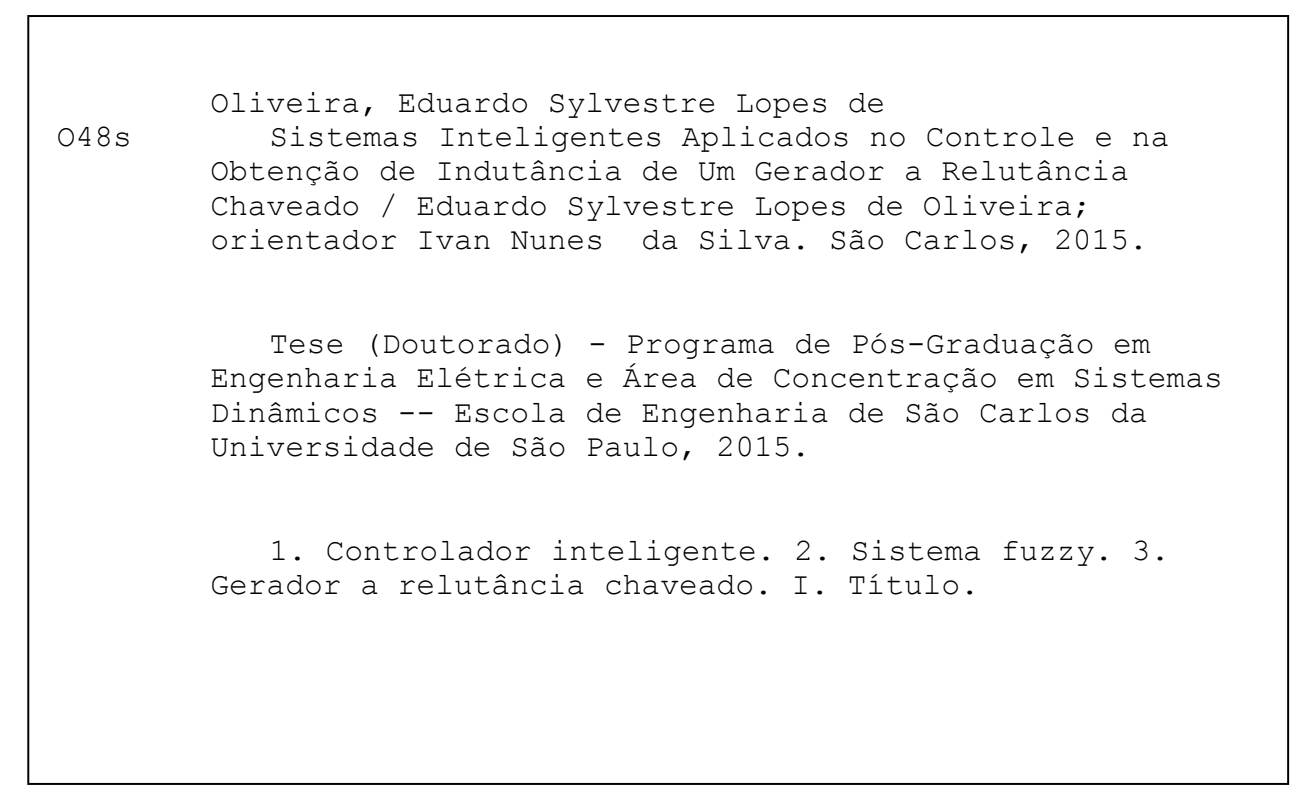


FOLHA DE JULGAMENTO

Candidato: Bacharel EDUARDO SYLVESTRE LOPES DE OLIVEIRA.

Título da tese: "Sistemas inteligentes aplicados no controle e na obtenção de indutância de um gerador a relutância chaveado".

Data da defesa: 04/08/2015

Comissão Julgadora:

Prof. Associado Ivan Nunes da Silva (Orientador)

(Escola de Engenharia de São Carlos/EESC)

Prof. Associado Diógenes Pereira Gonzaga

(Escola de Engenharia de São Carlos/EESC)

Prof. Dr. Darizon Alves de Andrade

(Universidade Federal de Uberlândia/UFU)

Prof. Dr. Manoel Luís de Aguiar

(Escola de Engenharia de São Carlos/EESC)

Prof. Dr. Augusto Fleury Veloso da Silveira

(Universidade Estadual de Goiás/UEG)
Resultado:
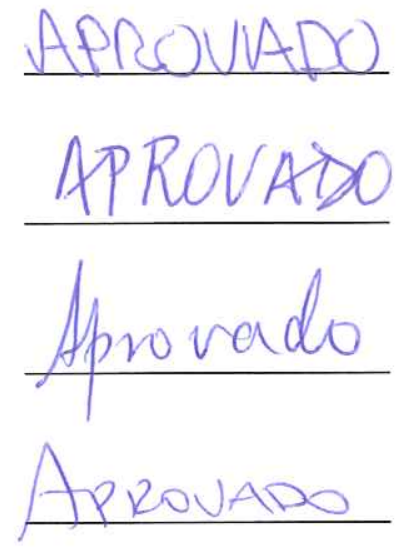

Aparvado

Coordenador do Programa de Pós-Graduação em Engenharia Elétrica:

Prof. Associado Luis Fernando Costa Alberto

Presidente da Comissão de Pós-Graduação:

Prof. Associado Paulo César Lima Segantine 

"Omnia Vincit Labor - Nada resiste ao trabalho." Euryclides de Jesus Zerbini $(1912-1993)$ 



\section{Agradecimentos}

Ao Prof. Dr. Ivan Nunes da Silva que agradeço pela orientação acadêmica e pelos ensinamentos para elaboração de projetos e artigos.

Ao Prof. Dr. Manoel Luis de Aguiar que atuou como co-orientador e, portanto, contribuiu de forma efetiva para o desenvolvimento do projeto. Graças ao seu brilhantismo, pensamento rápido e ideias inteligentes este trabalho pode ser confeccionado.

Aos amigos de laboratório LACEP e LAIPS, os quais não citarei nomes para não correr o risco de esquecer algum.

Aos funcionários da Universidade de São Paulo (USP/EESC/SEL), em especial às secretárias de Pós-Graduação, Marisa, Daniel e Jussara.

À CAPES (Coordenação de Aperfeiçoamento de Pessoal de Nível Superior), pelo auxílio financeiro concedido no período de realização desta pesquisa na forma de bolsa de estudos. 



\section{SUMÁRIO}

Resumo

Abstract

Lista de Abreviaturas .........................................................................................

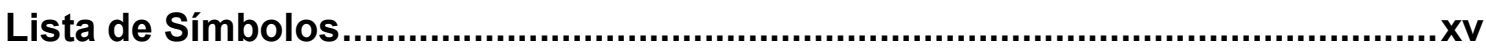

Lista de Figuras ..................................................................................................

Lista de Tabelas .............................................................................................ii

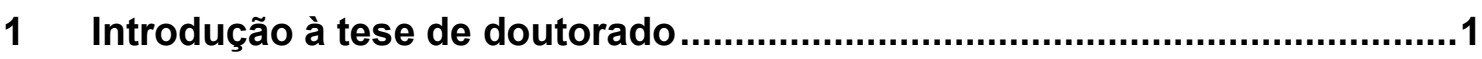

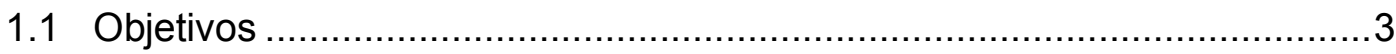

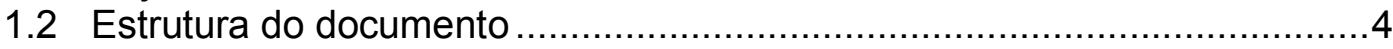

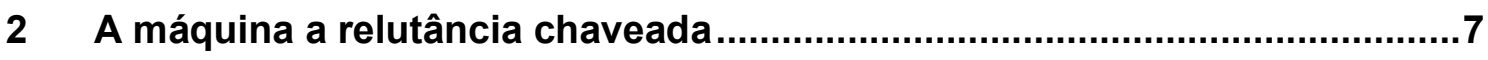

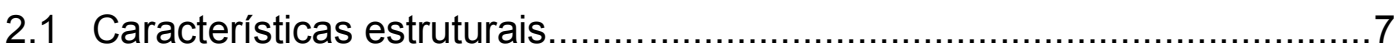

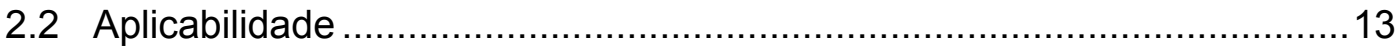

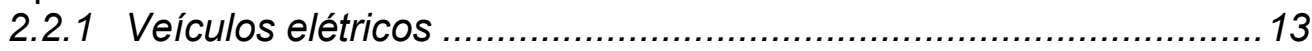

2.2.2 Motor-gerador de partida .................................................... 15

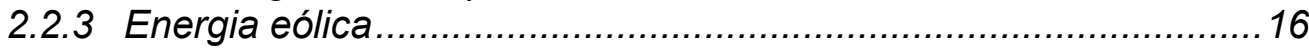

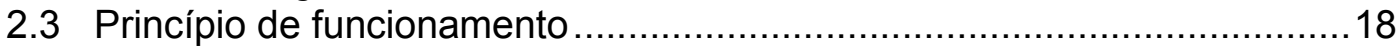

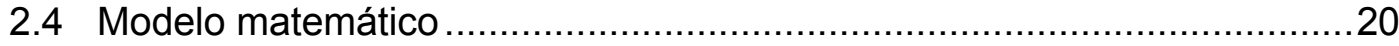

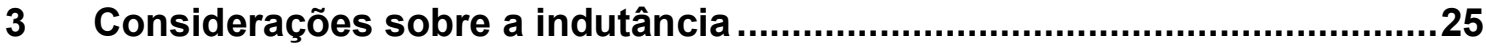

3.1 A indutância e aspectos construtivos do GRC ………........................25

3.2 A indutância em modelos computacionais .........................................28

3.3 Abordagem inteligente na detecção do perfil de indutância ........................31

3.3.1 Levantamento da base de dados ..............................................31

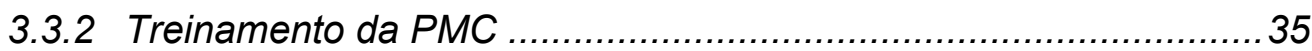

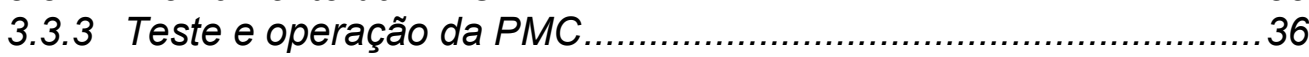

3.3.4 Resultados preliminares com a estratégia proposta .........................38

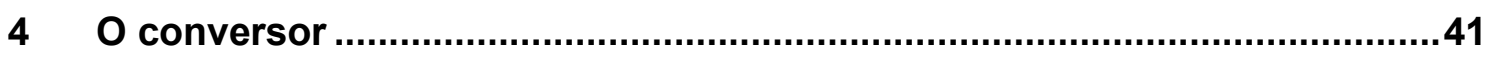

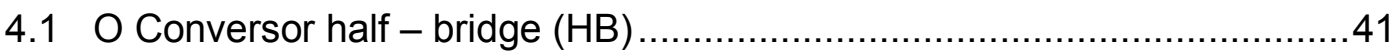

4.2 O conversor alternativo ..............................................................4

4.3 O conversor alternativo modificado (CAM) ......................................... 46

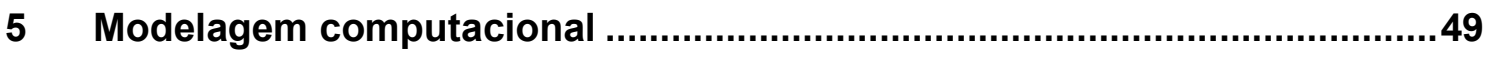

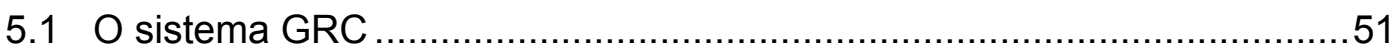

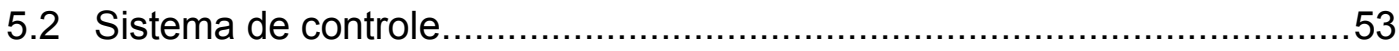

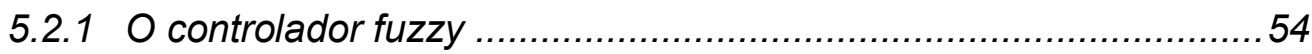

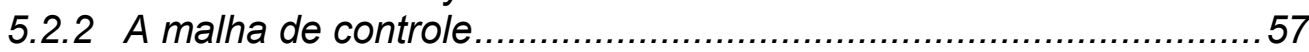

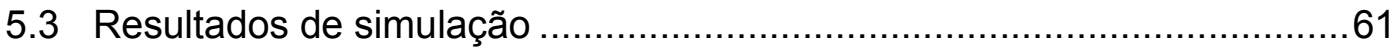

5.3.1 Resultados de simulação do SGRC em malha aberta ....................62

5.3.2 Resultados dinâmicos de simulação em malha fechada ................66 
5.3.3 Resultado de simulação do controlador fuzzy com carga e velocidade constante.

5.3.4 Resultado de simulação do controlador fuzzy com variação de velocidade.

5.3.5 Resultado de simulação do controlador fuzzy com variação de carga 79

6 Avaliações experimentais

6.1 Investigações experimentais do SGRC em malha aberta 85

6.2 Análise experimental em malha aberta da estratégia de controle adotada ..

6.3 Análise experimental do SGRC com controlador fuzzy .... 90

6.3.1 Controlador fuzzy embarcado em microprocessador ..................... 96

6.3.2 Bancada de testes ............................................................. 99

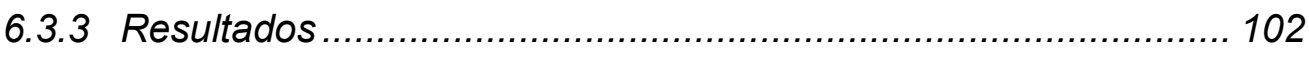

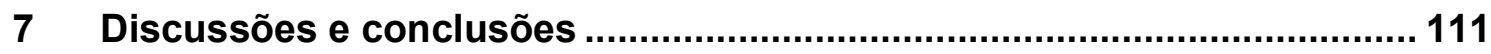

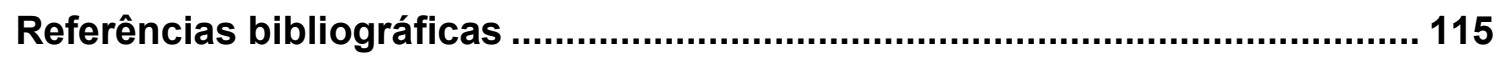




\section{Resumo}

OLIVEIRA, E. S. L. (2015). "Sistemas Inteligentes Aplicados no Controle e na Obtenção de Indutância de Um Gerador a Relutância Chaveado". Tese de Doutorado - Escola de Engenharia de São Carlos, Universidade de São Paulo, 2015.

Para acompanhar o atual crescimento de demanda energética mundial, novas topologias de geradores estão sendo pesquisadas, estando nesse nicho o Gerador a Relutância Chaveado. Para seu correto funcionamento é necessário que técnicas de controle sejam empregadas para garantir níveis estáveis de tensão gerada mediante variações de velocidade e/ou carga. Portanto, o objetivo deste trabalho é apresentar uma metodologia de um controlador fuzzy da tensão gerada para a máquina em questão. Uma simulação em Matlab Simulink é apresentada para um sistema de geração de energia utilizando um gerador a relutância chaveado integrada com a malha de controle fuzzy. Resultados da dinâmica do funcionamento do controlador fuzzy são apresentados. O Controlador fuzzy proposto apresentou bom desempenho ao manter a tensão gerada em níveis desejáveis frente a distúrbios de carga e de variação de velocidade no eixo do gerador. Trata-se de um controlador robusto e versátil que garante estabilidade de tensão gerada mesmo com a operação do sistema com velocidade variável e/ou variação de carga.

Palavras Chave: Controlador inteligente, sistema fuzzy, gerador a relutância chaveado. 



\section{Abstract}

OLIVEIRA, E. S. L. (2015). "Intelligent Systems Applied in Control and obtaining inductance of a Switched Reluctance Generator". Doctor Thesis - Engineering School of São Carlos, University of São Paulo, 2015.

Due to the growing demand of electric power energy, the engineering has to evolve by producing new efficient techniques and low cost equipment. Therefore, new electric power generator topologies have been studied, mainly switched reluctance generators due to their simple structure, reliability and low cost of fabrication. In order for a good operation of a switched reluctance generator, control techniques have to be applied to guarantee stable voltage levels under variable speed and load conditions. Hence, the objective of this work is to present a methodology based on fuzzy voltage controller for switched reluctance machine. Simulations are achieved in Matlab/Simulink for a power energy generation system using a switched reluctance generator with a fuzzy control loop. Results of the dynamic response of such controller are presented. The fuzzy controller could obtain good performance maintaining voltage levels in desired range. Therefore, the proposed controller showed to be robust, versatile and guarantee the voltage stability under speed and load variations.

Keywords: Intelligent Controller, Fuzzy System, Switched Reluctance Generator. 



\section{Lista de Abreviaturas}

A Unidade de corrente no SI - Ampère

AWG Escala americana normalizada para cabos e fios, do inglês:

American Wire Gauge

C1 Capacitor de saída para amortecer oscilações na carga

CA Corrente Alternada

CAM Conversor Alternativo Modificado

CC Corrente Contínua

D Razão Cíclica de D0

D0 Diodo de roda livre do conversor estático

D1 Diodo da fase 1 do conversor estático

D2 Diodo da fase 2 do conversor estático

D3 Diodo da fase 3 do conversor estático

F $\quad$ Unidade de capacitância no SI - Faraday

FCEM Força contra-eletromotriz

GRC Gerador a Relutância Chaveado

H Unidade de indutância no SI - Henry

HB Conversor meia ponte assimétrica, do inglês: half bridge

MOSFET Transistor de efeito de campo de metal-óxido semicondutor

MRC Máquina a Relutância Chaveada

P Sinal de disparo das chaves controladas

PMC Percepton Multicamadas

PWM Modulação por largura de pulso, do inglês: Pulse Width

Modulation 


$\begin{array}{ll}\text { Q0 } & \text { Chave controlada para controle de tensão do conversor } \\ & \text { estático } \\ \text { Q1 } & \text { Chave controlada da fase 1 do conversor estático } \\ \text { Q2 } & \text { Chave controlada da fase } 2 \text { do conversor estático } \\ \text { Q3 } & \text { Chave controlada da fase } 3 \text { do conversor estático } \\ \text { k } & \text { Fator multiplicativo } \\ \text { R1 } & \text { Resistência de carga } \\ \text { rad/s } & \text { Unidade de velocidade angular no SI - Radianos por } \\ & \text { segundos } \\ \text { SGRC } & \text { Sistema de Geração de energia com um gerador a } \\ & \text { Relutância Chaveado } \\ \text { V } & \text { Unidade de tensão no SI - Volts } \\ \Omega & \text { Unidade de resistência no SI - Ohm }\end{array}$




\section{Lista de Símbolos}

D

$i_{j}$

$J$

$L_{j}$

$L_{\max }$

$L_{\min }$

$R$

$R_{j}$

$s$

$t$

$T_{m}$

$T_{\text {emag }}$

$V_{j}$

$\alpha_{j}$

$\frac{d i_{j}}{d t}$

$\frac{d \theta}{d t}$

$\frac{\partial i_{j}}{\partial t}$

$\frac{\partial \lambda_{f}}{\partial t}$
Coeficiente de atrito viscoso

Corrente da fase $j$

Momento de inércia

Indutância de fase

Máxima indutância da fase

Mínima indutância da fase

Resistência ôhmica

Resistência da fase $j$

Segundos

Tempo

Conjugado mecânico

Conjugado eletromagnético

Tensão da fase $j$

Variável auxiliar da matriz de estados da fase $j$

Derivada temporal da corrente na bobina da fase $j$

Variação da posição angular do rotor em relação ao tempo

Derivada parcial da corrente na bobina da fase $j$

Derivada parcial do fluxo magnético na bobina da fase $j$ 


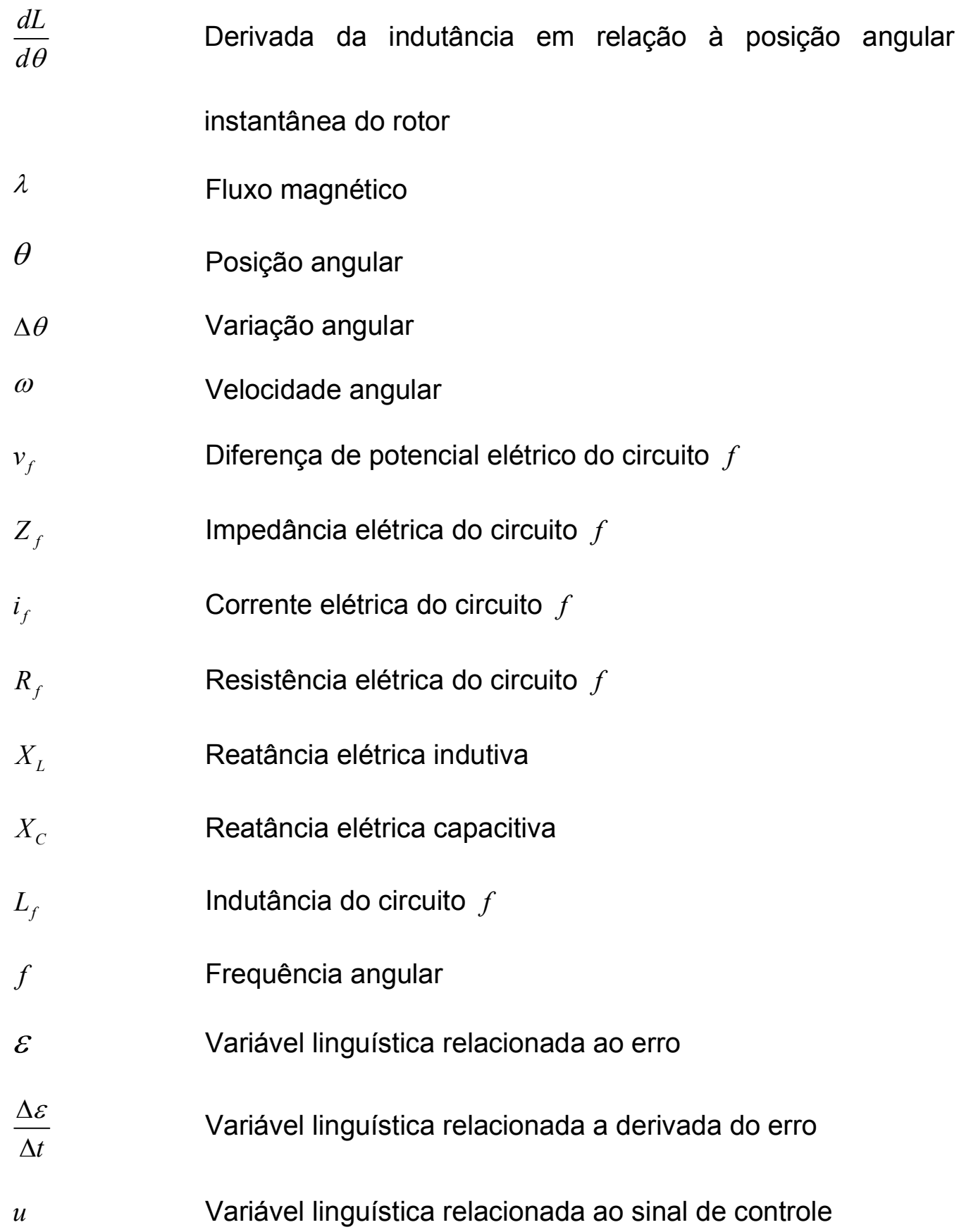




\section{Lista de Figuras}

Figura 1 - Estrutura em dupla saliência de uma MRC 6 x $4 \ldots \ldots \ldots \ldots \ldots \ldots \ldots \ldots \ldots \ldots \ldots$

Figura 2 - Perfil trapezoidal ideal de indutância ......................................... 19

Figura 3 - Arranjo duplo saliente do GRC e perfil de indutância para a posição alinhada.

Figura 4 - Arranjo duplo saliente do GRC e perfil de indutância para a posição desalinhada.

Figura 5 - Arranjo duplo saliente do GRC e perfil de indutância para as posições intermediárias

Figura 6 - Perfil trapezoidal e perfil triangular idealizado de indutância .29

Figura 7 - Perfil idealizado e perfil senoidal de indutância. 30

Figura 8 - Protótipo GRC 6 x 4 Trifásico. 32

Figura 9 - Curva de indutância real obtida por meio de um protótipo GRC. 34

Figura 10 - Topologia de PMC usada para a aproximação da indutância................36

Figura 11 - Superfície de indutância obtida por meio da PMC . ...........................37

Figura 12 - Perfil de indutância por estratégia neural e forma de onda de corrente para o GRC

Figura 13 - Tensão no barramento de saída (a) e corrente na fase do GRC (b) obtidos por meio do modelo neural que incorpora saturação magnética. 39

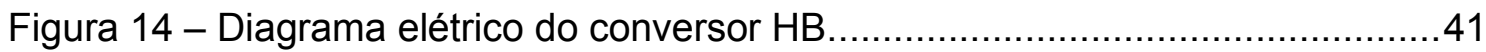

Figura 15 - Circuito de excitação do conversor HB. ....................................42

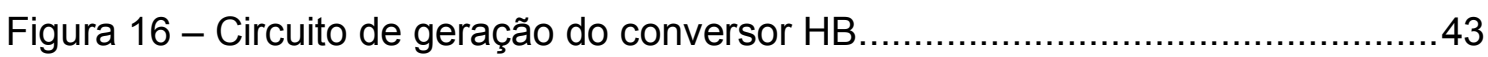

Figura 17 - Diagrama elétrico do conversor alternativo. ...............................44

Figura 18 - Circuito de excitação do conversor alternativo................................45

Figura 19 - Circuito de geração do conversor alternativo. ...............................46 
Figura 20 - Diagrama elétrico do conversor alternativo modificado. ....................... 47

Figura 21 - Circuito de roda livre do conversor alternativo modificado. ................... 47

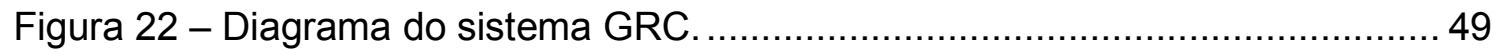

Figura 23 - Diagrama simulink do SGRC em malha aberta................................. 52

Figura 24 - Perfil de indutância com saturação magnética obtida por meio de uma

PMC

Figura 25 - Estratégia de modulação da chave Q0 do CAM...................................53

Figura 26 - Diagrama do controlador fuzzy. ………….................................... 55

Figura 27 - Variável linguística relacionada ao erro.................................................5 55

Figura 28 - Variável linguística relacionada à derivada temporal do erro. ............... 56

Figura 29 - Variável linguística relacionada a variável de controle (u)....................56

Figura 30 - Perfil de tensão de saída com velocidade variável em malha aberta. ...58

Figura 31 - Perfil de tensão de saída com variação de carga. .................................. 59

Figura 32 - Sistema GRC com malha de controle............................................... 60

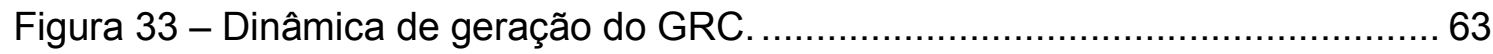

Figura 34 - Dinâmica de funcionamento da fase do GRC................................... 64

Figura 35 - Dinâmica de funcionamento das três fases do GRC............................ 64

Figura 36 - Tensão e corrente do barramento CC de entrada................................6 65

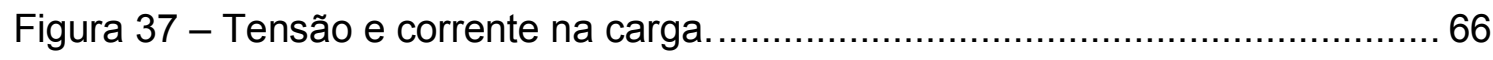

Figura 38 - Diagrama Simulink do sistema de controle fuzzy. .............................. 67

Figura 39 - Dinâmica de funcionamento de uma fase do GRC com malha de controle

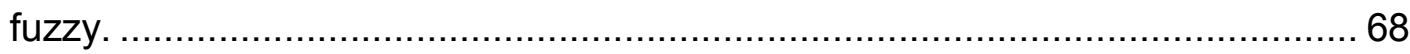

Figura 40 - Comparativo de corrente de excitação com o conversor alternativo e o

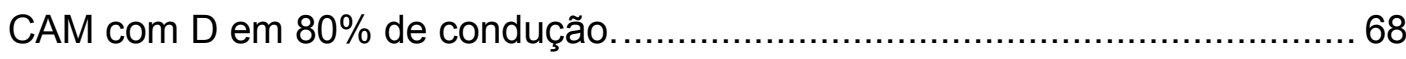

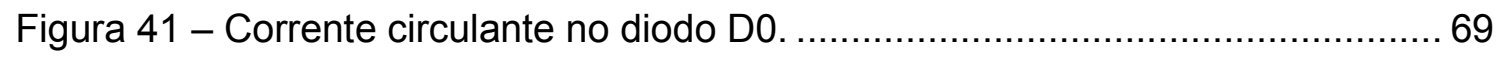


Figura 42 - Tensão e corrente na fonte de excitação do SGRC com controlador fuzzy. 70

Figura 43 - Influência do sinal de controle na tensão e na corrente de fase. .71

Figura 44 - Perfil de tensão da saída com velocidade de 1800 rpm em malha aberta e com controlador fuzzy.

Figura 45 - Perfis de tensão de saída com velocidade de 1800 rpm e controlador fuzzy para referências de $40 \mathrm{~V}$ e $60 \mathrm{~V}$. .74

Figura 46 - Tensão de saída do GRC em malha fechada com variação da tensão de referência. .75

Figura 47 - Perfis de tensão de saída em malha aberta com velocidades de 1000 rpm, 2000 rpm, 3000 rpm, 4000 rpm e 5000 rpm .76

Figura 48 - Perfil de Tensão de saída com controlador fuzzy para velocidade de $3000 \mathrm{rpm}$ .77

Figura 49 - Variação de velocidade em forma de degrau. .78

Figura 50 - Tensão de saída em malha aberta e em malha fechada. 79

Figura 51 - Tensão de saída para cargas de $11.1 \Omega, 16.1 \Omega$ e $21.1 \Omega$ em malha aberta .80

Figura 52- Tensão de saída para cargas de $11.1 \Omega, 16.1 \Omega$ e $21.1 \Omega$ com controlador fuzzy. .81

Figura 53 - Tensão de saída com variação de carga e atuação do controlador fuzzy.

Figura 54 - Bancada experimental de testes em malha aberta. ...........................86

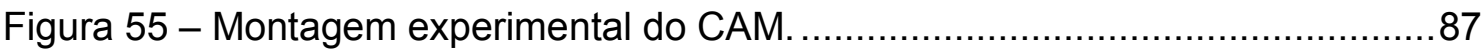

Figura 56 - Tensão e corrente na entrada do GRC em malha aberta. ……….........88

Figura 57 - Dinâmica de funcionamento de uma fase do GRC em malha aberta.....89 
Figura 58 - Tensão e corrente na saída do GRC em malha aberta. ....................... 90

Figura 59 - Módulo PWM analógico implementado. ....................................... 91

Figura 60 - Tensão e corrente na fase do GRC com modulação de Q0 em 50\%....92

Figura 61 - Corrente na fonte de excitação e corrente no diodo D0. ......................93

Figura 62 - Corrente em uma fase do GRC com variação da janela de condução de Q0. 94

Figura 63 - Resultados relacionando tensão de saída, razão cíclica (D), e a carga.94

Figura 64 - Resultados relacionando tensão de saída, razão cíclica (D) e a velocidade. 95

Figura 65 - Diagrama de blocos do controlador fuzzy de tensão para o sistema GRC.

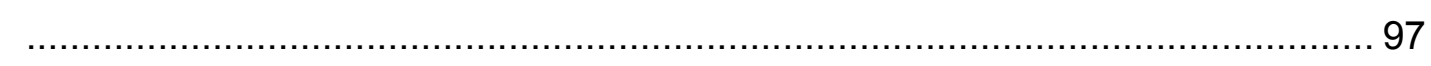

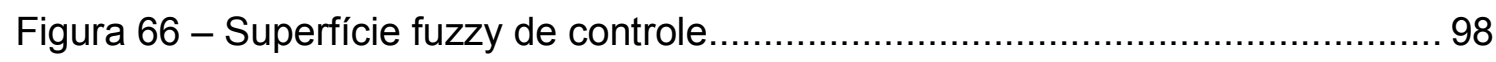

Figura 67 - Vista frontal da bancada experimental ...................................... 100

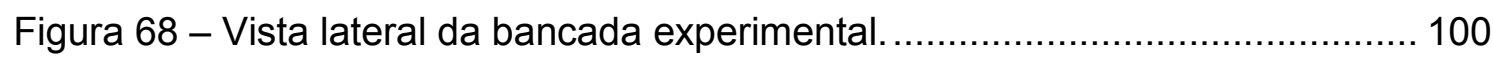

Figura 69 - Diagrama de blocos da banca experimental do sistema GRC com controlador fuzzy. 101

Figura 70 - Tensões de saída do SGRC para $30 \mathrm{~V}$ e $50 \mathrm{~V}$ de tensões referência. 103 Figura 71 - Razão Cíclica da chave Q0 para tensões referência de 30 V e 50 V. . 103 Figura 72 - Tensões e corretes de saída do GRC para tensões de excitação $80 \mathrm{~V}$ e $100 \mathrm{~V}$ 105

Figura 73 - Razão cíclica da chave Q0 para tensões de excitação de 80 V e 100 V. 105

Figura 74 - Tensões e correntes na saída do GRC para 1800 rpm e 3000 rpm de velocidade. 106

Figura 75 - Razão cíclica de Q0 para 1800 rpm e 3000 rpm de velocidade. 107 
Figura 76 - Dinâmica de tensão e corrente sobre variação de carga em malha

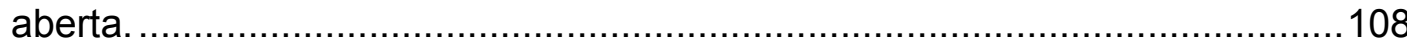

Figura 77 - Dinâmica de tensão e corrente sobre variação de carga com atuação do controlador fuzzy de tensão. 109 



\section{Lista de Tabelas}

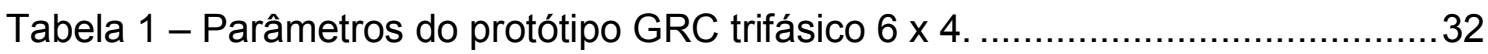

Tabela 2 - Nomenclatura dos termos primários.......................................55

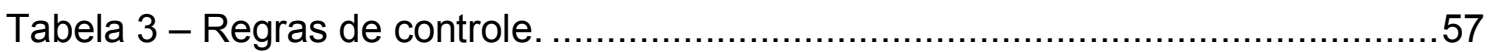





\section{Introdução à tese de doutorado}

O constante crescimento no consumo global de energia faz com que a geração de energia se desenvolva tendendo a acompanhar esse acréscimo, a fim de atender a demanda exigida. Com isso, um dos desafios é conseguir melhorar a eficiência dos equipamentos utilizados nos sistemas de geração e, por consequência, diminuição dos custos. Portanto, a engenharia tem que se recriar, com novas instigações e frentes de pesquisa para conseguir alavancar a demanda mundial instalada.

O atual sistema nacional de geração de energia consiste em grandes fontes geradoras que normalmente estão distantes das fontes consumidoras. Logo, o sistema elétrico é caracterizado por apresentar longas linhas de transmissão proporcionando quantidades significativas de perdas. Uma alternativa para evitar as perdas da transmissão, e que está acontecendo a pelo menos cinco anos, é a alocação de médias e pequenas fontes geradoras de energia próximas às grandes fontes consumidoras.

Comumente, nos sistemas de geração de energia elétrica, seja ele de grande, médio ou pequeno porte há sempre uma máquina síncrona ou de indução responsável por transformar a energia mecânica em energia elétrica. Porém, devido ao aperfeiçoamento da eletrônica de potência ao longo das décadas, estudos de novas topologias de geradores tornaram-se possíveis. 
Nesse aspecto, há uma crescente demanda de trabalhos da comunidade científica cujo foco principal é o estudo de novas topologias de máquinas voltadas para a geração de energia elétrica. Dentre essas máquinas, está o Gerador a Relutância Chaveado (GRC) por ser uma máquina de simples construção e apresentar um reduzido custo de fabricação.

Além do desenvolvimento da eletrônica de potência, o desenvolvimento do microprocessamento e do sensoriamento são outros fatores que favoreceram o desenvolvimento do estudo sobre GRC, principalmente para operação em velocidade variável, fazendo com que os GRC sejam candidatos de peso a serem empregados em pequenas fazendas eólicas de geração de energia. Adicionalmente, aproveitando-se do modo dual de funcionamento da máquina, há muitas pesquisas onde a Máquina a Relutância Chaveada (MRC) opera como motorgerador de partida.

Com as possibilidades de aplicação da máquina a relutância crescendo, a tendência é que um maior número de trabalhos investigando essa máquina aconteça de forma natural, pois há um crescente número de interessados em compreender o funcionamento e realizar as evoluções necessárias para que a máquina se torne uma realidade em sistemas de geração. Devido a isso, é possível encontrar um aumento significativo no número de trabalhos publicados sobre este conversor eletromecânico de energia, sendo a aplicação de técnicas de controle em GRC indispensáveis para que eles operem com resultados satisfatórios dentro de cada aplicação. 


\subsection{Objetivos}

Os objetivos gerais desta tese de doutorado consistem na investigação, desenvolvimento, projeto, implementação e validação de uma nova metodologia de controle inteligente que possa ser empregada em sistema de geração de energia com a utilização de um GRC, atuando como estabilizador da tensão de saída frente as perturbações no sistema causadas por: variação da fonte de excitação, variação de carga e variação de velocidade.

Já os objetivos específicos, estes podem ser definidos conforme apresentados na sequência:

1. Desenvolvimento de um conversor estático capaz de acionar o GRC e ao mesmo tempo possibilitar realizar o controle de tensão de saída;

2. Modelar o perfil de indutância do GRC utilizando redes neurais artificiais para a correta inserção de seus valores em modelos computacionais;

3. Realizar a modelagem computacional do GRC em malha aberta adequada ao novo conversor;

4. Realizar testes computacionais para constatar a dinâmica de funcionamento do GRC;

5. Desenvolver um controlador fuzzy capaz de manter a tensão gerada do sistema GRC estável;

6. Realizar a modelagem do controlador de tensão e inseri-lo no modelo computacional do GRC pré modelado em malha aberta;

7. Realizar testes computacionais e testar a funcionalidade do controlador fuzzy de tensão desenvolvido; 
8. Realizar a montagem e implementação de uma bancada de testes experimentais do GRC com malha de controle fuzzy;

9. Realizar ensaios do sistema GRC com o controlador fuzzy para a confirmação experimental de seu funcionamento.

Como resultado do trabalho deseja-se obter respostas sobre a funcionalidade desta máquina que possui características ímpares, e contribuir cientificamente com avanços tecnológicos a respeito de MRC quando geradores operando em conjunto com malha de controle de tensão.

\subsection{Estrutura do documento}

A disposição dos capítulos e conteúdo desta tese de doutorado se desenvolve da seguinte forma:

- Capítulo 2: apresenta um levantamento bibliográfico a respeito do tema. Traz um detalhamento da estrutura das MRC e sua importância para o seu correto funcionamento. Descreve com detalhes os princípios de funcionamento da MRC, apresentando sua modelagem matemática, mostrando vantagens e desvantagens e indicando as aplicações atuais das MRC;

- Capítulo 3: descreve o comportamento do perfil de indutância das MRC, e descreve as possíveis posições do arranjo duplo saliente. Descreve um ensaio experimental de rotor bloqueado. Por fim, descreve-se uma técnica neural para obter-se o perfil de indutância com influência da saturação magnética;

- Capítulo 4: apresenta topologia de conversores estáticos para acionamento do GRC. Destaca o conversor Half-Bridge, o conversor 
alternativo, e introduz uma nova topologia de conversor denominada conversor alternativo modificado. Os detalhes operacionais desses conversores são trabalhados neste capítulo;

- Capítulo 5: apresenta o modelo computacional realizado no software Matlab Simulink, o qual se configura em um modelo versátil, abrangendo todas as etapas de funcionamento da máquina, tanto em malha aberta quanto como a inserção do controlador fuzzy de tensão. Resultados de simulação em diversas partes do sistema são apresentados;

- Capítulo 6: Aborda as etapas para se conseguir realizar os ensaios experimentais do GRC com controlador fuzzy de tensão. Apresenta a montagem de uma banca de testes experimentais, com a qual foi possível realizar os ensaios. Resultados da dinâmica em malha aberta e com controlador fuzzy são apresentados, com destaque para o desempenho do controlador com o Sistema GRC (SGRC) sob perturbações de tensão de excitação, carga e velocidade

- Capítulo 7: apresenta as conclusões pertinentes ao trabalho, sendo que propostas para a continuidade do trabalho são também descritas.

- Referências Bibliográficas. 



\section{A máquina a relutância chaveada}

\subsection{Características estruturais}

No grande leque de topologias de máquinas elétricas, sejam elas de pequeno, médio ou grande porte, a MRC é caracterizada por apresentar um dos arranjos estruturais existentes mais simples, seja em sua parte mecânica ou elétrica (TEIXEIRA, 2008; FITZGERALD, 2003; OLIVEIRA, 2011). É composta por um arranjo duplo saliente de rotor e estator em aço laminados e maciços, e com enrolamentos de cobre restritos e concêntricos a cada dente do estator (KRISHNAN, 2001; MILLER, 1993; MILLER, 2001). Normalmente, os pares diametralmente opostos de dentes do estator são conectados em série e formam uma fase da máquina (TORREY, 2002; DIAS, 2011; SERAFIM, 2002), o que por conseguinte dará origem ao bipolo de magnetização da máquina. Construtivamente é um conversor eletromecânico de estrutura simples, podendo ser estudada em diversas configurações. Na Figura 1 é apresentada a estrutura de uma máquina do tipo $m \times n$, com seis dentes no estator e quatro dentes no rotor, onde $m$ e $n$ são os números de polos do estator e rotor, respectivamente. Nesta estrutura as MRC são polifásicas e as configurações $6 \times 4$, trifásica, e $8 \times 6$, tetrafásica são as comumente estudadas.

Além das estruturas polifásicas, ainda há a MRC monofásica, que são constituídas do mesmo número de polos no rotor e estator, ou seja, uma configuração do tipo $m \times m$. Em COELHO (2011) é apresentado um estudo comparativo de uma MRC monofásica, $6 \times 6$, e uma MRC trifásica, $6 \times 4$, ambas operando em modo gerador, onde se faz um estudo de funcionalidade e 
desempenho. Da mesma forma, em ANDRADE (2011) é mostrado o estudo comparativo de desempenho de duas MRC operando em modo motor, sendo uma monofásica, $6 \times 6$, e outra trifásica, $6 \times 4$. Em ambos os trabalhos, ANDRADE (2011) e COELHO (2011), notou-se dificuldades de operação das topologias monofásicas devido essas máquinas necessitarem maior capacidade de potência dos componentes semicondutores de seus acionamentos, o que, de certa forma, inviabiliza o desenvolvimento de testes eficazes. Portanto, essa justificativa é uma das premissas do porquê da comunidade científica se dedicar a pesquisar com mais detalhes as topologias polifásicas $m \times n$ da MRC.

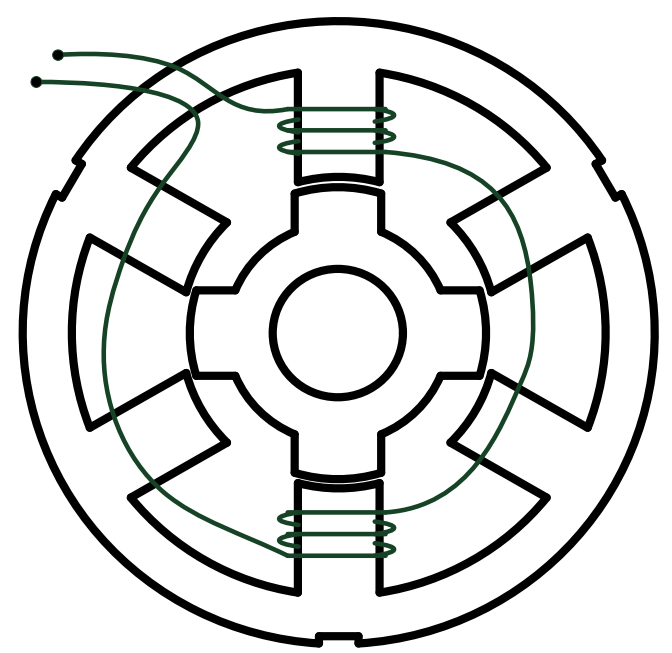

Figura 1 - Estrutura em dupla saliência de uma MRC 6 × 4 .

O fato da MRC constituir-se de enrolamentos restritos aos dentes do estator proporciona globalmente menor perda por efeito Joule. Este arranjo possibilita a ausência de escovas de contato, que juntamente com a ausência de imãs permanentes garante maior confiabilidade e uma evidente integridade física ao sistema. Esta junção de fatores permite a MRC trabalhar em uma ampla faixa de velocidade com menor risco de danos à estrutura da máquina. Por sua estrutura em dupla saliência, fica evidente a facilidade de refrigeração (TORREY, 2002), 
proporcionando maior relação potência/peso nesse tipo de máquina (FLEURY, 2008a).

Por se tratar de uma máquina robusta e confiável, a MRC se torna forte candidata a ser utiliza em ambientes inóspito. Evidenciando essa característica, em FLEURY (2008b) foi proposto um sistema complementar de geração de energia com a utilização de um GRC, $6 \times 4$, para ser empregado justamente em comunidades isoladas, ou em regiões que estão muito distantes de subestações e recebem energia de má qualidade, exatamente pela vantagem de não necessitar de frequentes manutenções.

Adicionalmente, por ser ausente de imãs e escovas, a MRC funciona bem em ambientes com vibração, poeira e umidade, fato este que foi evidenciado no trabalho de GREENHOUGH (1996). Ele apresenta aplicações da MRC em minas de carvão, tendo ainda a possibilidade de extrapolar para minas de bauxita, ferro e outros minérios.

Devido a características construtivas que garante boa taxa de resfriamento, a MRC é apta a operar em ambientes com alta temperatura. Em concordância, BRAUER (2011) desenvolveu um estudo, tendo como objetivo realizar, por meio de equações analíticas de condução de calor, a modelagem térmica de uma MRC. Com resultados computacionais e experimentais validaram o modelo proposto evidenciando a qualidade de refrigeração da máquina até mesmo em altas velocidades.

Na literatura correlata, inúmeras topologias de MRC são estudadas, mas sempre mantendo a estrutura duplo saliente característica da MRC, havendo maiores variações nos quesitos potência da máquina e no número de dentes do conjunto rotor-estator. Fica claro que, poucas pesquisas são realizadas com 
priorização de estudos em projetos e dimensionamentos de MRC, visto que, os trabalhos apresentados em KRISHNAN (2001), MILLER (1993), COSTA (2004), e TEIXEIRA (2008), que são a base para outras pesquisas de OLIVEIRA (2011b) e COELHO (2011b), constam com parâmetros empíricos para se realizar os cálculos analíticos e dinâmicos, além de variáveis, cuja elevada gama de valores contemplam satisfatoriamente o projeto. Ou seja, há uma lacuna a ser preenchida para se desenvolver projetos de MRC mais elaborados e fidedignos à realidade.

A MRC apresenta característica magnética fortemente não linear, pela geometria construtiva duplo-saliente, ocasionando dificuldades na realização de controles e acionamentos eficazes. Consequentemente, a MRC é caracterizada por operar com corrente, tensão e conjugado oscilantes (OLIVEIRA, 2010; OLIVEIRA, 2011b; COELHO, 2011b). Com os recentes aperfeiçoamentos dos componentes eletrônicos, em qualidade e confiabilidade, estes problemas estão sendo amplamente estudados e novas técnicas de controle surgindo para minimizar as deficiências desta máquina. Em BERNARDELI, (2008) e HENRIQUES (2004) é apresentado detalhadamente o estudo de controle e suavização de oscilações de conjugado e correntes, utilizando tópicos de inteligência artificial, rede neural e lógica fuzzy. Em FLEMING (2012) é apresentado uma metodologia de controle, com auxílio de ferramentas baseadas em técnicas de elementos finitos, para se conseguir o ponto ótimo de conjugado para cada valor de corrente, estratégia esta que diminui as perdas no cobre provenientes de uma excitação mal realizada. De mesma forma, com ferramentas computacionais baseadas em elementos finitos, BALATHANDAYUTHAPANI (2011) mostra que a estrutura do rotor de um MRC pode influenciar significativamente nas oscilações de conjugado da máquina, e que modificar o formato dos dentes das MRC pode auxiliar a minimizar as variações de 
conjugado. O trabalho de MIKAIL (2011) também mostra técnicas de suavização de conjugado em MRC baseado em coleta de importantes dados de correntes da máquina. Todas as pesquisas citadas tiveram resultados significativos, e contribuem para a minimização das deficiências da MRC.

Em aplicações em que são exigidos conjuntos de acionamentos elaborados, com utilização de componentes semicondutores de eletrônica de potência, a MRC torna-se competitiva.

Para operar em velocidade variável, máquinas convencionais precisam de um acionamento elaborado e utilizam-se de caixas de câmbio para realizar mudanças de velocidade, o que torna o uso da MRC interessante nestas aplicações (OLIVEIRA, 2011b). Neste aspecto, CARDENAS (2004) apresenta uma topologia de controle de um GRC, onde o foco principal é aplicação em velocidade variável, ou seja, uma realidade condizente com as plantas eólicas de geração. De forma semelhante, KOREBOINA (2012) mostra a modelagem de um sistema de controle de tensão de saída de um GRC para aplicações eólicas; porém, trata-se de um trabalho carente de resultados experimentais. Na mesma vertente, VIAJANTE (2013) apresenta uma modelagem de controle clássico aplicada a um GRC operando em velocidade variável. Portanto, nota-se uma crescente investigação da comunidade científica para as MRC operando em seu modo gerador, fato esse que não acontecia na década de 90 , ou até mesmo nos anos 2000 , onde a preocupação maior dos pesquisadores era voltada para o modo motor de funcionamento das MRC.

Por se tratar de uma máquina com acionamento sequencial das fases, a comutação (liga - desliga) dos componentes semicondutores do conversor estático proporciona a descontinuidade de conjugado, tensão e corrente, e com isso inevitavelmente ocorre o aparecimento de vibrações mecânicas e ruídos sonoros, 
que podem se intensificar de acordo com a velocidade de funcionamento e/ou comutação das chaves do conversor estático. Essa característica traz certo desconforto e priva a máquina de algumas aplicações. Em busca da diminuição desta desvantagem, trabalhos realizados mostram que alterações nos parâmetros construtivos da máquina podem ajudar a suavizar as vibrações e ruídos acústicos. Mais recentemente, um trabalho apresentado em LECOINTE (2004) mostra uma abordagem no domínio da frequência que, com a inserção de enrolamentos auxiliares na máquina, pode-se injetar corrente de supressão ao ruído, diminuindo significativamente a magnitude das frequências harmônicas indesejadas criadas pelo chaveamento do conversor estático.

A MRC é intrinsicamente uma máquina de $\mathrm{CC}$, e com isso necessita de uma fonte de tensão $\mathrm{CC}$ e conversor estático para realizar o acionamento de suas fases. Como as fases são acionadas de modo sequencial, e existe um instante correto para se realizar a excitação e/ou energização, a MRC necessita de um sistema eletrônico para disparo das chaves controladas, e de sensores de posição, o que é uma desvantagem. Sensores de posição são estruturas frágeis, e seu correto funcionamento e posicionamento é indispensável para o bom funcionamento de uma MRC, podendo sua falha acarretar sérios problemas a todo o sistema. Sendo assim, técnicas para remoção dessas estruturas são bem vindas, e na comunidade cientifica encontra-se várias vertentes de trabalhos com esse intuito, sendo que técnicas alicerçadas em tópicos de sistemas inteligentes são os mais encontrados. Como exemplo, pode-se citar o trabalho apresentado por DE ARAUJO PORTO HENRIQUES (2011) que utiliza um sistema neurofuzzy para realizar automaticamente a estimação da posição do rotor, onde dados experimentais feitos em um pequeno protótipo MRC $6 \times 4$ valida a técnica utilizada. De modo 
semelhante, em VAN TREEK (2009) foi apresentada uma técnica de estimação da posição do rotor por meio da identificação da indutância da fase no próprio acionamento da máquina, o que torna possível a remoção dos sensores de posição.

Mesmo com grandes qualidades, a MRC ainda não é fortemente utilizada na indústria, pois o seu funcionamento não acontece de forma simplificada como o motor de indução, que é a máquina elétrica mais usada atualmente e pode ser ligada diretamente à rede elétrica, verificando apenas qual configuração de tensão e de partida se deseja utilizar (COELHO, 2011b). Por se tratar de uma máquina essencialmente $\mathrm{CC}$, há certa dificuldade de aceitação da MRC em razão da planta mundial de energia ser em CA. Adicionalmente, existe uma confiável estrutura de sistemas de acionamentos baseada em máquinas CC e de indução (OLIVEIRA, 2011b). Assim, pesquisas para aprimorar e garantir total estabilidade e eficiência da MRC são bem vindas, para avalizar que, tratando-se de aplicações especiais, onde são exigidos acionamentos elaborados ou operação com velocidade variável, a MRC se destacará e ocupará grande fatia desse mercado.

\subsection{Aplicabilidade}

\subsubsection{Veículos elétricos}

Devido ao apelo em prol do desenvolvimento sustentável, numerosas pesquisas voltaram-se para a concepção de carros elétricos e carros híbridos, evitando-se o uso de combustíveis fósseis, que além de poluente é uma fonte finita de energia (OLIVEIRA, 2011b). Assim, hoje há uma tendência a se desenvolver

veículos elétricos das mais variadas formas, para torná-los competitivos financeiramente frente às formas comuns de propulsão automotiva. 
Existe na atualidade vários veículos elétricos e/ou híbridos que são baseados em arquiteturas de motores construídos com imãs permanentes ou em motores síncronos, acarretando problemas funcionais devido a necessidade de baixa temperatura de funcionamento e o aumento de custos causados pelos preços dos imãs e à mão de obra necessária para instalá-lo (RUBA, 2012). Por isso, está em voga o conceito de se conseguir soluções alternativas para desenvolver máquinas elétricas mais baratas e confiáveis, especialmente concebidas para este fim. A MRC por operar bem em alta temperatura, em grande variedade de velocidade e/ou conjugado operacional, ganha destaque. Além disso, é importante que a máquina apresente uma alta densidade de potência, diminuindo o peso do automóvel e não agregando perdas ao sistema. Portanto, novamente, a MRC ganha realce nessa aplicação.

Como exemplo desta aplicação, em ABBASIAN (2010) foi desenvolvido um novo desenho de uma MRC voltado exclusivamente para propulsão de veículos, onde seu novo design, constituído agora de dois rotores e um estator contribui para conseguir alto conjugado da máquina.

Da mesma forma, em FUJISHIRO (2006) é apresentada a construção de um carro, com uma nova topologia de MRC, onde se observa um estator interno bobinado com o rotor externo girante. Tal adaptação tornou-se necessária por ser investigado a atuação de uma MRC diretamente ligada ao eixo motriz do veículo.

Em RUBA (2012), testes foram realizados em uma MRC de baixa tensão e alta corrente, para ser aplicado em veículos automotores especiais de pequeno porte, no caso específico em cadeiras de rodas. Sendo assim, há pesquisas sendo desenvolvidas para melhorar as condições dos equipamentos disponíveis para pessoas fisicamente prejudicadas, auxiliando na acessibilidade e qualidade e vida. 


\subsubsection{Motor - gerador de partida}

Uma característica básica das máquinas elétricas é o modo dual de funcionamento, ou seja, ela pode funcionar como motor ou gerador. Nas MRC a dualidade de funcionamento está relacionada ao instante em que é realizado o acionamento das fases da máquina, assim como foi salientado previamente neste capítulo.

Sabido disso, a MRC conseguir operar como motor-gerador de partida chama bastante atenção das indústrias automobilística e aeroespacial. Basicamente, a ideia de um motor-gerador de partida consiste em operar a máquina como motor no ato da partida do automóvel, e quando estiver em pleno funcionamento, a máquina receber a função de gerador, suprindo energia para os componentes eletrônicos do veículo. Como resultado, a operação do conjunto garante maior rendimento, junção de duas máquinas em uma só, e menor custo do conjunto. Ademais, a MRC é a única máquina que opera em modo gerador sem imãs permanentes e sem enrolamentos de cobre no rotor, sendo este mais um atrativo para essa aplicação.

Em SILVEIRA (2010) um estudo com dados experimentais é apresentando para um motor gerador de partida automotivo. $\mathrm{O}$ trabalho tem como objetivo realizar o controle do modo de funcionamento da MRC (motor ou gerador) dependendo da necessidade. A técnica utilizada é atuar no instante em que ocorre a condução das fases por meio de microprocessadores.

Seguindo o mesmo raciocínio, em SILVEIRA (2009) o autor utiliza técnicas de controle clássico para garantir níveis estáveis de tensão em um motor-gerador de partida. Para controlar a tensão, atuou-se diretamente no tamanho da janela de condução de cada uma das fases, enquanto para a mudança do modo motor-gerador ou 
vice-versa atuou-se no instante em que ocorria condução nas chaves. Os trabalhos apresentados em SILVEIRA (2009) e SILVEIRA (2010), por se tratar da mesma equipe de pesquisa, com vários autores em comum, assume-se que são trabalhos complementares, com o intuito de agregar mais credibilidade a MRC.

$\mathrm{Na}$ linha aeroespacial, a força aérea americana com o projeto More Electric Aircraft foi o grande responsável pelo aumento de trabalhos relacionados à MRC atuando como motor-gerador de partida (FLEURY, 2008). Sua aplicabilidade ganhou destaque no programa aeronáutico americano devido à possibilidade de redução significativa dos sistemas hidráulicos nas aeronaves, consequentemente redução de peso e volume, fator esse destacado como uma das metas do projeto.

A simulação de uma MRC para a aplicação no projeto More Electric Aircraft pode ser encontrada em SKVARENINA (1997) e um projeto desta máquina foi apresentado em MACMIM (1989), de acordo com FLEURY (2008) e COELHO (2011b).

Outras aplicações em sistemas aeroespaciais podem ser encontradas na literatura. Pesquisas que variam desde aprimoramento da estrutura da máquina para esta aplicação em específico (POWELL, 2003), estratégias de controle para operação de sistemas aeronáuticos (JIANBO, 2011), estudo de tolerância à faltas da MRC para ser empregado em bombas de combustíveis de aeronaves (CHEN, 2009), são apresentadas, e seus resultados vão de encontro ao objetivo do projeto americano de tornar as aeronaves mais elétricas.

\subsubsection{Energia eólica}

Com a vantagem de operar em uma larga faixa de velocidade, a MRC tem sido intensamente estudada para aplicações eólicas. 
Atualmente, os sistemas eólicos são caracterizados pelo funcionamento com geradores de indução duplamente alimentados, ou então geradores síncronos. Ambos necessitam de conversores eletrônicos e caixas de engrenagens para a regulagem de velocidade. A MRC também necessita de conversor eletrônico; porém, ao se pensar em empregá-la com elevado número de pares de polos, a MRC dispensa a utilização de caixa de câmbio, podendo ser empregada diretamente ao eixo do aero gerador, dispensando o uso de óleo lubrificantes, gerando menor manutenção e menor ruído acústico (JEBASEELI, 2010). Seu controle de velocidade, visto que nesta aplicação a MRC funciona unicamente como gerador, é realizada por meio do tamanho da janela de excitação, aumentando ou diminuindo o conjugado opositor ao movimento do aero gerador, frenando ou acelerando assim o sistema.

Sistemas eólicos convencionais trazem máquinas com rotores bobinados, escovas e/ou imãs permanentes, elementos estes ausentes nas topologias de MRC. Assim, a MRC apresenta alguns atrativos perante às máquinas comumente empregadas nesse sistema.

$\mathrm{Na}$ tentativa de identificar uma topologia mais eficiente para a geração eólica, JEBASEELI (2010) realizou a comparação de três MRC, sendo elas polifásicas $6 \times 4,12 \times 8$ e $8 \times 6$. Foi constatado que todas as configurações funcionam bem, com destaque para a configuração $6 \times 4$ trifásica. Esta configuração apresentou melhor rendimento ao ser analisado em um sistema eólico com ventos de média potência.

Com o intuito de atender comunidades isoladas onde ainda não há o acesso a uma rede de transmissão de energia, em OLIVEIRA (2010b) foi apresentado um sistema híbrido eólico-fotovoltaico de geração de energia por meio de uma MRC. 
Como a MRC necessita de uma excitação em CC, a fonte solar exerceria essa função, enquanto o conjugado mecânico seria fornecido pela fonte eólica.

Recentes pesquisas têm se empenhado em desenvolver métodos de controle para coordenar e assegurar uma geração de um sistema eólico com GRC. Em CARDENAS (2005) é apresentado uma metodologia de controle, com resultados experimentais estáveis para operações em baixas e medias velocidade, de um gerador eólico a relutância. Da mesma forma, em XIAOSHU (2011) foi apresentada a topologia de um controlador de tensão, com resultados experimentais, utilizando técnicas de redes neurais artificiais.

\subsection{Princípio de funcionamento}

As MRC operam segundo o princípio de máxima energia armazenada no circuito magnético na máquina, ou seja, da mínima relutância. Assim sendo, quando as fases da máquina são energizadas, cada uma a seu instante, os dentes do rotor mais próximos aos polos energizados de estator tende-se a alinhar a estes, reduzindo a relutância desse circuito magnético (BILGIN, 2008). A topologia em dupla saliência promove modificações no "caminho" do fluxo com o deslizar dos polos, que por sua vez, ocasiona consideráveis alterações na indutância de cada fase. Logo, a indutância por fase da máquina é altamente variável, apresentando valores de máximos no alinhamento dos dentes, e de mínimos no total desalinhamento dos dentes. Um perfil idealizado e didático do perfil de indutância pode ser visto na Figura 2.

A MRC funciona bem como motor e como gerador. Sua atuação está relacionada com os ângulos de disparo das chaves do conversor. Ao disparar a chave de uma fase onde a taxa de variação da indutância pela posição angular é 
positiva, a MRC opera como motor. Se a taxa de variação for negativa, opera como gerador (SAWATA, 2001). Portanto, um mesmo conversor pode acionar a máquina nas duas situações, não necessitando de troca de componentes, i.e., se o conversor possuir período específico de desmagnetização das bobinas. Em geral, o conversor mais utilizado na bibliografia correlata é o conversor em ponte assimétrica, do inglês half-bridge (HB). Entretanto, para GRC, conversores alternativos se mostraram mais eficientes e baratos nesta mesma aplicação (FLEURY, 2008b), e neste trabalho uma nova topologia de conversor será apresentada para possibilitar o controle da tensão de saída.

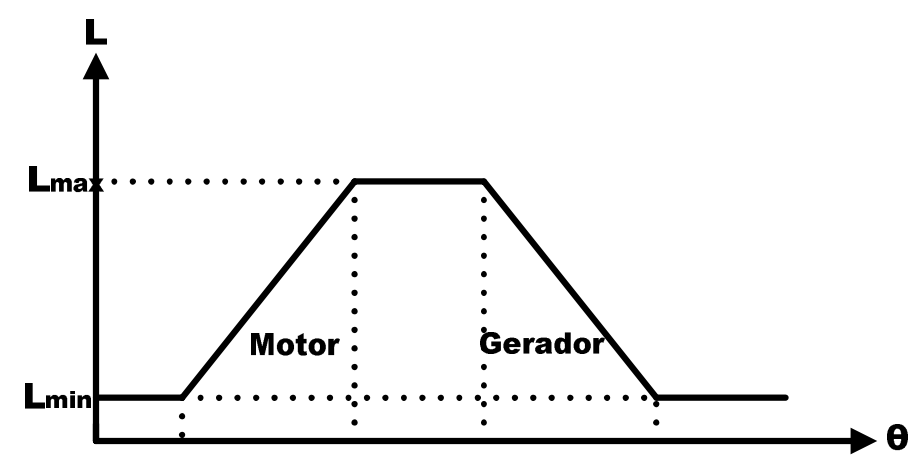

Figura 2 - Perfil trapezoidal ideal de indutância

Outro aspecto importante a respeito da MRC é a operação em condição de saturação magnética (DIAS, 2011; OLIVEIRA, 2013). Essa característica se beneficia do conceito de que na região de saturação magnética o fluxo concatenado pelo circuito torna-se pouco dependente dos valores de corrente da máquina, sendo a indutância ou a variação dela o grande responsável por sustentar os valores de fluxo magnético concatenado.

Para a operação da MRC em modo motor, o pulso de tensão é aplicado na fase no período que ocorre o crescimento do perfil da curva de indutância, e se, neste instante a máquina está saturada, o fluxo concatenado apresenta um valor 
praticamente constante, e se os valores de indutância estão sendo incrementados, logo acarretará em uma diminuição do valor da corrente na fase, pois como já se é sabido, a corrente na bobina da fase é diretamente proporcional ao fluxo magnético e inversamente proporcional a indutância da fase. Tratando-se de motor, isto diminui as perdas no cobre e proporciona menores especificações de condutores para a máquina, garantindo maior rendimento e menor custo.

Para operação em modo gerador da MRC parte-se do mesmo princípio, porém, agora o pulso de tensão é aplicado na fase no período de decaimento da curva de indutância. Considerando a máquina saturada com valor de fluxo magnético constante, os valores de indutância vão decrementando gradativamente e proporciona o aumento no valor de corrente da fase. Tratando-se de um gerador, isto garante maior quantidade de energia que será desmagnetizada na carga, ou barramento CC de saída, melhorando o rendimento.

\subsection{Modelo matemático}

Para o melhor entendimento do princípio de funcionamento de uma MRC, neste tópico será apresentada a modelagem matemática da máquina de forma sucinta e breve, pois o modelo matemático desta máquina encontra-se bastante consolidado. Um equacionamento matemático mais elaborado e rico em detalhes pode ser encontrado em outras literaturas (FLEURY, 2008; COELHO, 2011b; DIAS, 2011; COSTA, 2004).

Como o objeto de estudo deste trabalho é um GRC trifásico $6 \times 4$, a modelagem aqui apresentada se destinará a representar esta máquina em questão, podendo se extrapolar para qualquer MRC com pequenas modificações. 
Para cada par de polos diametralmente opostos do GRC, a tensão presente em seus terminais pode ser descrita como:

$$
v=R \cdot i+\frac{\partial \lambda}{\partial t}
$$

onde:

$i$ é a corrente que circula na bobina,

$R$ é a resistência ôhmica interna,

$\lambda$ é o fluxo magnético enlaçado pela bobina $\mathrm{e}$

$t$ é o tempo.

Como é sabido que:

$$
\lambda=L \cdot i
$$

e sendo ( $L$ ) a indutância do circuito, a interação de (1) e (2) resulta em:

$$
v=R \cdot i+L \cdot \frac{\partial i}{\partial t}+i \cdot \omega \cdot \frac{\partial L}{\partial \theta}
$$

onde:

$\omega$ é a velocidade angular e

$\theta$ é a posição angular.

Os membros do segundo termo de (3) representam respectivamente a queda de tensão na resistência interna da máquina, a queda de tensão devido ao efeito indutivo da bobina e a força contra eletromotriz (FCEM), a qual depende da taxa de variação da indutância pela posição, da intensidade de corrente e da velocidade angular. Portanto:

$$
F C E M=i \cdot \omega \cdot \frac{\partial L}{\partial \theta}
$$


Os GRC têm a tendência natural dos polos de rotor e estator permanecerem alinhados quando as bobinas são excitadas. Quando uma força externa fornece conjugado mecânico deslocando o rotor, ocorre o surgimento de uma FCEM contrária ao sentido do movimento, tentando restabelecer o equilíbrio, acarretando no aparecimento de um conjugado eletromagnético restaurador. A equação que engloba os aspectos mecânicos é dada por:

$$
T_{m}=-T_{\text {emag }}+D \cdot \omega+J \cdot \frac{d \omega}{d t}
$$

onde:

$T_{m}$ é o conjugado mecânico aplicado,

$T_{\text {emag }}$ é o conjugado eletromagnético,

$J$ é o momento de inércia e

$D$ é o atrito viscoso.

Como existem três pares de polos diametralmente opostos, e cada par com sua indutância própria e sua corrente instantânea, o conjugado eletromagnético pode ser dado por:

$$
T_{\text {emag }}=\left(\frac{1}{2} \cdot i_{1}^{2} \cdot \frac{\partial L_{1}}{\partial \theta}+\frac{1}{2} \cdot i_{2}^{2} \cdot \frac{\partial L_{2}}{\partial \theta}+\frac{1}{2} \cdot i_{3}^{2} \cdot \frac{\partial L_{3}}{\partial \theta}\right)
$$

Considerando (3), (5) e (6) o modelo pode ser melhor analisado se apresentado em equações matriciais. Logo: 


$$
\begin{aligned}
& {\left[\begin{array}{c}
\dot{i_{1}} \\
\dot{i_{2}} \\
\dot{i_{3}} \\
\dot{\omega} \\
\dot{\theta}
\end{array}\right]=\left[\begin{array}{ccccc}
-R_{1} / L_{1} & 0 & 0 & -2 \cdot \alpha_{1} / L_{1} & 0 \\
0 & -R_{2} / L_{2} & 0 & -2 \cdot \alpha_{2} / L_{2} & 0 \\
0 & 0 & -R_{3} / L_{3} & -2 \cdot \alpha_{3} / L_{3} & 0 \\
\alpha_{1} / J & \alpha_{2} / J & \alpha_{3} / J & -D / J & 0 \\
0 & 0 & 0 & 1 & 0
\end{array}\right] \times} \\
& {\left[\begin{array}{l}
i_{1} \\
i_{2} \\
i_{3} \\
\omega \\
\theta
\end{array}\right]+\left[\begin{array}{ccccc}
1 / L_{1} & 0 & 0 & 0 & 0 \\
0 & 1 / L_{2} & 0 & 0 & 0 \\
0 & 0 & 1 / L_{3} & 0 & 0 \\
0 & 0 & 0 & 1 / J & 0 \\
0 & 0 & 0 & 0 & 0
\end{array}\right] \times\left[\begin{array}{c}
v_{1} \\
v_{2} \\
v_{3} \\
T_{m} \\
0
\end{array}\right]}
\end{aligned}
$$

onde:

$$
\alpha_{1}=\frac{1}{2} \cdot i_{1} \cdot \frac{\partial L_{1}}{\partial \theta}, \alpha_{2}=\frac{1}{2} \cdot i_{2} \cdot \frac{\partial L_{2}}{\partial \theta}, \alpha_{3}=\frac{1}{2} \cdot i_{3} \cdot \frac{\partial L_{3}}{\partial \theta}
$$

As equações (7) e (8) descrevem o modelo matemático do GRC e está pronto para ser inserido em programas computacionais capazes de resolver equações diferenciais por meio de iterações numéricas, onde os valores das indutâncias e de suas derivadas são pontos de atenção na construção do modelo computacional. 



\section{Considerações sobre a indutância}

\subsection{A indutância e aspectos construtivos do GRC}

Tal como enunciado nas seções anteriores, a indutância de fase da máquina e sua variação temporal é um fator decisivo para o funcionamento de um GRC. Com a aproximação, alinhamento e afastamento dos polos de rotor em relação aos polos excitados do estator, implica em um perfil oscilante de indutância na fase. Visto isso, torna-se interessante ressaltar três posições importantes do conjunto rotor-estator: a posição alinhada, a posição desalinhada, e as posições intermediárias.

A posição alinhada ocorre quando o par de polos excitados do estator está totalmente alinhado com o par de polos do rotor, como apresentado na Figura 3. Esta posição apresenta os maiores valores de indutância, pois apresentam menor entreferro e consequentemente menor relutância magnética. Nesta posição, todas as grandezas estão equilibradas e estáveis, portanto, mesmo com a existência de tensão nos enrolamentos da fase não acarretará em produção de conjugado mecânico, e vice-versa, pois não há variação de indutância nesta posição.

A Figura 3 também mostra o perfil didático típico da curva de indutância de uma face do GRC, onde a área destacada representa o período em que o GRC encontra-se na posição alinhada. Na Figura 3 esta posição apresenta um patamar, mas se os dentes de estator e rotor tiverem o mesmo arco polar a posição alinhada aconteceria em um único instante de tempo, dando ao perfil idealizado da indutância uma forma triangular, e não mais trapezoidal. 


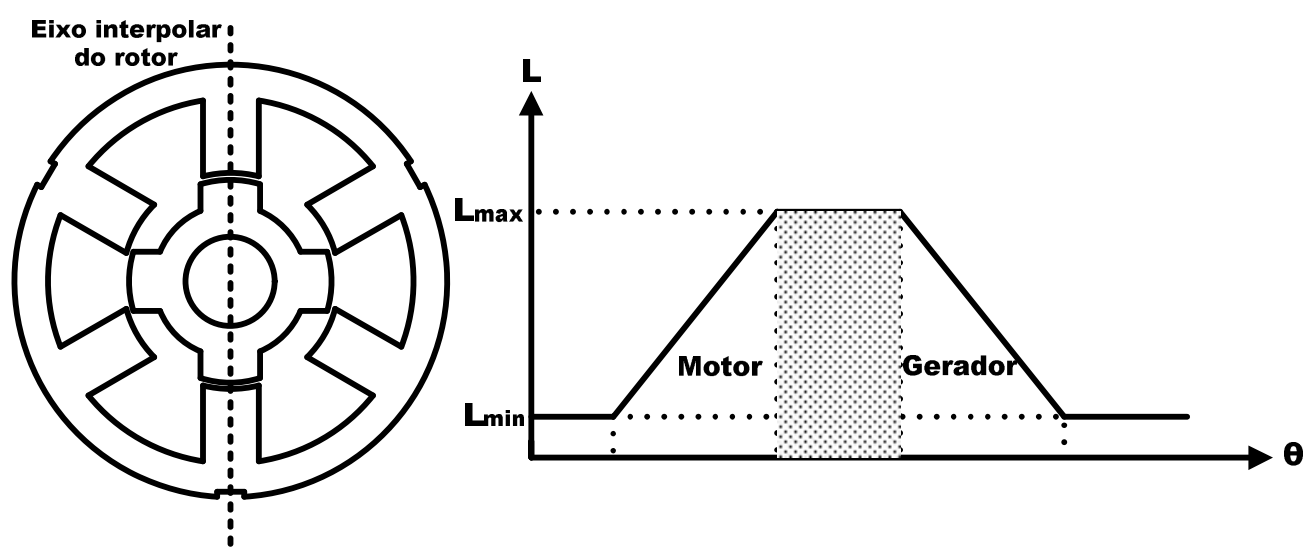

Figura 3 - Arranjo duplo saliente do GRC e perfil de indutância para a posição alinhada.

A posição desalinhada ocorre quando o par de polos energizados do estator está alinhado com as posições interpolares do rotor, mostrado didaticamente na Figura 4. Assim como na posição alinhada, nesta posição não ocorre variação de indutância; porém, os valores de indutância são os menores possíveis como pode ser observado na área destacada no perfil de indutância da Figura 4. Nesta posição as grandezas estão em equilíbrio, mas caso uma força externa promova o aparecimento de um mínimo deslocamento do rotor, fará com que o conjunto tende a atingir a posição alinhada, que oferece equilíbrio estável. Adicionalmente, como apresenta maior relutância magnética, esta posição dificilmente sofrerá com saturação magnética, e como o GRC tem a particularidade de operar em região de saturação, não se deve energizar a fase neste instante.

As posições compreendidas entre a posição de alinhamento e a posição de desalinhamento são denominadas de posições intermediárias, e são nessas posições que se torna possível a produção de conjugado útil, seja ele mecânico ou eletromagnético. Nestas posições as grandezas envolvidas estão em desequilíbrio, e a indutância não possui mais valor fixo. 
Analisando a Figura 5 e adotando o sentido de rotação horário para o rotor da máquina, nota-se que o valor de indutância se incrementa até alcançar seu máximo, ou seja até alcançar a posição de alinhamento, e é nesse período que se deve ser feito a excitação para o modo motor da máquina, sendo representado didaticamente pela curva ascendente do perfil de indutância da Figura 5.

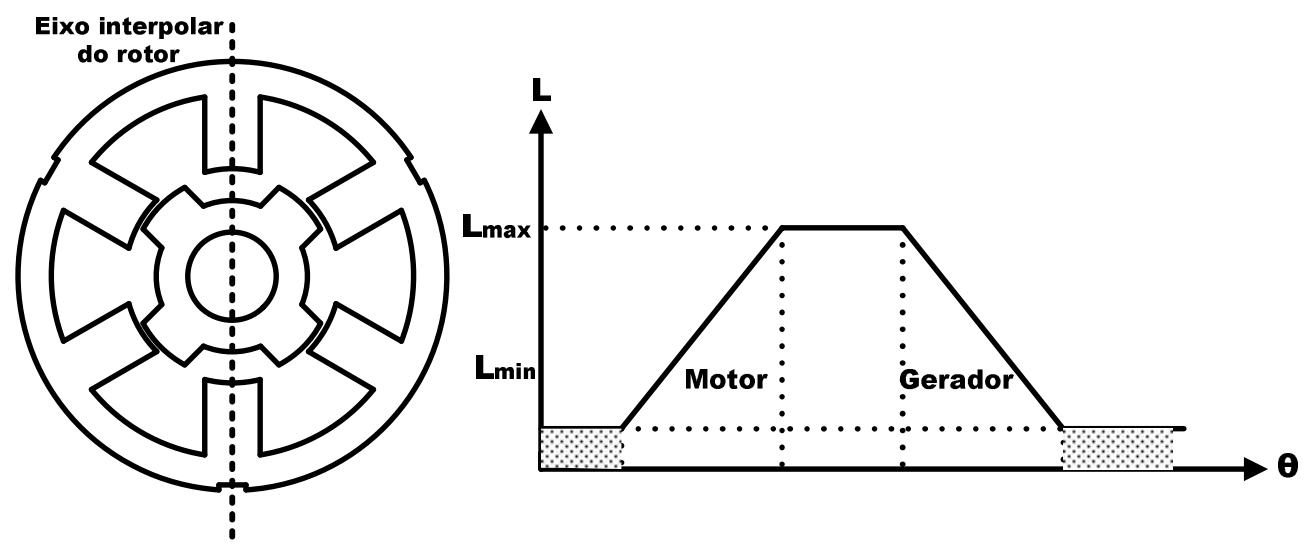

Figura 4 - Arranjo duplo saliente do GRC e perfil de indutância para a posição desalinhada.

Verificando a Figura 5 e agora adotando o sentido horário de movimentação do rotor, o valor de indutância se decrementa até chegar ao seu menor valor, ou seja, até atingir a posição desalinhada, e é nesse período que se deve realizar a excitação para o modo gerador da máquina, representado didaticamente pela curva descendente do perfil de indutância da Figura 5. 


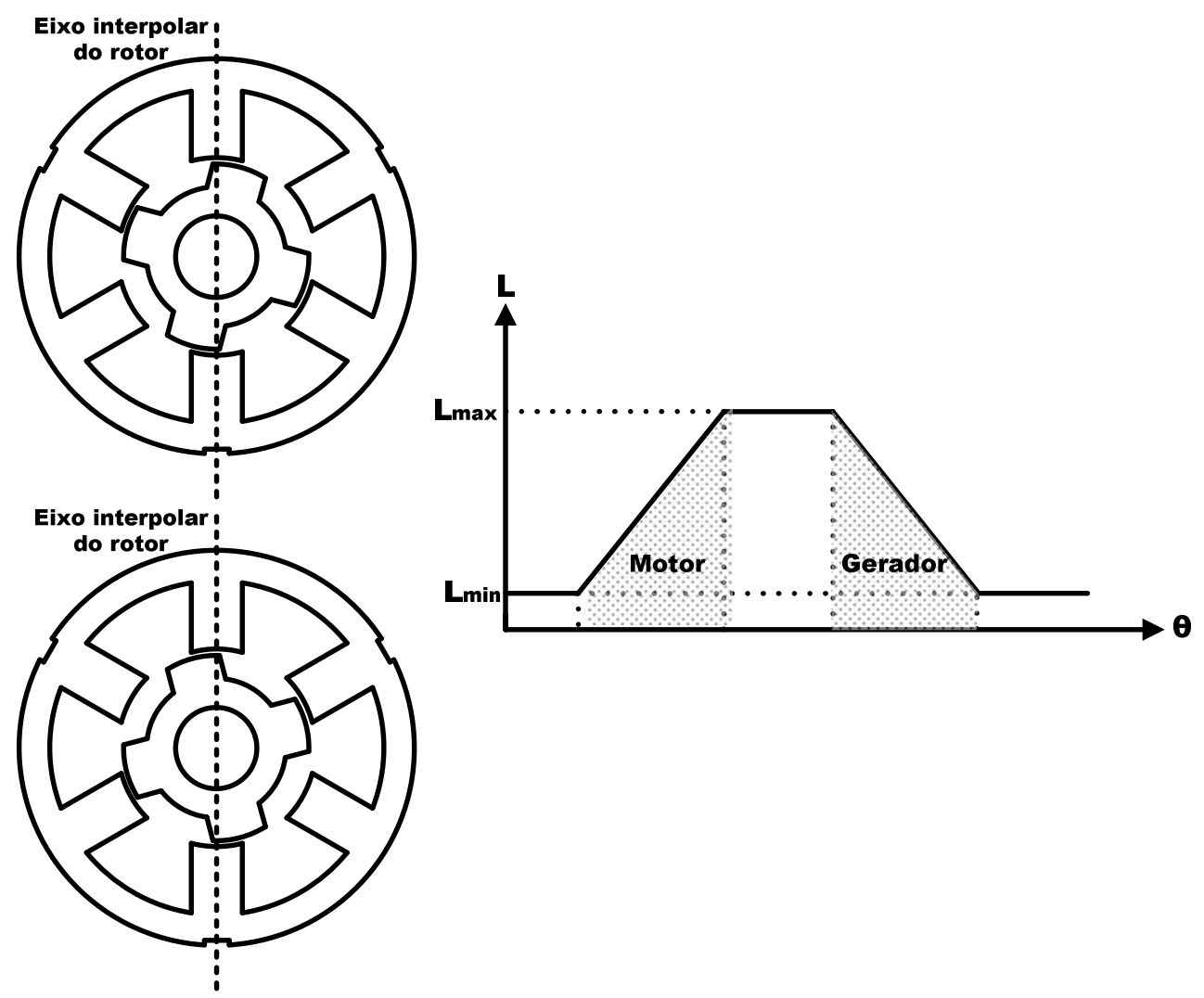

Figura 5 - Arranjo duplo saliente do GRC e perfil de indutância para as posições intermediárias.

\subsection{A indutância em modelos computacionais}

Na Seção 2.4 foi apresentado o modelo matemático de um GRC. Pode-se concluir que o modelo matemático é altamente dependente dos valores instantâneos de indutância e de sua derivada pela posição do rotor. Logo, estar ciente do comportamento de tais variáveis torna-se indispensável para que se consiga realizar o modelo da máquina fidedigno à realidade.

Assim sendo, existe na literatura algumas técnicas e modelos capazes de aproximar os valores dos perfis da indutância, e de posse desses valores, alimentar uma simulação computacional de um GRC em operação. 
O modelo mais simples para o perfil de indutância é o modelo idealizado. Trata-se de uma aproximação linear da indutância constituído apenas por segmentos de retas a partir de pontos de máximos e mínimos dos valores de indutância. Este modelo proporciona um perfil triangular de indutância nos casos em que os dentes de estator e rotor possuírem o mesmo tamanho de arco polar e um perfil trapezoidal de indutância para tamanhos diferentes de arcos polares de estator e rotor. Mesmo com seu caráter linear deste modelo, que facilita os cálculos computacionais, ele já se encontra em desuso, pois agrega consideráveis erros às simulações computacionais. Os dois perfis (trapezoidal e triangular) de indutâncias que são apresentados na Figura 6 estão aqui representado apenas com ferramentas didáticas capazes de facilitar o entendimento da operação da MRC.

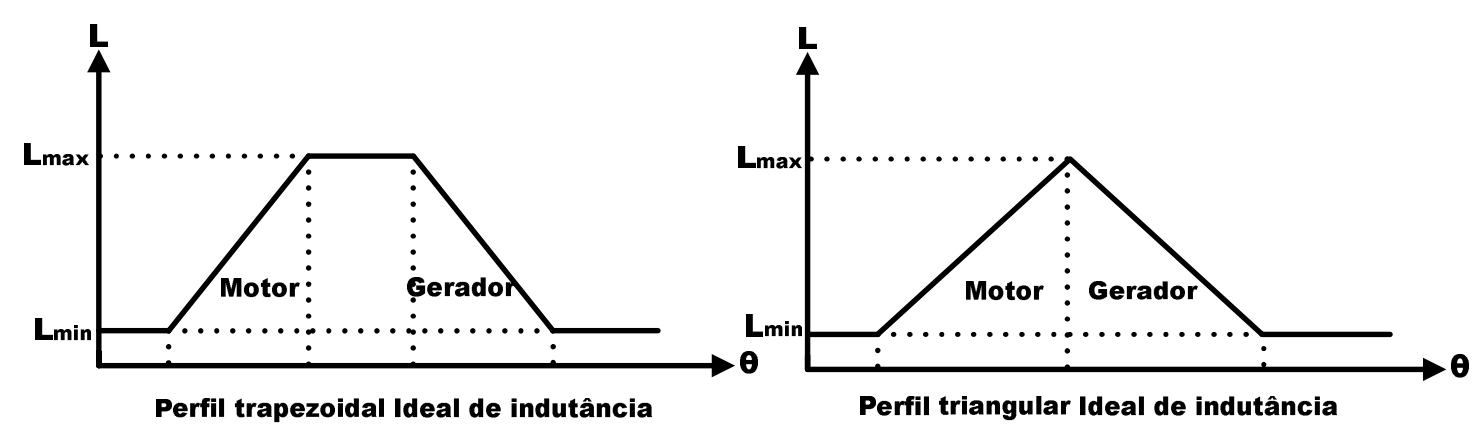

Figura 6 - Perfil trapezoidal e perfil triangular idealizado de indutância.

Uma evolução do modelo idealizado é o modelo senoidal para cálculo de indutância. Este modelo é uma aproximação a partir de senos e cossenos do modelo idealizado. Tais aproximações torna o perfil mais semelhante ao perfil real, sendo um aprimoramento para cálculo da indutância, mas ainda inserindo erros ao sistema computacional. A Figura 7 apresenta uma comparação do modelo idealizado e o modelo senoidal para cálculo de indutância.

Outra técnica utilizada é a representação da indutância por meio de expansão analítica da série de Fourier. A estratégia para esta representação é a 
utilização de um segmento de reta para representar cada um dos diferentes níveis de correntes e posições do rotor possíveis. Assim sendo, as relações de fluxo, corrente e posição da máquina podem ser representados analiticamente, incluindo a não linearidade entre elas, englobando a parcela de saturação magnética existentes ao modelo matemático, o que agrega confiabilidade ao modelo. Uma modelagem matemática completa desta técnica pode ser observada em (VIAJANTE, 2013), onde os autores comprovam sua funcionalidade ao comparar com resultados experimentais da máquina em questão.

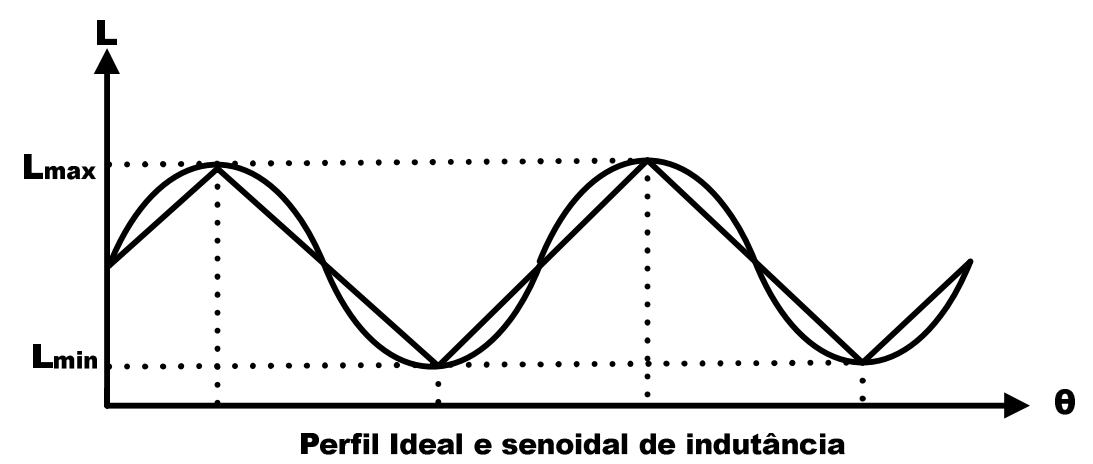

Figura 7 - Perfil idealizado e perfil senoidal de indutância.

Esta técnica torna-se confiável, mas por ser constituída da expansão da série de Fourier, caso esta expansão conste com número elevado de elementos, agrega um grande peso computacional para o cálculo da indutância, sendo uma adversidade da técnica ao se considerar sistemas online de funcionamento da MRC ou ao se embarcar em microprocessadores. Nessa vertente, este trabalho apresentará uma técnica embasada em sistemas inteligentes para a detecção da indutância da máquina incluindo a saturação magnética. 


\subsection{Abordagem inteligente na detecção do perfil de indutância}

No modelo matemático utilizado para a simulação da máquina nota-se a alta dependência dos valores de indutância das fases e de suas respectivas derivadas pela posição angular do rotor. Por esta variável ser altamente oscilante e não linear, vários modelos para o cálculo da indutância agrega significativos erros ao sistema, e/ou culmina em grande esforço computacional para realizar seu cálculo.

Visando a inserção no modelo computacional dos valores corretos dessa variável, com reduzido custo computacional, uma metodologia alternativa é bemvinda, e a opção encontrada foi a emprego de sistemas inteligentes para realizar esta função. A abordagem inteligente para o problema faz uso de uma rede neural artificial, mais precisamente a rede Percepton multicamadas (PMC) com o algoritmo de treinamento backpropagation. Esta topologia de rede foi a escolhida por ser uma estrutura de funcionamento simples e o algoritmo de treinamento apresenta bons resultados ao se aplicar em aproximações funcionais (DA SILVA, 2010).

O método proposto para o cálculo da indutância consta de três etapas e serão detalhadas nesta seção.

\subsubsection{Levantamento da base de dados}

No ano de 2009, um grupo de pesquisa iniciou trabalhos na Escola de Engenharia de São Carlos da Universidade de São Paulo, cujo o objetivo principal era estudos em MRC, sendo este grupo o precursor dos estudos que contempla este tema na Escola. Como resultados de seus esforços, o grupo publicou doze artigos e foi defendida duas dissertações de mestrado. Como herança para projetos futuros foi construída duas MRC, uma monofásica $6 \times 6$, e uma trifásica $6 \times 4$. A máquina trifásica, mostrada na Figura 8, é objeto de estudo deste trabalho, com alguns de 
seus parâmetros mostrados na Tabela 1. O protótipo em questão apresenta 140 espiras por fase montadas com fio 14 AWG.
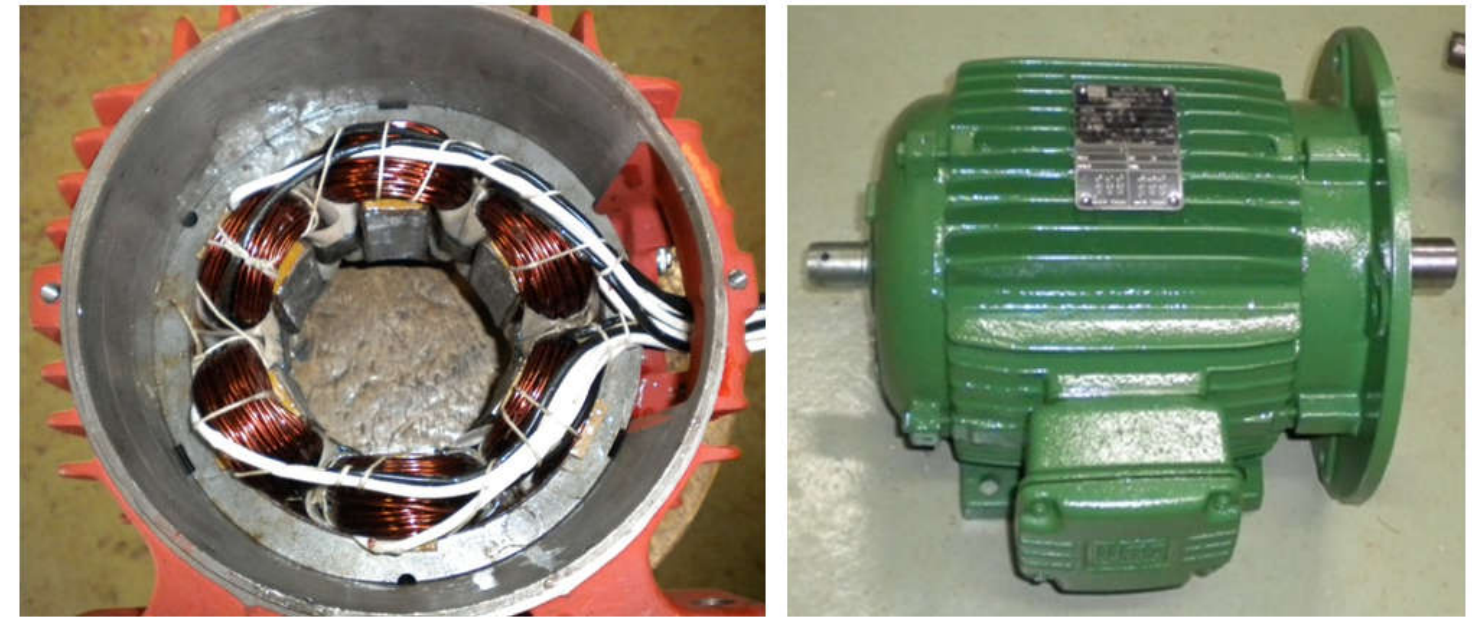

Figura 8 - Protótipo GRC 6 x 4 Trifásico.

Tabela 1 - Parâmetros do protótipo GRC trifásico 6 × 4 .

\begin{tabular}{|cc|}
\hline Parâmetros & Valor \\
\hline Diâmetro interno & $80 \mathrm{~mm}$ \\
\hline Diâmetro externo & $160 \mathrm{~mm}$ \\
\hline Comprimento da pilha & $55 \mathrm{~mm}$ \\
\hline Comprimento do dente do estator & $20,71 \mathrm{~mm}$ \\
\hline Comprimento do dente do rotor & $23,38 \mathrm{~mm}$ \\
\hline Culatra do estator & $12,42 \mathrm{~mm}$ \\
\hline Culatra do rotor & $12,42 \mathrm{~mm}$ \\
\hline Altura do dente do estator & $27,58 \mathrm{~mm}$ \\
\hline Altura do dente do rotor & $9,83 \mathrm{~mm}$ \\
Entreferro & $0,3 \mathrm{~mm}$ \\
\hline Diâmetro do eixo & $34,9 \mathrm{~mm}$ \\
\hline Número de espiras por fase & 140 \\
\hline
\end{tabular}


A fim de levantar um banco de dados para possibilitar a utilização da ferramenta neural, ensaios experimentais de rotor bloqueado foram realizados armazenando-se ponto a ponto os valores de corrente da fase, posição angular e a respectiva indutância do GRC experimentado.

O ensaio é realizado com o rotor bloqueado em uma posição especifica e excitando-se uma fase com uma fonte CA variável de frequência fixa. A excitação é feita em níveis, estabelecendo uma ampla variação de tensão por corrente. $O$ procedimento e repetido para cada novo incremento da posição do rotor, até que o mesmo passe da posição alinhada para desalinhada em relação ao estator excitado.

Para o cálculo da indutância de fase $(L)$ partiu-se da lei de Ohm, sendo definida em (9):

$$
v_{f}=Z_{f} \cdot i_{f}
$$

onde:

$v_{f}$ representa a diferença de potencial elétrico do circuito,

$Z_{f}$ é a impedância elétrica da fase e

$i_{f}$ é a corrente elétrica.

A indutância total de uma associação em série de elementos passivos é dada por (10). $O$ ensaio de rotor bloqueado apresenta $X_{C}=0$.

$$
Z_{f}=\sqrt{R_{f}^{2}+\left(X_{C}-X_{L}\right)^{2}}
$$

onde:

$R_{f}$ é a resistência elétrica,

$X_{C}$ é a reatância elétrica indutiva e

$X_{L}$ é a reatância elétrica capacitiva. 
No caso do GRC, a reatância indutiva é expressa por (11) com a frequência de alimentação do circuito dada em rad/s. Assim, a indutância de cada fase pode ser obtida por (12).

$$
\begin{gathered}
X_{L}=\omega_{f} \cdot L_{f} \\
L=\left[(v / i)^{2}-R^{2}\right]^{1 / 2} \times(2 \pi f)^{-1}
\end{gathered}
$$

Ao fim do ensaio experimental, obteve-se um extenso conjunto de dados que representam a função $L(\theta, i)$, graficamente apresentada na Figura 9. De posse desse conjunto de dados, onde há uma relação de entradas (posição angular e corrente da fase) gerando sua respectiva saída (indutância), foi possível modelar a rede neural artificial para obtenção do perfil de indutância do GRC, sendo também possível a apresentação da influência da saturação magnética da máquina.

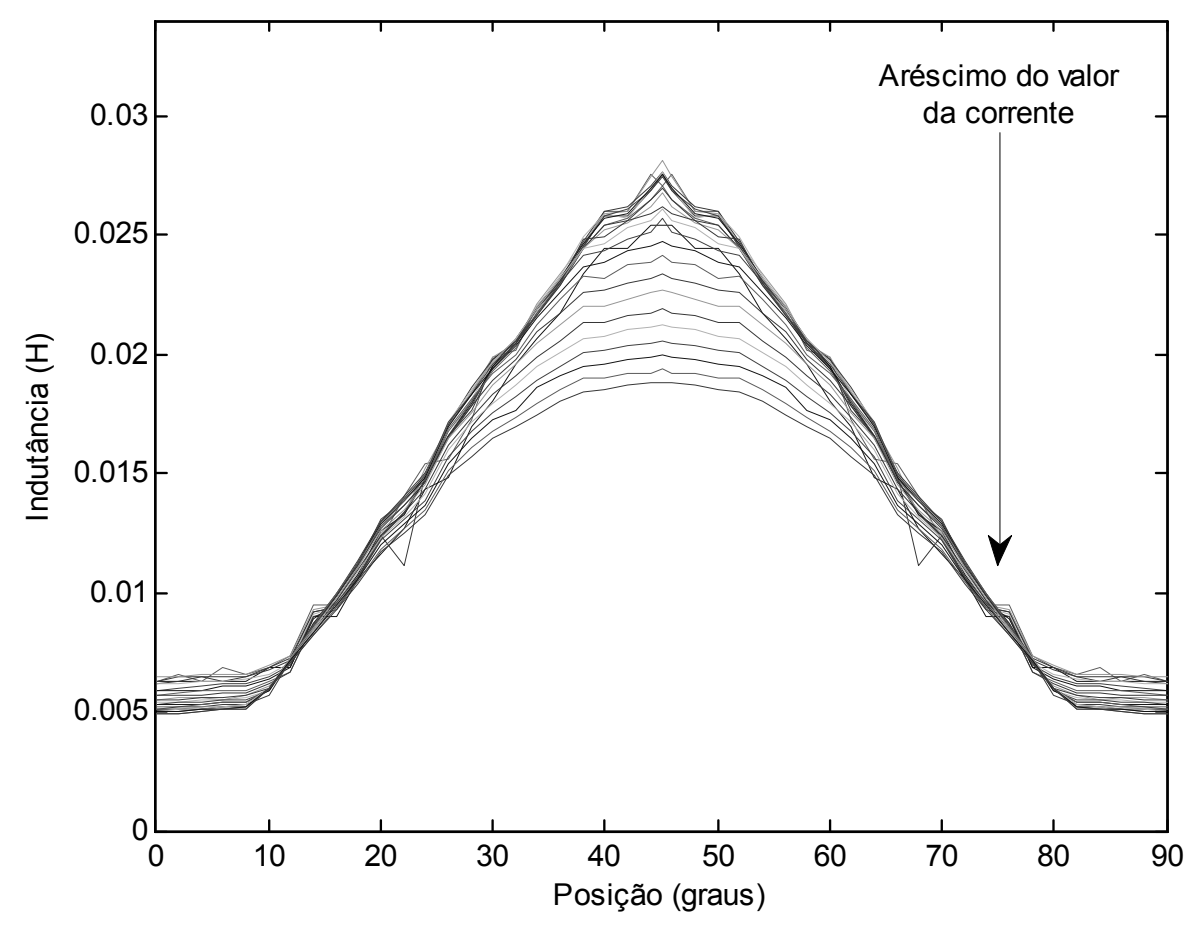

Figura 9 - Curva de indutância real obtida por meio de um protótipo GRC. 


\subsubsection{Treinamento da PMC}

O objetivo da PMC proposta é realizar uma aproximação funcional em três dimensões para generalizar os valores de indutância a partir de um par ordenado de corrente da fase e posição angular do rotor, formando uma função do tipo $L(\theta, i)$, ou seja, o objetivo é mapear o sistema a partir de dados de entrada e saída. Assim sendo, tem-se que a PMC apresenta duas entradas $(\theta, i)$ e uma única saída, $(L)$.

Segundo DA SILVA (2010) e ANTHONY (2009) uma rede PMC com apenas uma única camada escondida é capaz de generalizar e mapear qualquer função contínua no espaço das funções reais. Porém, por apresentar melhor desempenho no processo de treinamento, a PMC escolhida foi constituída de duas entradas, duas camadas escondidas com quatro neurônios na primeira camada $\left(\mathrm{M}_{11}, \mathrm{M}_{12}, \mathrm{M}_{13} \mathrm{e}\right.$ M14) quatro neurônios na segunda camada ( $M_{21}, M_{22}, M_{23}$ e $\left.M_{24}\right)$, e uma camada de saída com um único neurônio $\left(\mathrm{M}_{3}\right)$, conforme apresentado na Figura 10.

Para o treinamento da PCM, foram utilizados $75 \%$ do banco dos dados experimentais e os $25 \%$ restantes foram utilizados para validar a rede, a fim de constatar sua eficiência em generalizar o processo.

A PMC foi modelada com função de ativação do tipo tangente hiperbólica nas camadas intermediarias e com a função de ativação do tipo linear para a camada de saída. A escolha das funções de ativação foi baseada levando em conta que o neurônio da camada de saída tem como função realizar a combinação linear das funções de ativação tangente hiperbólica dos neurônios das camadas anteriores, apresentando então menor gasto computacional. Foi adotada a taxa de aprendizagem de 0,01 . A precisão do processo foi estabelecida em 10e-8 e com o 
máximo de 1000 épocas de aprendizagem. Foi empregado o momentum com valor de 0.9 .

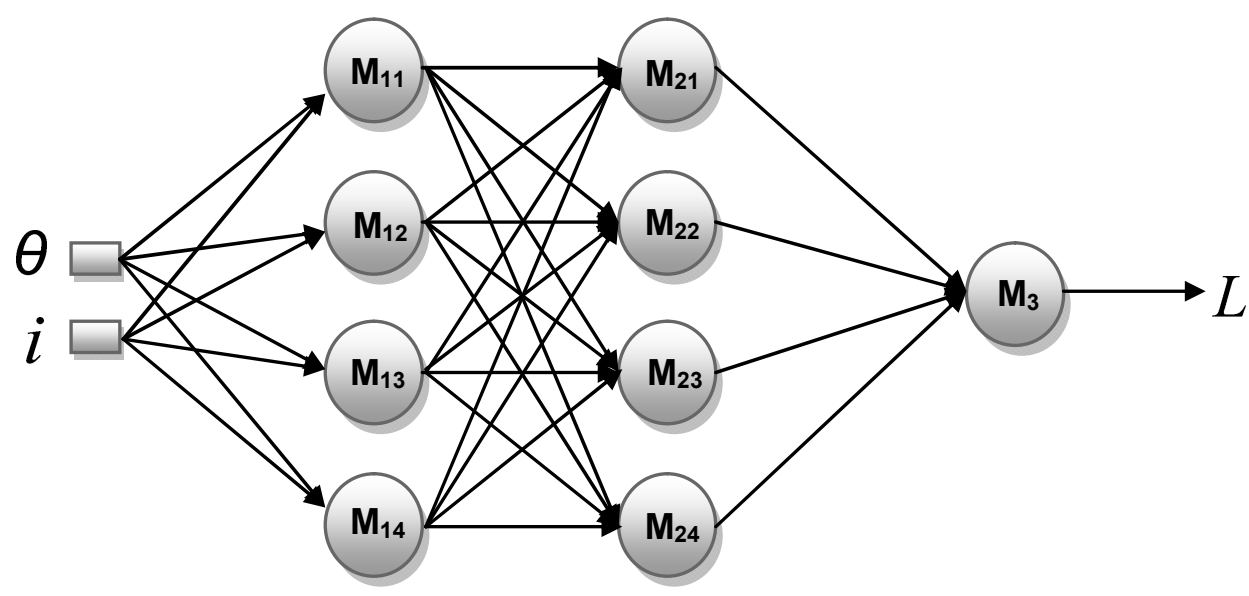

Figura 10 - Topologia de PMC usada para a aproximação da indutância.

O objetivo da PMC é mapear uma superfície de indutância a partir de uma base de dados. Por ser uma base de dados experimental, está inserido nela erros provenientes de leitura de equipamentos ou erros de calibração dos equipamentos de medições. Assim, houve uma preocupação do projetista em não superdimensionar a PMC com grandes quantidades de neurônios para não culminar no problema de Overfitting, podendo a rede não se tornar generalista.

\subsubsection{Teste e operação da PMC}

Com a parcela do banco de dados não utilizada para o treinamento, fez-se o teste e a validação da PMC proposta. O sistema se comportou de forma generalista, e foi capaz de mapear o problema abordado. Em alguns pontos de operação a rede neural obteve erros razoavelmente elevados ao ser comparar com o banco de dados experimental, em torno de $10 \%$, mas isso é explicado pelos erros inseridos no banco de dados devido medidas manuais e/ou calibrações dos equipamentos. Portanto, 
além de realizar o mapeamento da curva de indutância, a PMC também operou como filtro para eliminação de ruídos indesejados.

A resposta da PMC para todo o banco de dados pode ser visto na Figura 11. Nota-se que o perfil da indutância sofre influência da posição angular do rotor, com seu valor máximo na posição de 45 graus (alinhamento dos polos) e também sofre influência da corrente da fase. Com o aumento da corrente, os valores da indutância decaem, o que é explicado pela saturação do material ferromagnético do rotor e estator da máquina.

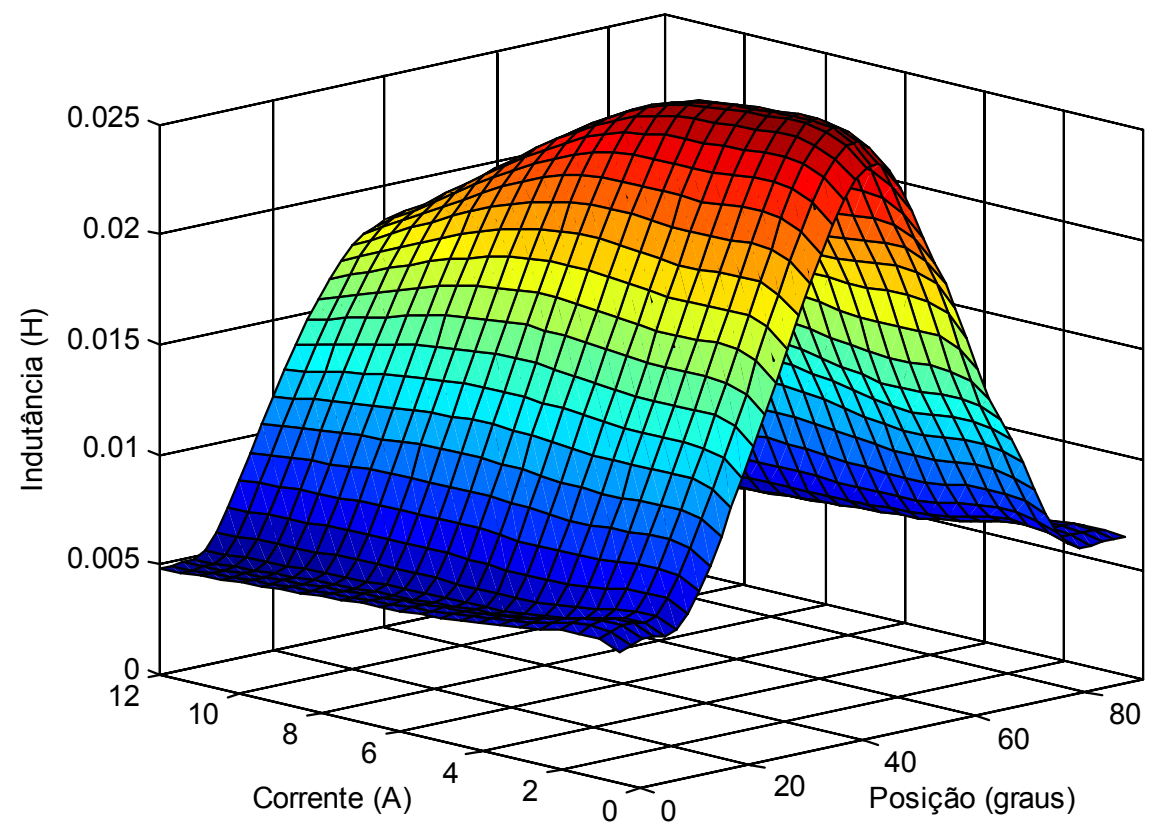

Figura 11 - Superfície de indutância obtida por meio da PMC.

Para a fase de operação da PMC, o conjunto de pesos sinápticos e limiares de ativação foram inseridos no modelo computacional do GRC, por meio de uma SFuncion, onde a cada passo iterativo da simulação a PMC recebe os sinais de $(\theta)$ e (i) fornecidos pelo próprio sistema e fornece o valor de $(L)$ dando então 
continuidade na simulação, ou seja, a rede neural opera simultaneamente com a simulação do SGRC.

\subsubsection{Resultados preliminares com a estratégia proposta}

A fim de verificar a correta dinâmica da nova estratégia neural adotada para o cálculo de indutância, a Figura 12 apresenta o comportamento da indutância para um ciclo de geração da máquina. Nota-se que com o aumento da corrente da fase ocorre pequenas oscilações no perfil de indutância, evidenciando a dependência da posição rotórica e da corrente da fase para o seu cálculo, indicando que o modelo representa adequadamente a saturação magnética

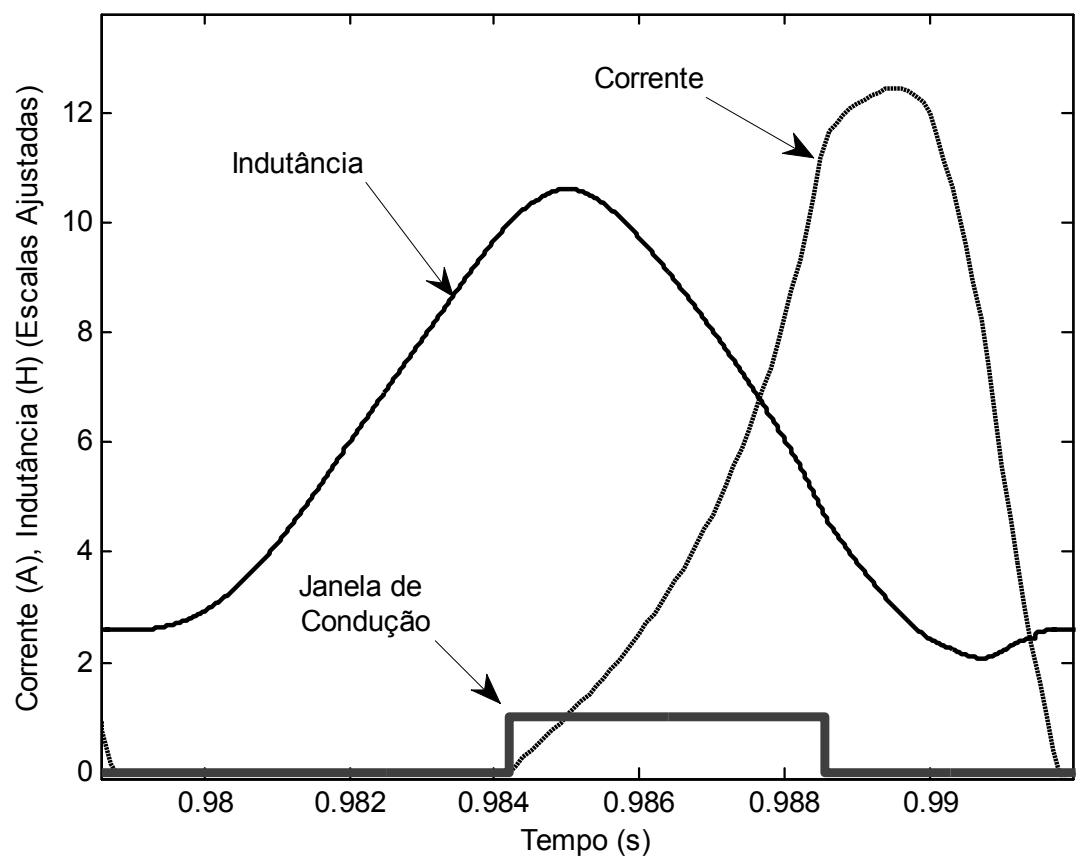

Figura 12 - Perfil de indutância por estratégia neural e forma de onda de corrente para o GRC.

Na Figura 13 (a) é mostrado o perfil de tensão de saída utilizando o modelo neural para inserção de saturação magnética. A partir do momento que inicia-se a excitação do GRC, a tensão no barramento de saída começa a subir atinge o pico 
de $86 \mathrm{~V}$ e estabiliza-se em torno de $75 \mathrm{~V}$, valor este que se mantem estável até o termino da simulação. Este pico inicial de tensão é explicado porque as correntes das fases assumem valores grandes no início da simulação, Figura 13 (b), proporcionando uma maior excitação e consequentemente maior tensão no barramento de saída. Com o decorrer da simulação as correntes assumem valores nominais e a tensão do barramento de saída se estabiliza, ou seja, o GRC simulado com a proposta neural de inclusão da saturação magnética no modelo é estável e representa corretamente o funcionamento de um GRC real.
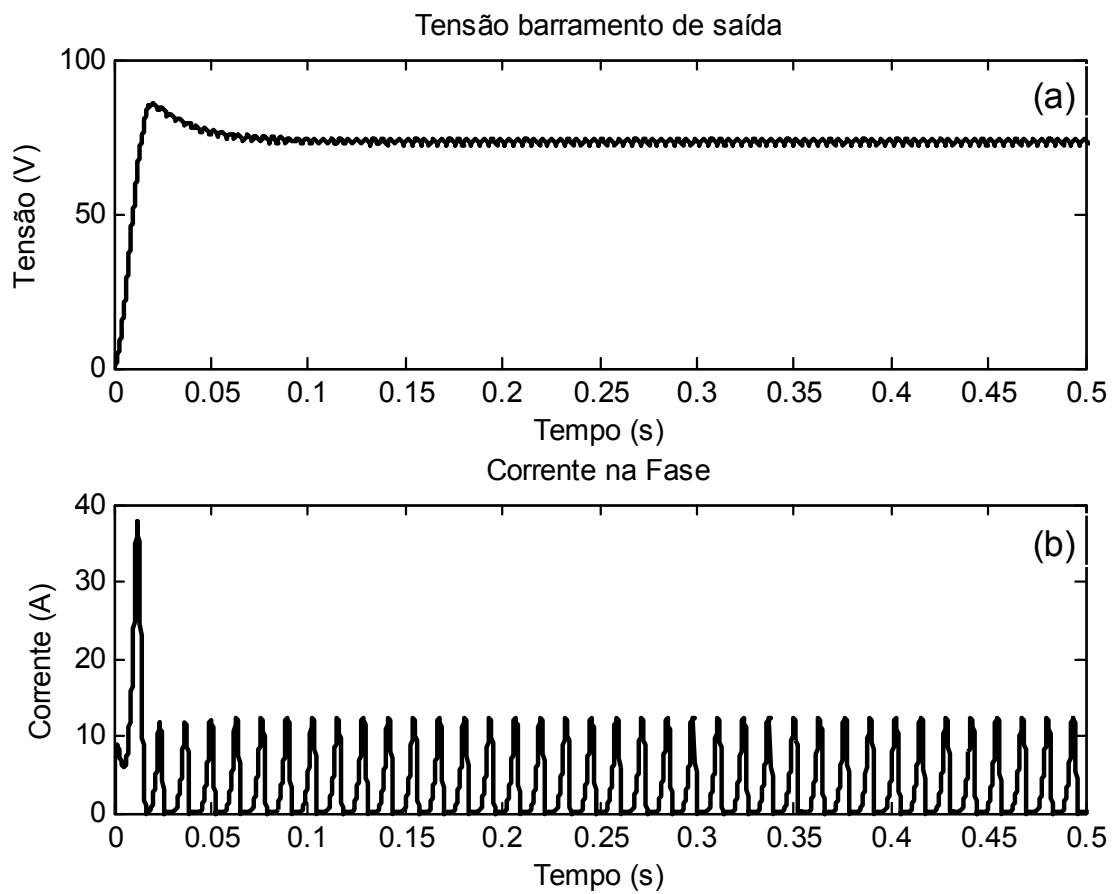

Figura 13 - Tensão no barramento de saída (a) e corrente na fase do GRC (b) obtidos por meio do modelo neural que incorpora saturação magnética. 



\section{0 conversor}

O GRC é intrinsecamente de CC, necessitando de um conversor chaveado e um driver de acionamento para seu funcionamento correto e eficiente. Em geral, o conversor utilizado para acionamentos de GRC é o conversor Half-Bridge, por herança do seu modo motor de funcionamento.

\subsection{O Conversor half - bridge (HB)}

O conversor HB apresenta quatro componentes semicondutores por fase, e em seu ciclo de funcionamento apresenta duas etapas que merecem ser ressaltadas, representando os períodos de excitação e de geração da máquina. A Figura 14 apresenta o esquemático elétrico do conversor HB para três fases.

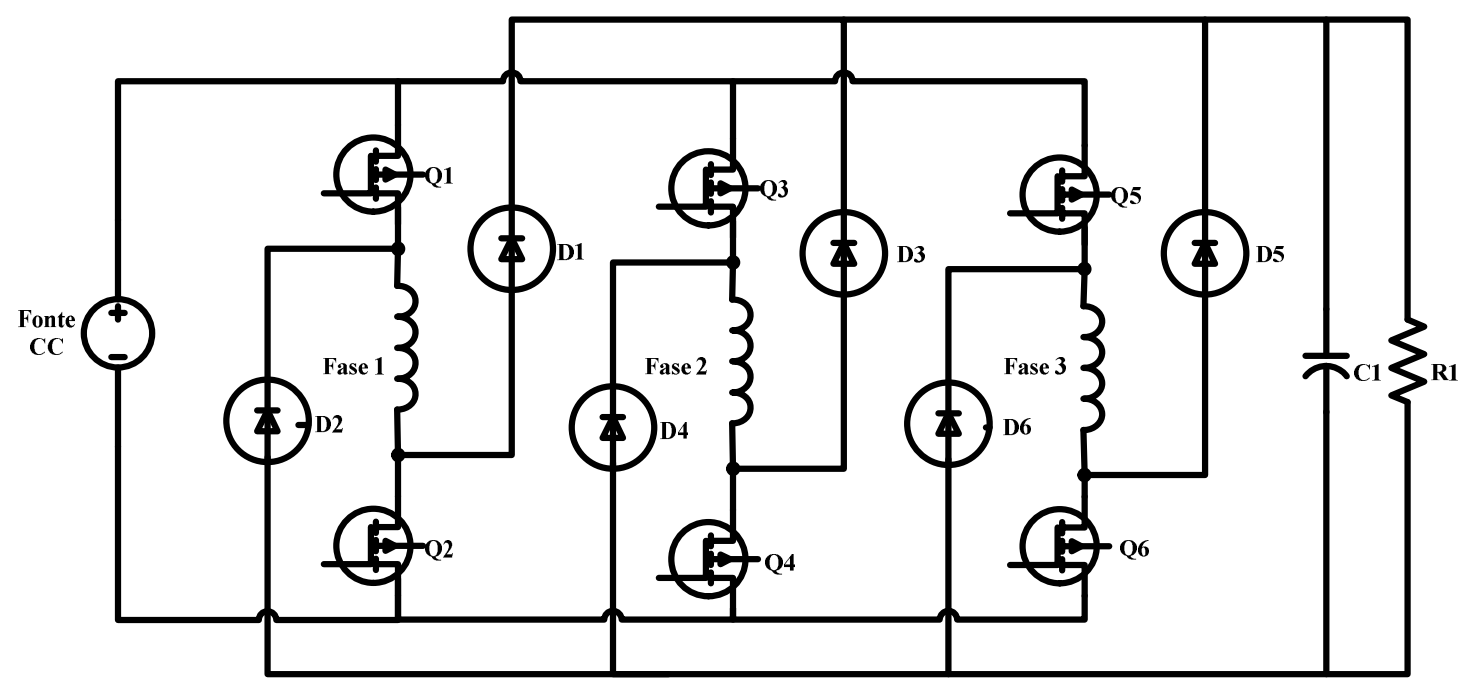

Figura 14 - Diagrama elétrico do conversor HB. 
Analisando seu funcionamento, e tendo a fase 1 do conversor como referência, a Figura 15 destaca a etapa de excitação deste conversor. Nesta etapa, as chaves Q1 e Q2 entram em condução fechando o circuito entre a fonte CC de excitação e a bobina da fase. Os diodos D1 e D2 estão reversamente polarizados e não entram em condução, logo a carga R1 e C1 não fazem parte do circuito de excitação da máquina. Este período tem a duração de 30 graus mecânicos e começa a partir do alinhamento dos dentes do conjunto estator-rotor excitado.

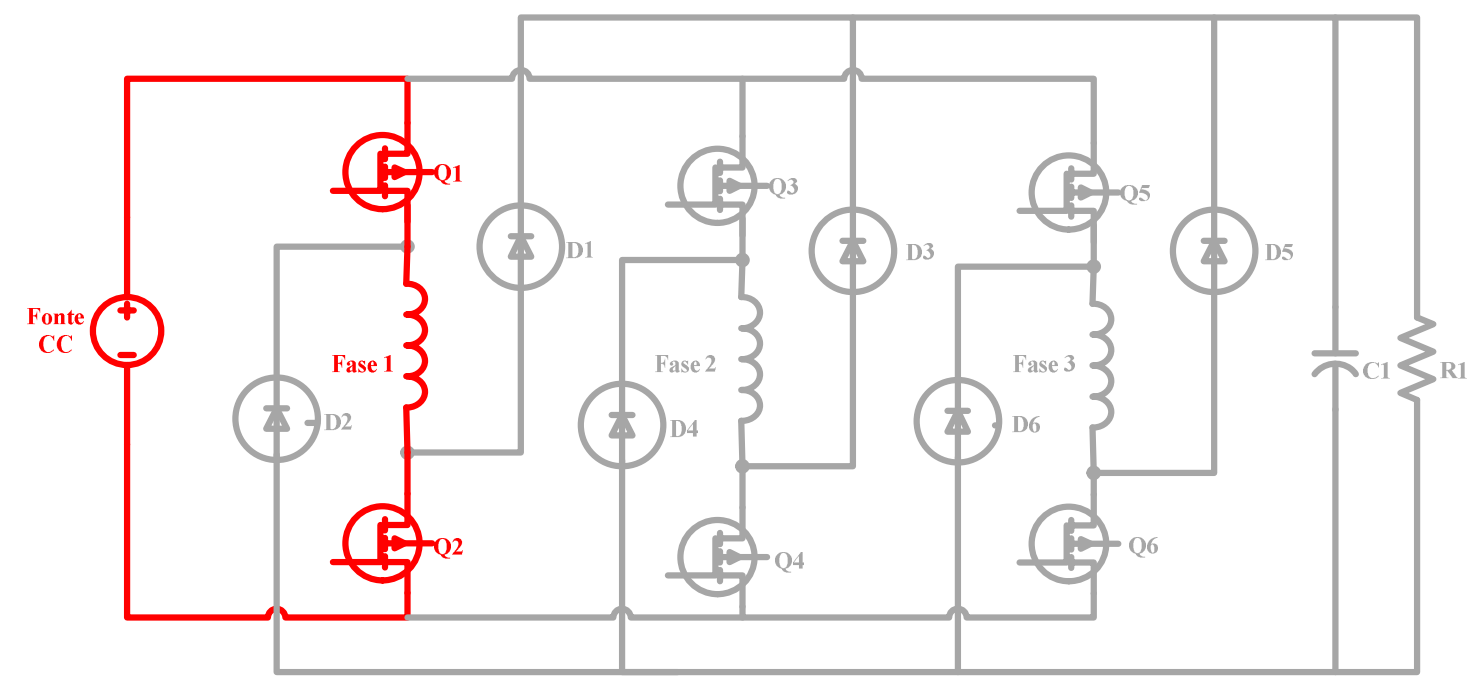

Figura 15 - Circuito de excitação do conversor HB.

Percorridos os trinta graus mecânicos, as chaves Q1 e Q2 deixam de conduzir, retirando a fonte CC de excitação do circuito. Como ocorreu armazenamento de energia nos enrolamentos da fase, esta bobina passa a suprir energia para o sistema, ganhando o aspecto de fonte. Agora, assumindo o capacitor C1 carregado, os diodos D1 e D2 estão diretamente polarizados e entram em condução, e toda energia armazenada na bobina da fase é enviada para a carga resistiva R1 e para o capacitor C1. Esta etapa é aquela de geração da máquina e pode ser observado no esquemático elétrico da Figura 16. 
Em virtude de toda energia ser entregue à carga no acionamento de um GRC, torna-se desnecessário realizar a desmagnetização das fases por meio de dois diodos de roda livre após o desligamento das chaves principais. Neste contexto, o conversor HB é ideal para sistemas onde a MRC opera como gerador e motor, por exemplo em motores-geradores de partida; mas, outras topologias especialmente criadas para o GRC estão sendo estudadas com a proposta de agregar simplicidade, economia, confiabilidade e eficiência.

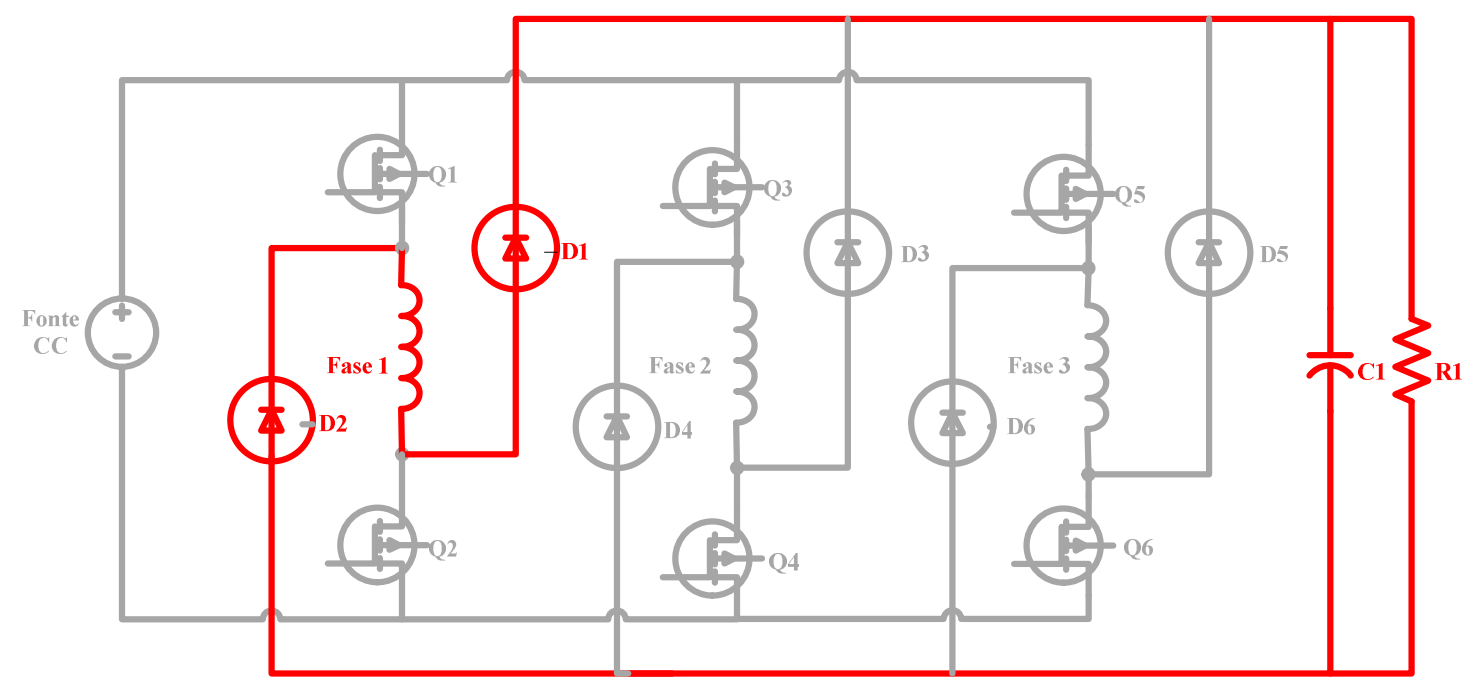

Figura 16 - Circuito de geração do conversor HB.

\subsection{O conversor alternativo}

Como já mencionado, estudos de novas topologias de conversores para o funcionamento em modo gerador da máquina a relutância estão sendo estudadas. Nesse aspecto, em FLEURY (2008) é apresentada uma comparação de três conversores para o acionamento de MRC, dentre os quais duas novas topologias concebidas especialmente para o GRC são confrontadas com o tradicional $\mathrm{HB}$, e apresentam resultados satisfatórios de economia, rendimento e confiabilidade. 
Como os conversores alternativos estudados por FLEURY (2008) obtiveram bons resultados, e são especialmente desenvolvidos para operar no modo gerador da MRC, neste trabalho será utilizado uma das topologias desenvolvidas por FLEURY (2008), Figura 17, e será aqui denominada de conversor alternativo.

O conversor alternativo é caracterizado por apresentar apenas dois componentes semicondutores por fase, sendo para fase 1, o diodo D1 e uma chave controlada Q1, diferente do tradicional conversor HB que apresenta o dobro de componentes. Em seu funcionamento, o conversor alternativo apresenta duas etapas distintas de funcionamento, são eles: o de excitação e o de geração.

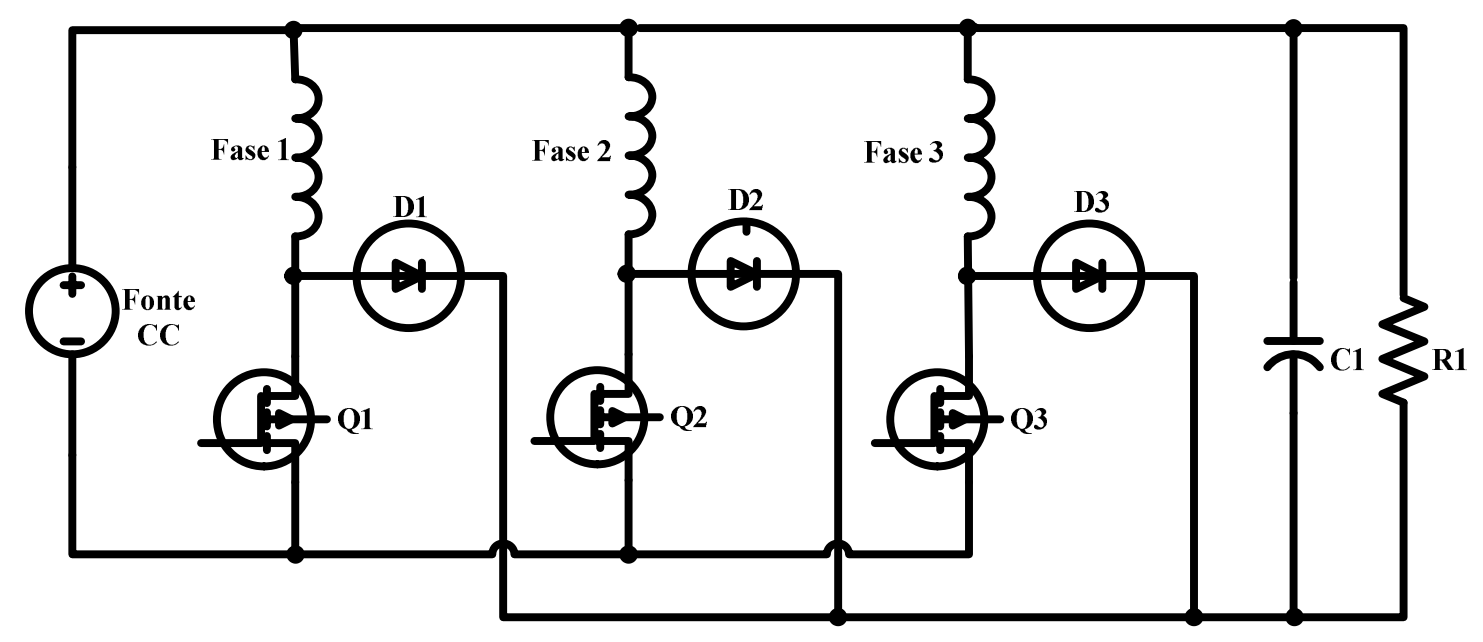

Figura 17 - Diagrama elétrico do conversor alternativo.

A Figura 18 destaca o circuito ativo do conversor na etapa de excitação para a fase 1. Essa etapa inicia-se quando a chave controlada Q1 é acionada, determinando o caminho entre a fonte $\mathrm{CC}$ e a bobina do GRC, recebendo pulsos de tensão. Admitindo-se o capacitor C1 carregado, o diodo D1 encontra-se reversamente polarizado nesta etapa e o período de excitação não apresenta nenhum efeito sobre a carga. 
A etapa de geração da fase 1 inicia-se quando a chave controlada Q1 deixa de conduzir e a FCEM armazenada na bobina de fase 1 torna-se a fonte de alimentação do circuito. O diodo D1 entra em condução e é determinado o caminho que a energia gerada é entregue a carga, finalizando o ciclo. Para as demais fases o raciocínio é análogo. Para a fase 1 esta etapa de funcionamento é destacada na Figura 19

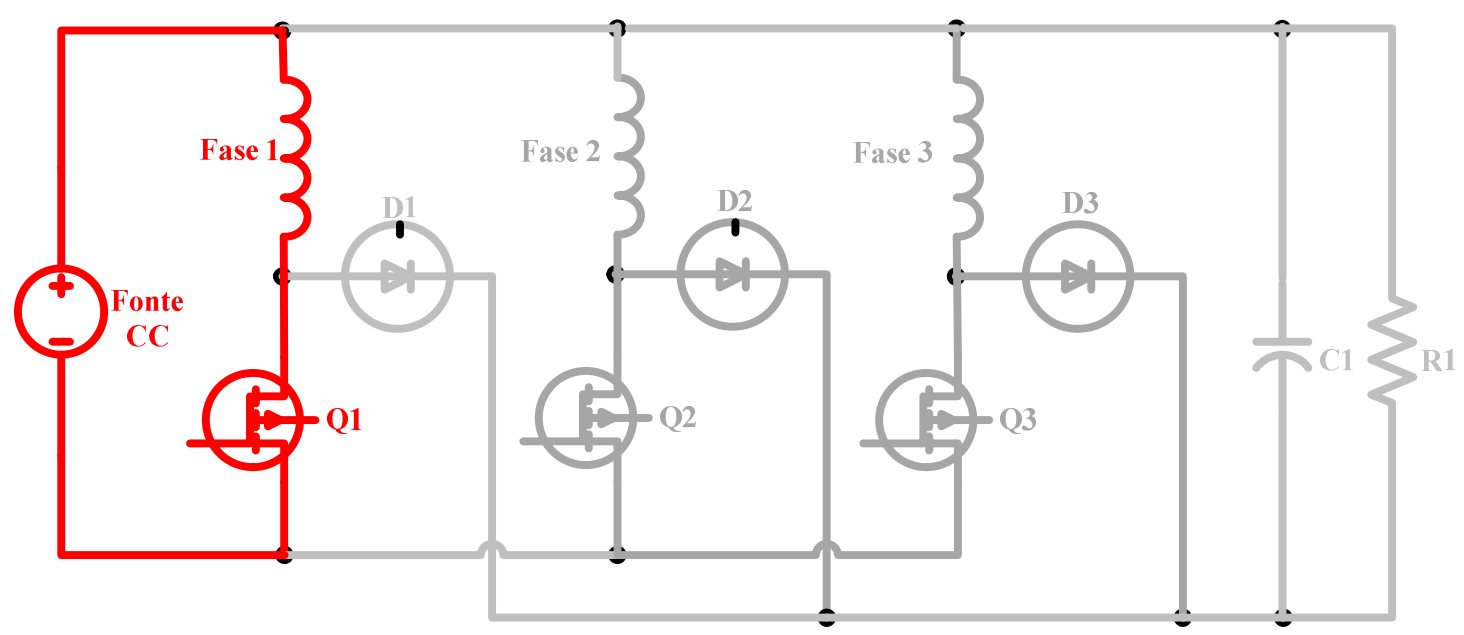

Figura 18 - Circuito de excitação do conversor alternativo.

Como o nível de tensão gerada está diretamente relacionado com a quantidade de energia que foi utilizada para realizar a excitação do GRC, uma estratégia para conseguir estabilizar a tensão na saída do GRC é atuar diretamente na fonte CC de excitação, ou seja, limitar e/ou controlar a quantidade de energia que fará a excitação dos enrolamentos das fases da máquina. Portanto, para tornar esta variável controlável, este trabalho propõe uma modificação no conversor alternativo proposto por FLEURY (2008). 


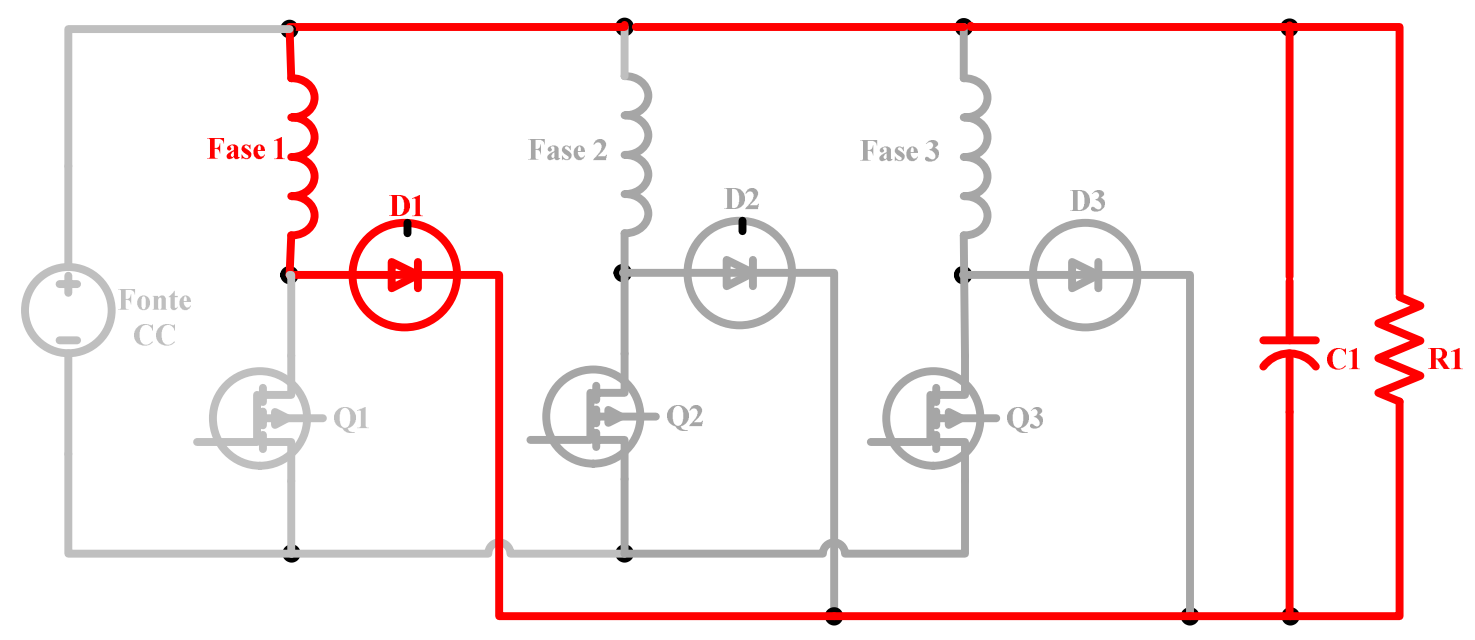

Figura 19 - Circuito de geração do conversor alternativo.

\subsection{O conversor alternativo modificado (CAM)}

Uma proposta para se conseguir um conversor controlável foi adicionar uma nova chave controlada Q0 e um novo diodo D0 ao circuito do conversor alternativo, e sua nova topologia pode ser observada na Figura 20. Esta modificação permite limitar e/ou controlar a energia de excitação entregue às bobinas do GRC. Agora, o conversor consta com três etapas de funcionamento, que são a de excitação e de geração já detalhadas na seção anterior e mais uma etapa de roda livre proveniente da inserção do diodo D0 ao circuito.

Para a fase 1, a etapa de roda livre ocorre quando a chave controlada Q1 está em condução e a chave Q0 está aberta. Nessa etapa ocorre limitação da energia vinda da fonte CC e melhor aproveitamento da energia mecânica, visto que o circuito ativo é alimentado apenas pela FCEM armazenada na bobina da fase 1 . Esta etapa se repete para as demais fases. A Figura 21 destaca esta etapa de funcionamento. 


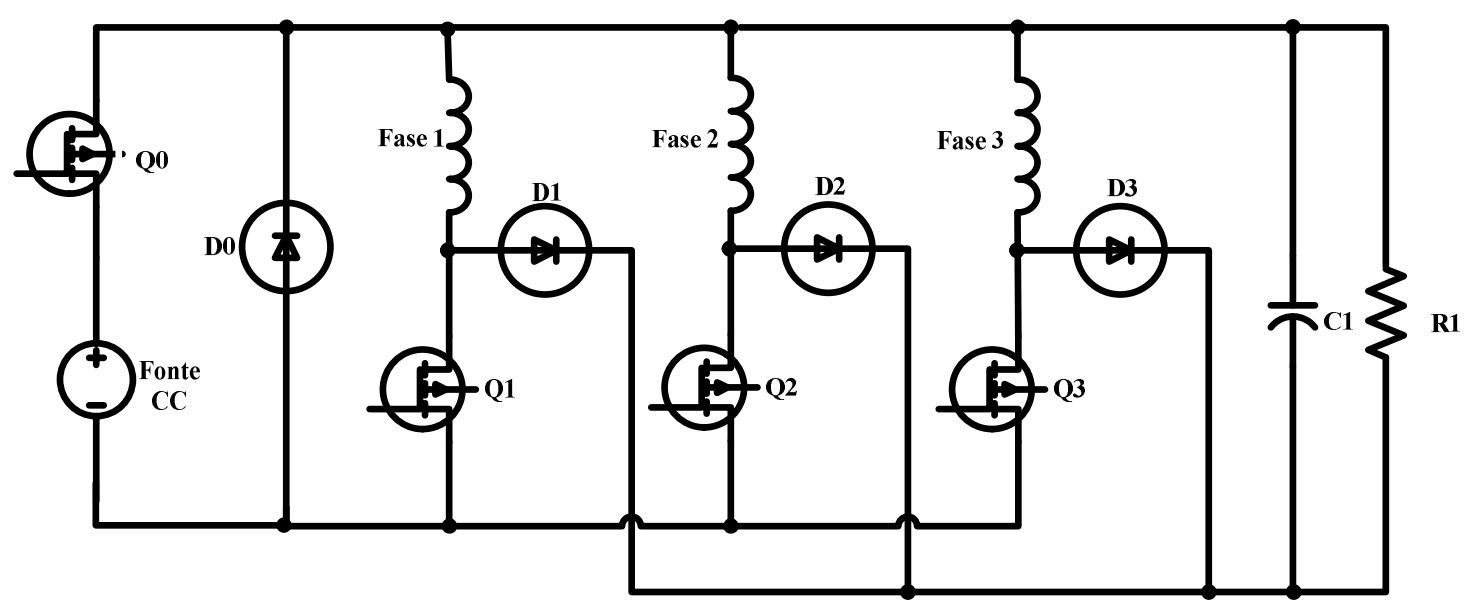

Figura 20 - Diagrama elétrico do conversor alternativo modificado.

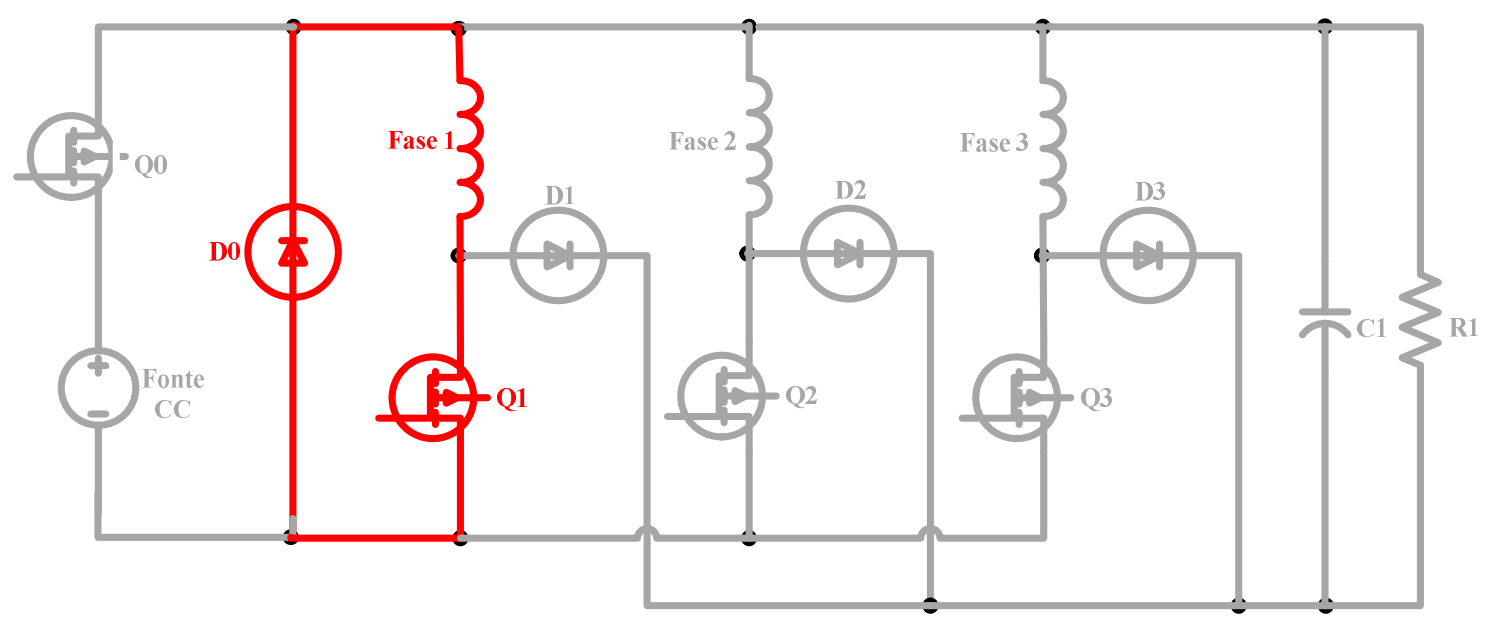

Figura 21 - Circuito de roda livre do conversor alternativo modificado.

Ao se analisar o esquemático elétrico da Figura 20, fica claro que a chave Q0 exerce a função de adicionar a fonte CC ao circuito, ou então removê-la. Com esta característica evidenciada, e que seu chaveamento (liga-desliga) não está atrelado a velocidade de funcionamento do GRC (característica esta pertencentes às demais chaves controladas do circuito), pode-se inserir um sinal PWM com frequência elevada ao gate da chave Q0, onde esse sinal é a resposta de uma 
planta de controle mediante uma situação pré-determinada. Logo, o conversor alternativo modificado agrega a particularidade de ser controlável por um sinal externo, e por esta razão o CAM foi o conversor utilizado neste trabalho. 


\section{Modelagem computacional}

A Figura 22 mostra o diagrama de blocos para o SGRC proposto. Ele consta com uma entrada elétrica e uma entrada mecânica originando uma saída elétrica. $\mathrm{Na}$ entrada mecânica inclui-se um inversor de frequência ligado a um motor de indução trifásico, fornecendo conjugado mecânico e com possibilidades de trabalhar faixas especificas de velocidades. Trata-se de uma vantagem ao se pensar em testes experimentais.

É sabido que o GRC é uma máquina inertemente passiva, i.e., não tem a capacidade de auto excitação, necessitando então de uma fonte de energia externa (Bernardeli, 2011). Para isso, a entrada elétrica do sistema foi idealizada com uma fonte variável de tensão CA associada a uma ponte retificadora. Esse conjunto constitui a excitação da máquina.

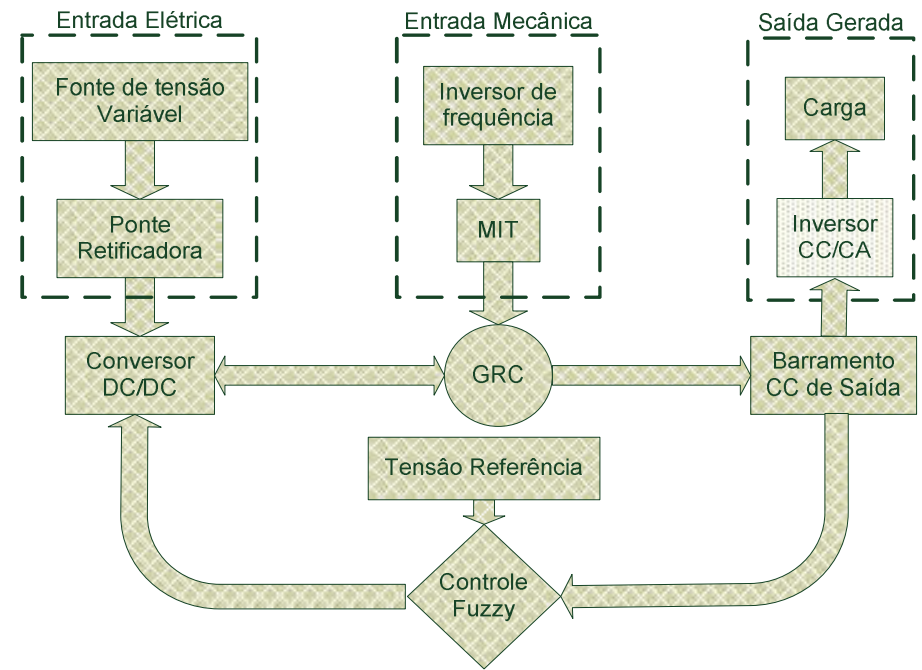

Figura 22 - Diagrama do sistema GRC.

Por sua natureza CC de geração, o sistema GRC necessita de um inversor CC/CA na saída elétrica para o abastecimento de cargas convencionais CA. 
Almejando essa inserção, técnicas de controle torna-se interessante para tornar a tensão gerada com a menor variação possível e a consequente simplificação do inversor CC/CA. É valido ressaltar que este trabalho não tem o foco na inserção do inversor CC/CA ao sistema, e sim estabilizar a tensão CC gerada.

As simulações do sistema apresentadas no esquemático da Figura 22 foram desenvolvidas no software Matlab Simulink com uso do SimPowerSystem. O modelo foi projetado para desenvolver a simulação de um GRC $6 x 4$. No modelo foram inseridas as equações de sua dinâmica e a cada passo suas variáveis são atualizadas. O CAM foi o conversor utilizado para acionar a máquina nas simulações.

A simulação é baseada em um protótipo pré-existente, construído para testes em bancada experimental, o mesmo utilizado para o ensaio de rotor bloqueado. Portanto todos os parâmetros, perfis de indutância, limites de corrente, capacitores, resistores, chaves controladas e diodos foram adequados para representar a bancada experimental. Os dados da máquina foram apresentados na Tabela 1

As simulações realizadas se dividem em três partes:

- Modelagem completa do sistema GRC trifásico $6 \times 4$, tendo como parâmetros os dados de um pequeno protótipo em uma bancada de ensaios experimentais;

- Modelagem de um controlador inteligente de tensão para o sistema GRC proposto e;

- Análise de resultados obtidos na modelagem computacional. 


\subsection{O sistema GRC}

O modelo matemático do GRC é avaliado usando um sistema computacional contendo as equações de sua dinâmica, em que as entradas são as tensões e a velocidade angular. As saídas são as correntes, conjugado mecânico e posição do rotor. Este conjunto de valores é usado para a junção do acionamento do conversor com a dinâmica da máquina, e a cada passo iterativo os valores das variáveis são realimentados. Apenas a informação da posição do rotor e o sinal de saída do controlador são suficientes para o acionamento adequado das chaves controladas do conversor. Os componentes eletrônicos foram modelados por meio do toolbox SimPowerSystem devido à praticidade e simplicidade de implementação.

A Figura 23 mostra o diagrama completo da simulação proposta. Nele constam as partes referentes ao CAM (acionamento), ao GRC, ao suprimento de energia, ao controle de disparo das chaves e à carga.

Na modelagem do GRC foi utilizado o perfil de variação de indutância obtido por meio da rede neural PMC detalhada na Seção 3.3. Com isso, os efeitos de saturação magnética foram considerados na simulação, agregando maior qualidade ao sistema. Uma nova representação gráfica da indutância de fase pode ser vista na Figura 24.

O desenvolvimento desta simulação foi tema principal do trabalho de mestrado desenvolvido por OLIVEIRA (2011b) e COELHO (2011b), e é apresentada de forma breve e objetiva neste trabalho. Para uma modelagem completa ou uma abordagem com mais detalhes, sugere-se o estudo destes trabalhos. 


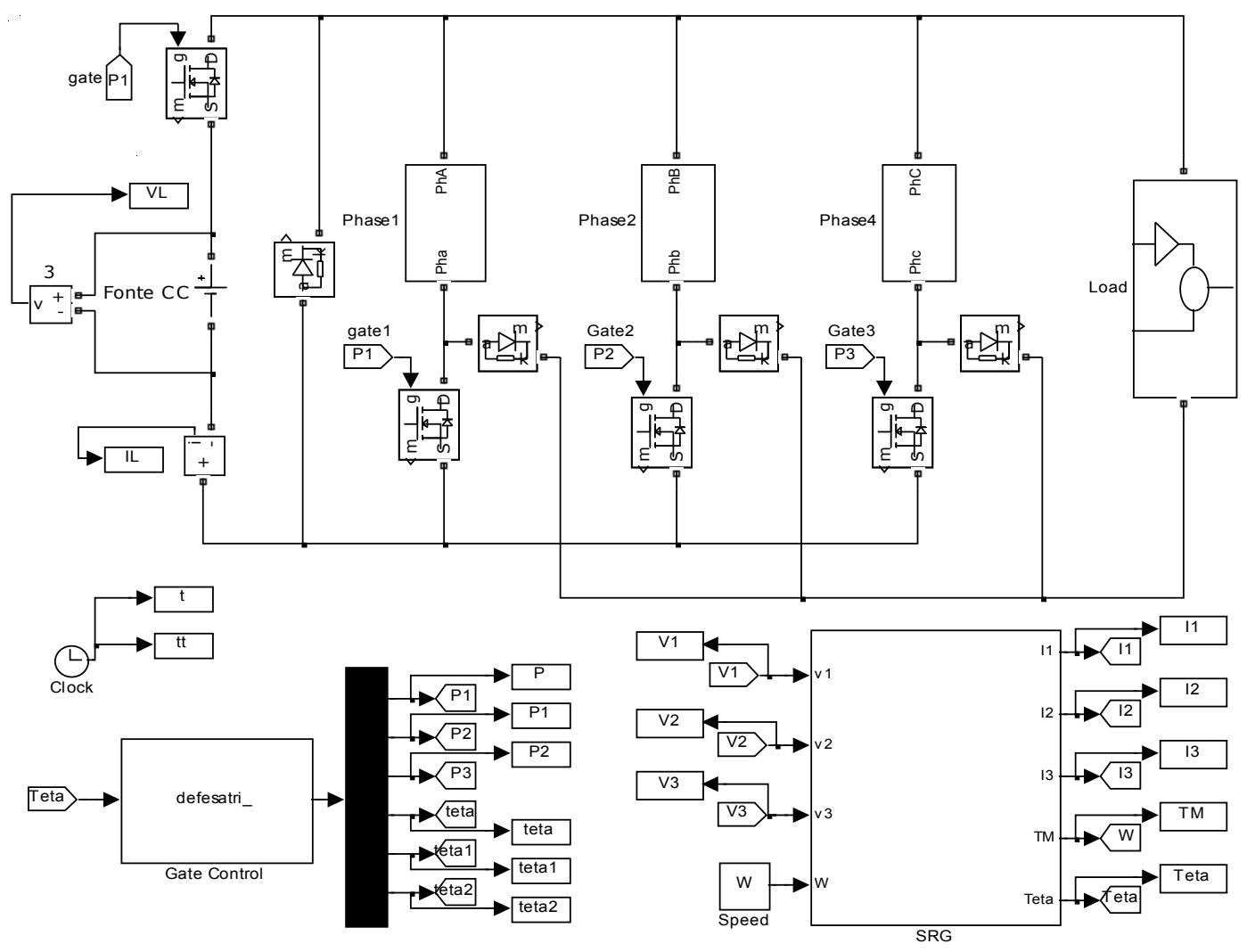

Figura 23 - Diagrama simulink do SGRC em malha aberta.

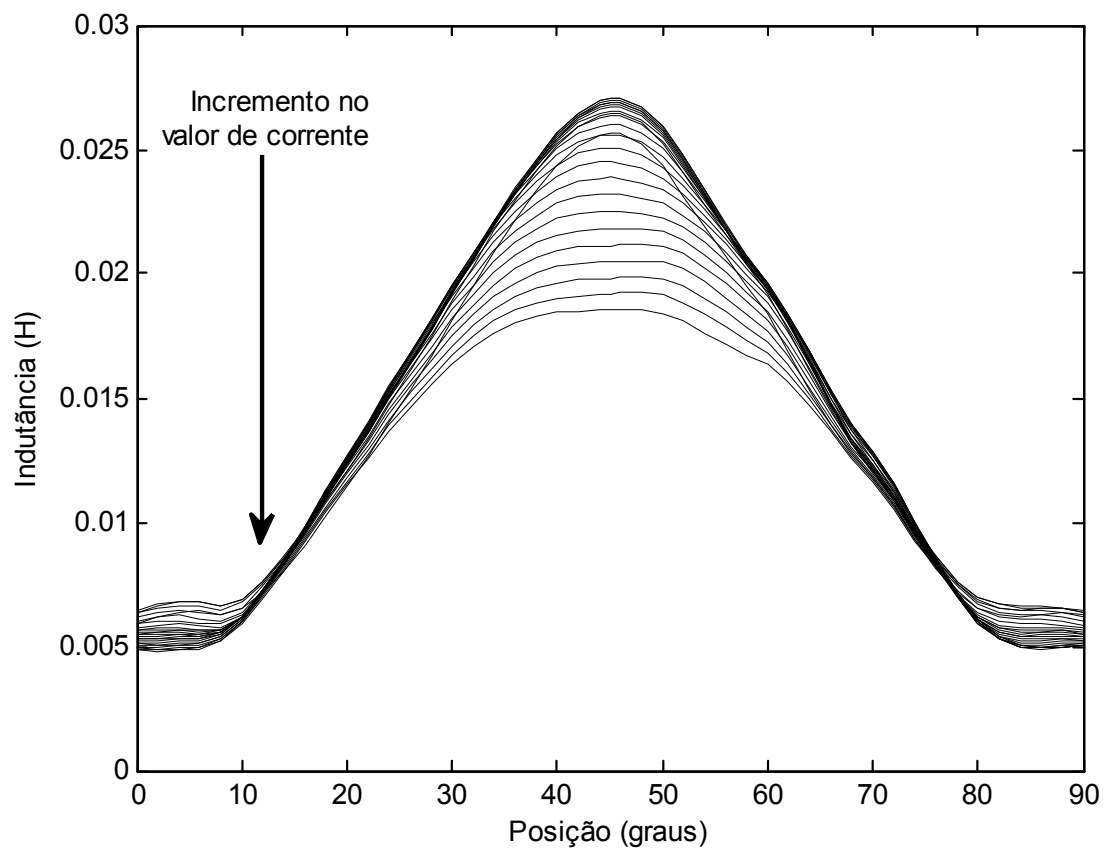

Figura 24 - Perfil de indutância com saturação magnética obtida por meio de uma PMC. 


\subsection{Sistema de controle}

A estratégia de controle empregada consiste em atuar na tensão de excitação quando houver alguma perturbação de carga e/ou velocidade no sistema, mantendo a tensão de saída próxima da tensão referência. Para isso, controla-se a quantidade de energia que a fonte de excitação entrega ao sistema, modulando-se a operação de Q0 no conversor, ou seja, varia-se a razão cíclica de Q0 (D).

A modulação de Q1, Q2 e Q3 está associada ao perfil de indutância da máquina e apresentam largura fixa em um terço do período da curva de indutância e suas frequências variam de acordo com a velocidade de rotação da máquina.

Para Q0 a frequência de modulação é fixa e a variação de D ocorre por meio da comparação entre o sinal de saída do controlador fuzzy e uma portadora triangular com $10 \mathrm{kHz}$ de frequência. Assim, consegue-se variar de 0\% a $100 \%$ do valor de tensão da fonte de excitação tal como mostra a Figura 25.

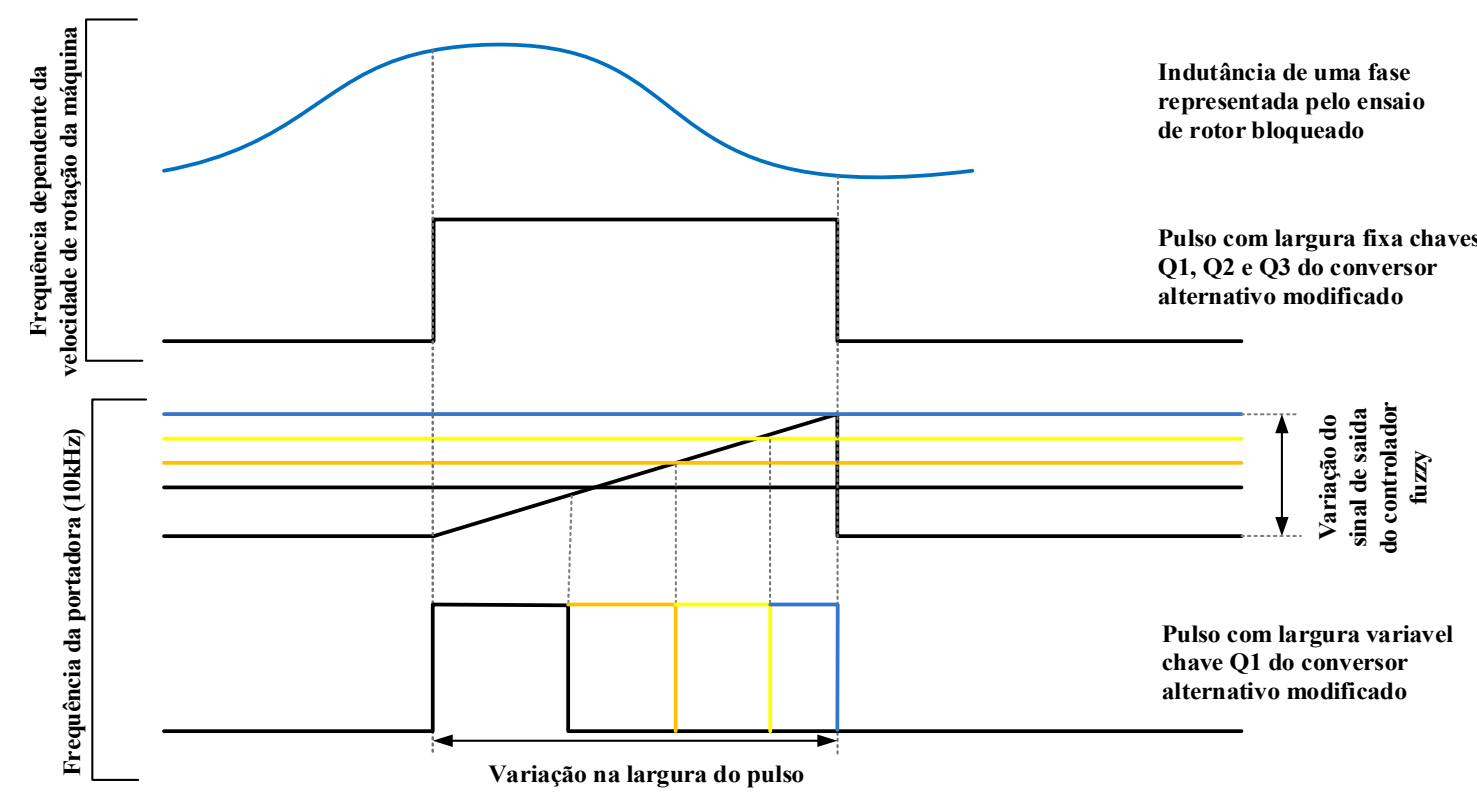

Figura 25 - Estratégia de modulação da chave Q0 do CAM.

A simulação do sistema de controle inteligente de tensão foi realizada em duas etapas: 
- Elaboração do controlador inteligente de tensão, com suas regras e parâmetros específicos e;

- Adequação e inserção do controlador inteligente de tensão ao sistema GRC previamente simulado.

\subsubsection{O controlador fuzzy}

Para a concepção do controlador foi utilizada técnicas de sistemas inteligentes, sendo sistemas fuzzy o adotado para a modelagem. A Figura 26 apresenta o diagrama esquemático do sistema fuzzy de controle aplicado para controlar a tensão de saída do SGRC. O conjunto de regras linguísticas é representado da forma "se <antecedente> então <consequente>", as quais definem as decisões associadas ao controle do processo. Todo o processo de inferência fuzzy baseia-se na regra de Modus ponens generalizada.

O controlador fuzzy consta com duas variáveis linguísticas de entrada e uma de saída. As entradas são o erro $(\varepsilon)$, que consiste na comparação do valor de tensão gerada com a tensão de referência e a derivada temporal do erro $(\Delta \varepsilon / \Delta t)$. $\mathrm{A}$ saída $(u)$ é o sinal que atuará na planta para manter a tensão de saída em níveis desejáveis.

As variáveis linguísticas estão definidas por funções de pertinências simétricas e foram utilizadas funções triangulares e trapezoidais para minimizar o custo computacional (MARTINS, 2007).

Devido à dinâmica altamente não linear de funcionamento do GRC, torna-se complexo realizar seu controle (XIANG, 2011). Portanto, para conseguir obter 
resultado satisfatório, cada variável linguística foi concebida com sete termos primários, cuja nomenclatura é apresentada na Tabela 2.

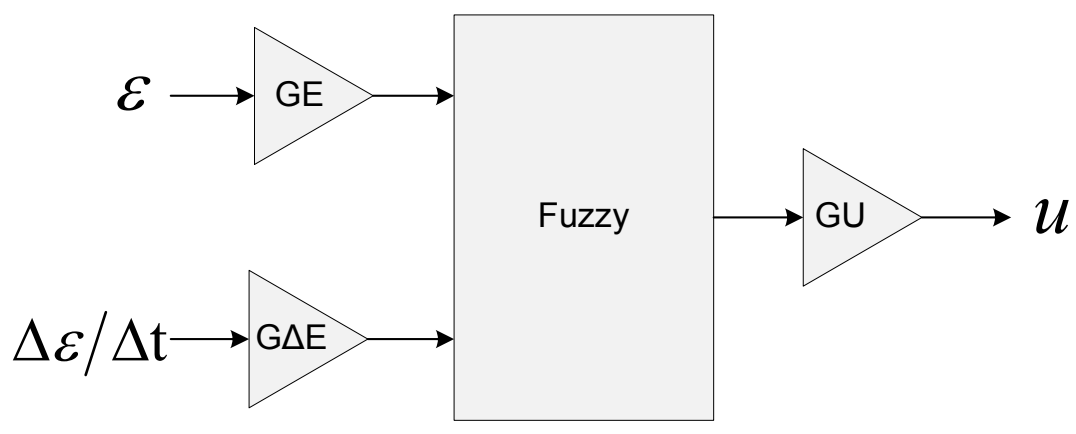

Figura 26 - Diagrama do controlador fuzzy.

A Figura 27 apresenta as funções de pertinências que definem os conjuntos associados aos termos primários da variável linguística $\varepsilon$. A Figura 28 e a Figura 29 fazem o mesmo para $\Delta \varepsilon / \Delta \mathrm{t}$ e $u$, respectivamente.

Tabela 2 - Nomenclatura dos termos primários.

\begin{tabular}{|c|c|c|c|c|c|c|}
\hline \multicolumn{7}{|c|}{ Termos Primários } \\
\hline NG & NM & NP & ZZ & PP & PM & PG \\
\hline $\begin{array}{c}\text { Negativo } \\
\text { Grande }\end{array}$ & $\begin{array}{c}\text { Negativo } \\
\text { Médio }\end{array}$ & $\begin{array}{c}\text { Negativo } \\
\text { Pequeno }\end{array}$ & Zero & $\begin{array}{c}\text { Positivo } \\
\text { Pequeno }\end{array}$ & $\begin{array}{c}\text { Positivo } \\
\text { Médio }\end{array}$ & $\begin{array}{c}\text { Positivo } \\
\text { Grande }\end{array}$ \\
\hline
\end{tabular}

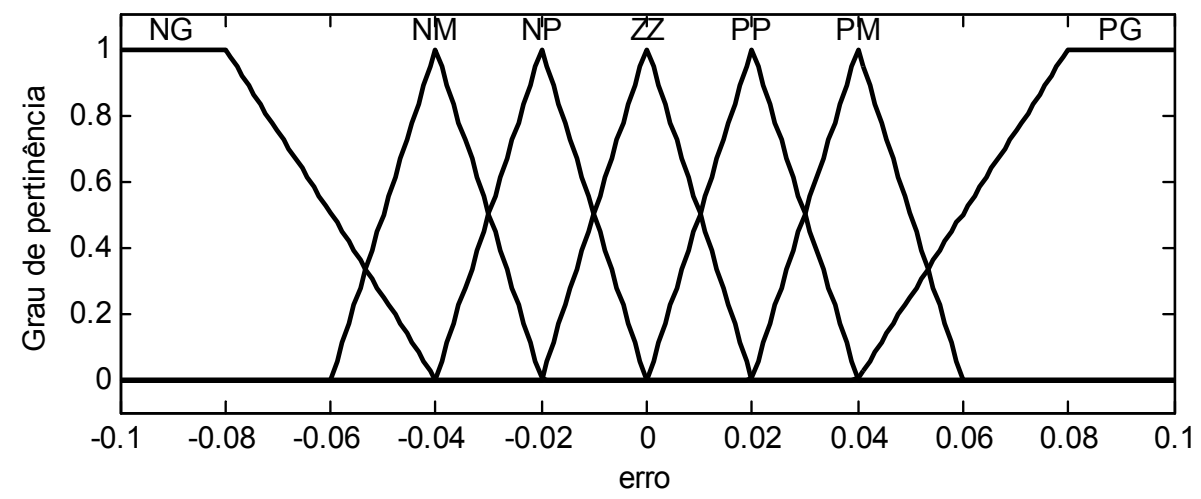

Figura 27 - Variável linguística relacionada ao erro. 
Foi utilizada a implicação de Mamdami, com a composição max-min, para realizar a interpretação das regras e associar devidamente os graus de pertinência durante o processo de inferência fuzzy. O conectivo "e" é representado pelo operador min e o conectivo "ou" pelo operador max, além do operador min na implicação e max na agregação. Para a transformação do conjunto fuzzy de saída em valores precisos pontuais foi utilizado o método de centro de área.

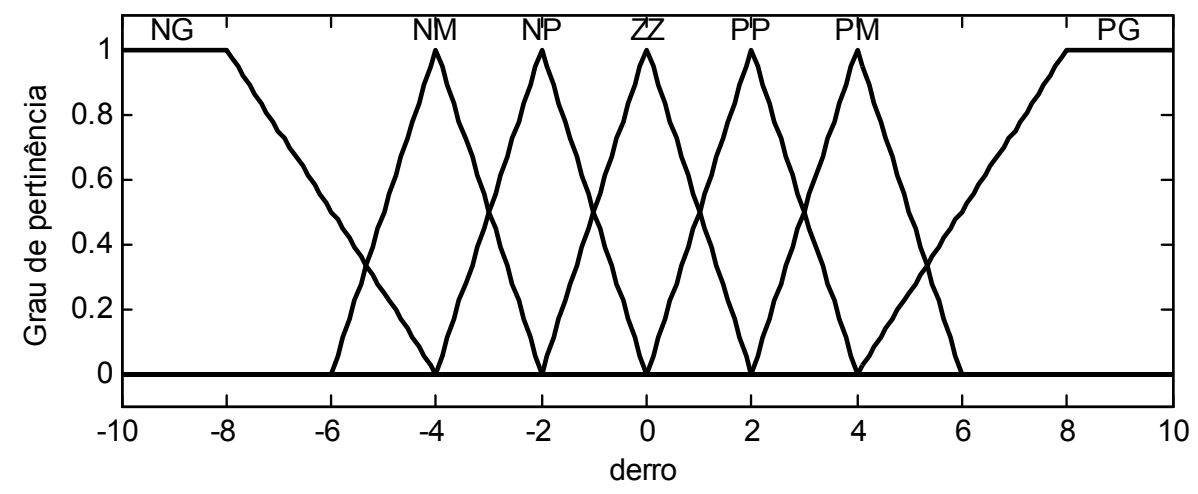

Figura 28 - Variável linguística relacionada à derivada temporal do erro.

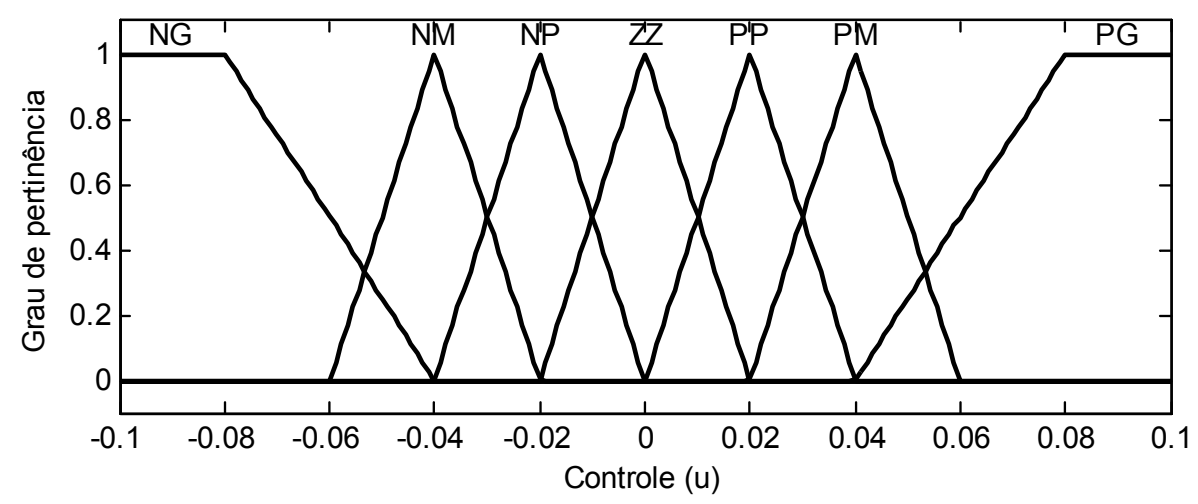

Figura 29 - Variável linguística relacionada a variável de controle (u).

O conjunto de regras de controle é apresentado na Tabela 3. Ele foi obtido por meio da experiência do especialista após análise qualitativa do sistema, e também por conhecimento prévio em estratégias de controle. 
Tabela 3 - Regras de controle.

\begin{tabular}{|c|c|c|c|c|c|c|c|}
\hline$\Delta \varepsilon / \Delta \mathrm{t}, \varepsilon, u$ & PG & PM & PP & $z Z$ & NP & NM & NG \\
\hline PG & PG & PG & PM & & & & \\
\hline PM & $P G$ & PM & PP & - & - & $\therefore$ & - \\
\hline PP & $P G$ & PM & PP & - & & & \\
\hline ZZ. & PG & PM & PP & $Z Z$ & $\mathrm{NP}$ & NM & NG \\
\hline NP & $\therefore$ & $\therefore$ & - & - & $\mathrm{NP}$ & NM & NG \\
\hline NM & - & - & - & _. & $\mathrm{NP}$ & NM & NG \\
\hline NG & - & D & - & - & NM & NG & NG \\
\hline
\end{tabular}

\subsubsection{A malha de controle}

É sabido que o SGRC tem a característica de operar bem em uma grande gama de velocidades. Porém, ao se variar a velocidade de operação do GRC, a resposta do sistema em níveis de tensão de saída não é constante.

Acordando com a afirmação, um ensaio computacional foi efetuado com o SGRC em malha aberta, onde se variou de forma linear a velocidade de operação de 1100 rpm até alcançar o patamar de 4500 rpm, sem alterar as outras variáveis do sistema. Como resposta a tensão na saída sofre variação, apresentando declive de geração com o aumento da velocidade. A Figura 30 mostra a resposta deste ensaio.

Ao se pensar em operação do SGRC em plantas que tem a característica de operação em velocidade variável, como por exemplo aplicações eólicas, o SGRC não consegue manter fixa a tensão na saída, o que leva a dispendiosos projetos de inversores CC/CA inseridos diretamente na saída da planta para prover potência alternada à carga. Portanto, é interessante a utilização de técnicas de controle para 
tornar a tensão de saída com a menor variação possível e a consequente simplificação do inversor CC/CA.
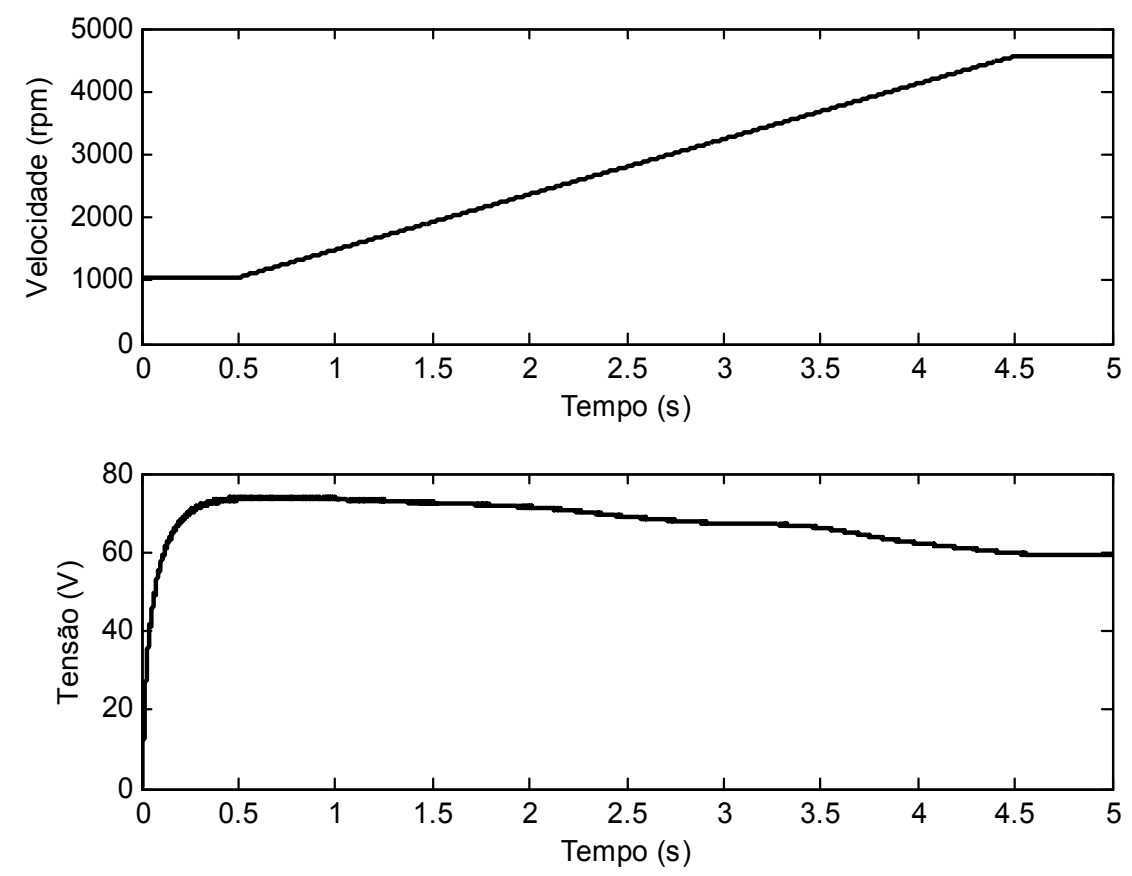

Figura 30 - Perfil de tensão de saída com velocidade variável em malha aberta.

Outra característica do SGRC é a dependência da tensão gerada com a carga que está sendo suprida por ele. Como trata-se de um barramento CC de energia, o qual deseja manter estável, a carga considerada é puramente resistiva. A Figura 31 apresenta o resultado do ensaio. O ensaio iniciou-se com a resistência de 11.1 $\Omega$. adicionou-se $5 \Omega$ a este valor de carga no instante [1.0 s]. Acrescentou-se mais $5 \Omega$ a este valor no instante [2.0 s], que se manteve constante até o fim da simulação.

Diferentemente dos geradores a indução ou geradores síncronos, com o acréscimo da carga no barramento de saída do SGRC ocorre o aumento da tensão do barramento e a diminuição dos valores de corrente. Este comportamento é esperado, pois o GRC opera injetando corrente ao sistema, ou seja, tem a 
característica de uma fonte de corrente, diferentemente dos geradores convencionais que são interpretados como fonte de tensão.

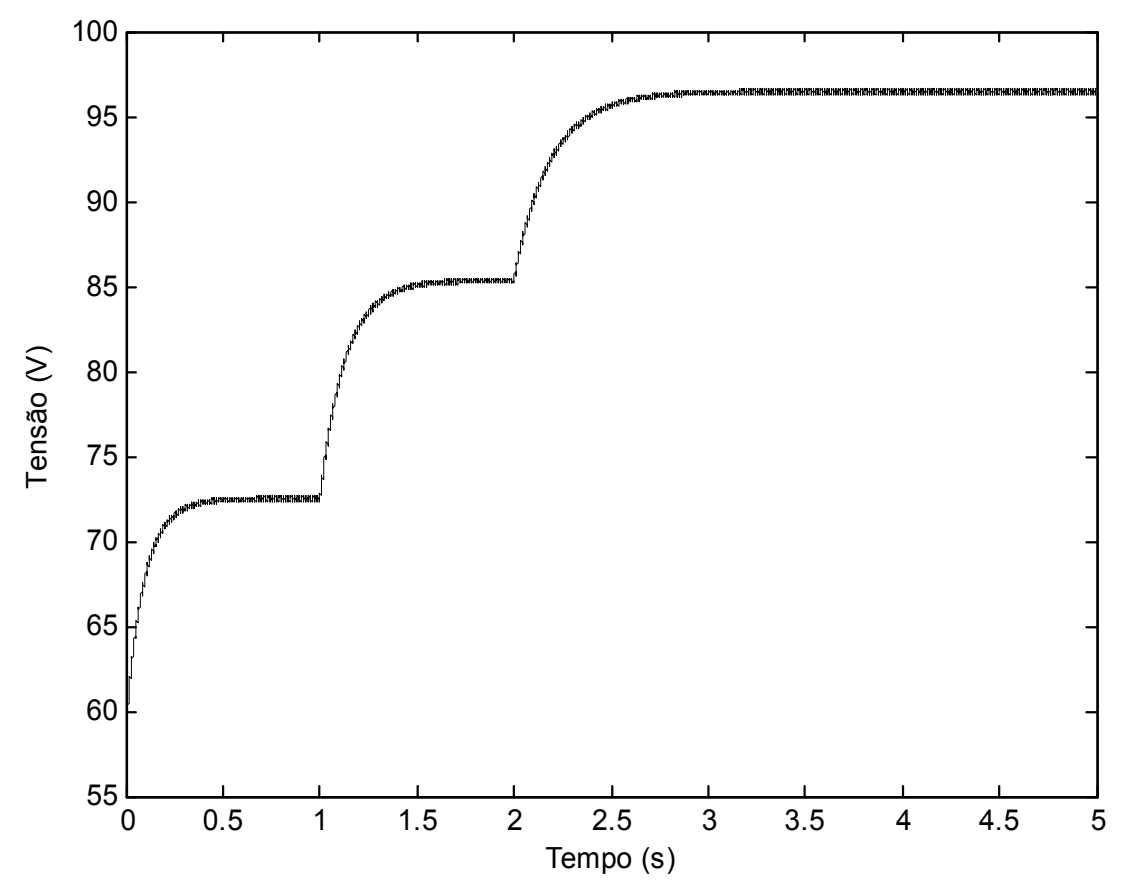

Figura 31 - Perfil de tensão de saída com variação de carga.

Com o objetivo de reduzir ou suavizar as variações do barramento de saída do SGRC provenientes da operação em velocidade variável e/ou mudança da carga abastecida por este barramento, este trabalho então propõe um método de controle inteligente alicerçado em sistema fuzzy. Uma simulação de malha de controle foi elaborada com auxílio do software Matlab Simulink. Toda a programação foi realizada por diagramas de blocos, linguagem esta característica do Simulink, o que tornou-se cômodo realizar a interligação com o SGRC, previamente simulado neste mesmo ambiente. Apenas o núcleo do controlador foi modelado em linhas de código e agregado à simulação por meio de uma S-Function. A Figura 32 apresenta a modelagem da malha de controle para a planta GRC. 
A estratégia de controle empregada consiste em atuar na tensão de excitação quando houver variação de velocidade e/ou carga para manter a tensão de saída próxima da tensão referência. Para isso, controla-se a quantidade de energia que a fonte de excitação entrega para o sistema, modulando-se a operação da chave Q0 no CAM, indicado na Figura 20.

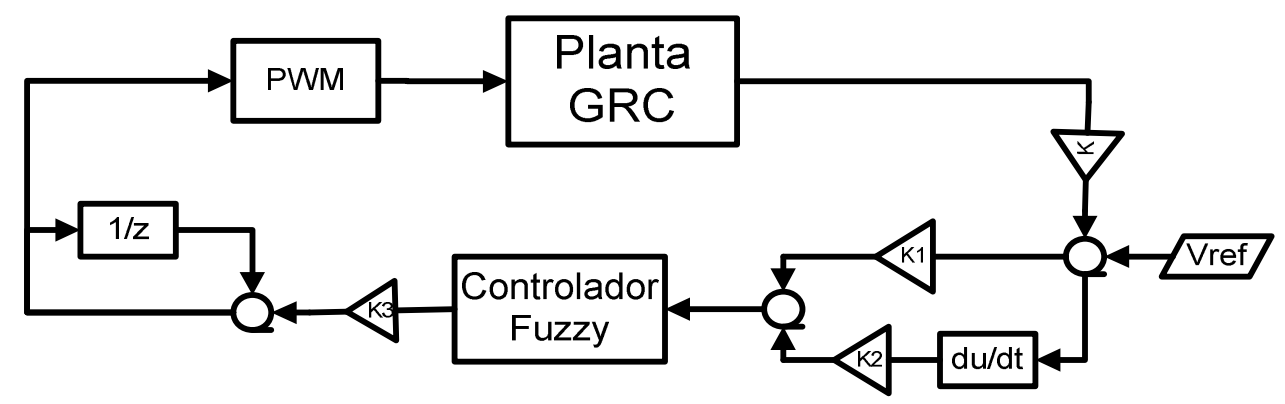

Figura 32 - Sistema GRC com malha de controle.

A operação da planta de controle inteligente consiste basicamente em analisar os valores de tensão do barramento de saída do GRC, compará-lo com uma referência pré-estabelecida e tornar a diferença desta comparação, ou seja, o erro, o menor possível, a fim de manter o barramento de saída constante. Para isso, a variável erro é uma variável de entrada do controlador fuzzy. Para se ter a informação comportamental de tendência da variável erro, foi realizado a derivada temporal do erro, e esta nova variável também foi inserida como entrada do controlador fuzzy.

Após ser alimentado com as variáveis de entrada, o núcleo do controlador realiza todas as iterações de lógica fuzzy necessárias e gera um sinal de controle na saída. O sinal de saída do controlador fuzzy é inserido como sinal de referência para um modulador PWM (com $10 \mathrm{kHz}$ de portadora), sendo este o responsável por acionar a chave Q0 do CAM. Como a planta GRC a ser controlada é bastante complexa e altamente não linear, um controlador fuzzy incremental foi utilizado, ou 
seja, a cada passo da simulação o valor do sinal de saída do controlador fuzzy é incrementado com o valor do passo anterior do sinal de saída. Esta técnica visa minimizar erros no valor de regime da tensão do barramento de saída, agregando aqui maior qualidade ao controlador.

\subsection{Resultados de simulação}

Com auxílio do modelo computacional do SGRC, foram realizadas simulações sobre diferentes aspectos, tais como: variação de velocidade, variação de carga e variação de tensão de excitação com o sistema operando em malha aberta e malha fechada. Estes ensaios simulados visavam conhecer o comportamento de geração do GRC sobre vários aspectos.

Para a modelagem, o GRC supre uma carga de $11.1 \Omega$ em paralelo com um capacitor de $18 \mathrm{mF}$. Para as chaves foram utilizados MOSFET do Toolbox SimPowersys do Simulink, com resistência interna de $0.2 \Omega$ e diodos com resistência interna de $0.011 \Omega$, com queda de tensão de $0.8 \mathrm{~V}$, que são os valores especificados em datasheet para o MOSFET IRFP240 e o diodo SKR26/08. Já que fazem parte do circuito, seus valores também foram considerados na análise computacional. $O$ enrolamento das fases consta com resistência de $0.33 \Omega$ para cada fase, com seu perfil de indutância mostrado na Figura 24. Uma fonte CC ajustada com tensão constante de $60 \mathrm{~V}$ foi utilizada como sistema de excitação das bobinas de fase. $\mathrm{A}$ velocidade de operação do sistema foi mantida fixa em 1800 rpm.

Os dados apresentados como parâmetros de entrada da simulação são mantidos como padrão para todas as simulações apresentadas neste trabalho, a salvo as simulações onde deseja-se realizar a mudança de alguma variável para 
estudar o comportamento do sistema mediante esta perturbação, onde será devidamente ressaltada essa escolha.

\subsubsection{Resultados de simulação do SGRC em malha aberta}

A estratégia empregada nas simulações apresentadas neste trabalho foi adotar um acionamento sequencial das fases do GRC, cada uma em seu tempo específico, durante um período correspondente a 30 graus mecânicos. Visando melhor desempenho do modelo computacional, vários testes foram realizados com o objetivo de se obter a posição de início da excitação. A posição que obteve melhor desempenho foi alcançada iniciando-se a excitação da fase a 5 graus antes da posição de total alinhamento. Este ponto é onde o GRC testado trouxe maior volume de geração. Para o sistema em malha aberta, a chave controlada Q0 do CAM permaneceu sempre fechada, pois sua operação não é interessante para o sistema sem a malha de controle.

A Figura 33 mostra a dinâmica de funcionamento do GRC. Ela consta com a janela de condução das chaves controladas, a corrente de excitação e o pulso de corrente gerada nas três fases. Como as fases do GRC são acionadas de forma sequencial, cada uma a seu tempo, as janelas de condução não se sobrepõe; porém, ao término da janela de condução de uma fase inicia-se a janela da fase seguinte. Percebe-se na Figura 33 que o período de excitação de cada fase é diferente, e que o período de geração da fase está compreendido na janela de

excitação de outra fase, ou seja, enquanto uma fase é excitada outra fase está entregando energia para a carga. Nota-se também, que a parcela de corrente correspondente ao período de geração chega a zero antes do término da janela de 
condução da fase seguinte, ou seja, esta máquina tem a caraterística de uma dinâmica descontinua de geração de energia.

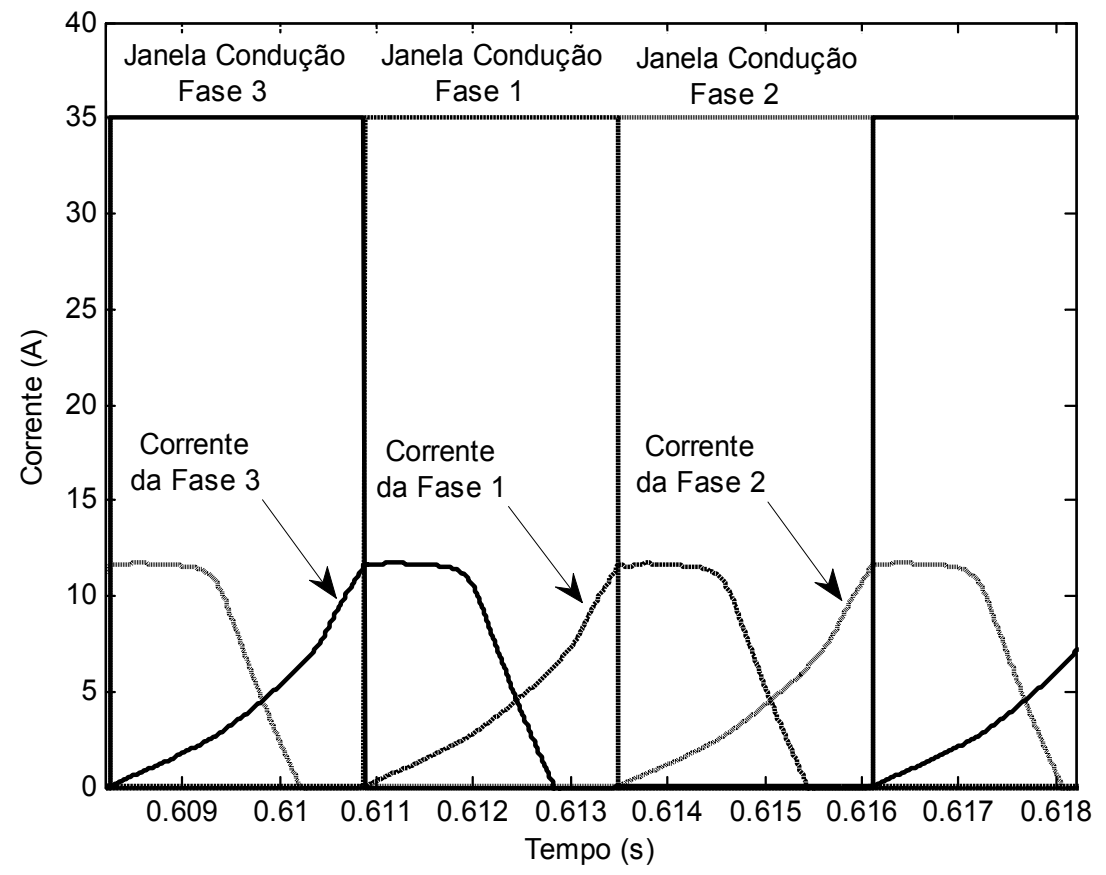

Figura 33 - Dinâmica de geração do GRC.

A Figura 34 mostra a dinâmica de funcionamento de uma fase. Durante o processo de excitação, as chaves estão conduzindo e o diodo não; logo, a tensão de excitação é a mesma da fonte de excitação menos as perdas causadas pelas chaves controladas. Durante todo esse período ocorre a elevação da corrente. Quando as chaves controladas não estão conduzindo, os diodos estão diretamente polarizados e conduzem. Como resultado, neste período, a tensão nos terminais do enrolamento é uma FCEM, funcionando como uma fonte de tensão, que alimenta o capacitor e a carga. A Figura 35 traz a mesma dinâmica, porém para as três fases do GRC. 


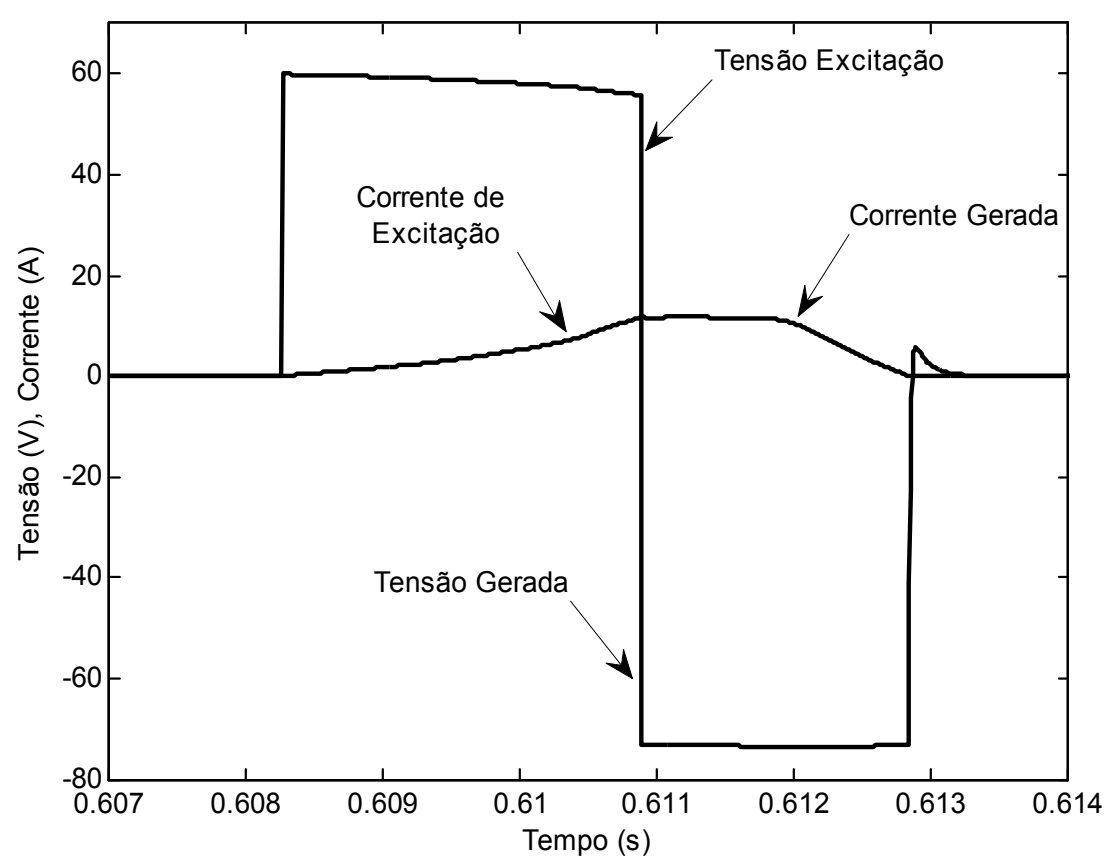

Figura 34 - Dinâmica de funcionamento da fase do GRC.

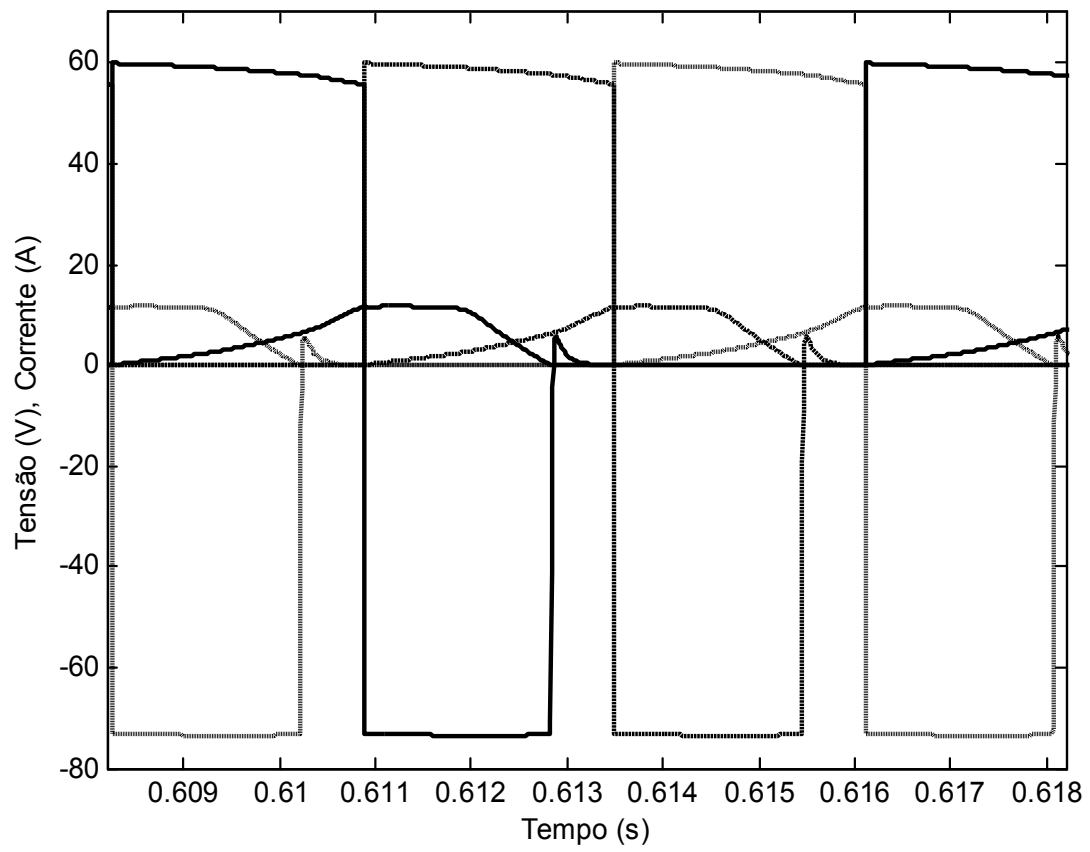

Figura 35 - Dinâmica de funcionamento das três fases do GRC. 
A Figura 36 mostra o formato das ondas de tensão e corrente no barramento CC que alimenta o sistema. Os picos de correntes representados são provenientes da excitação das fases do GRC que se repetem sucessivamente. Fica evidenciado que o período de geração de cada fase não apresenta influencia para o barramento CC de excitação, visto que a corrente gerada não aparece no barramento.

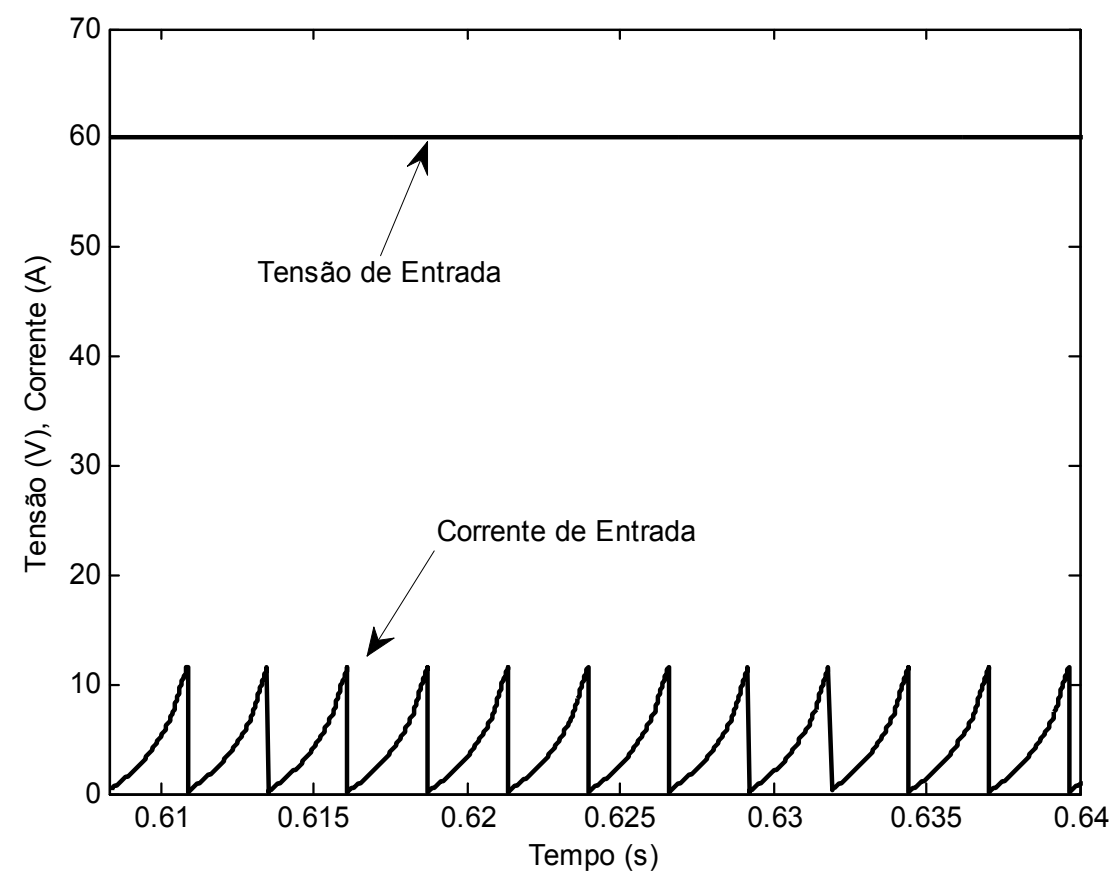

Figura 36 - Tensão e corrente do barramento CC de entrada.

A Figura 37 mostra os perfis de tensão e corrente que são entregues para a carga. Por se tratar de uma máquina de acionamento sequencial, o GRC sofre com descontinuidades de energia entregue às cargas. Para suavizar essas descontinuidades foi empregado um capacitor em paralelo com a carga, o qual fornece energia à carga quando a máquina não o faz. 


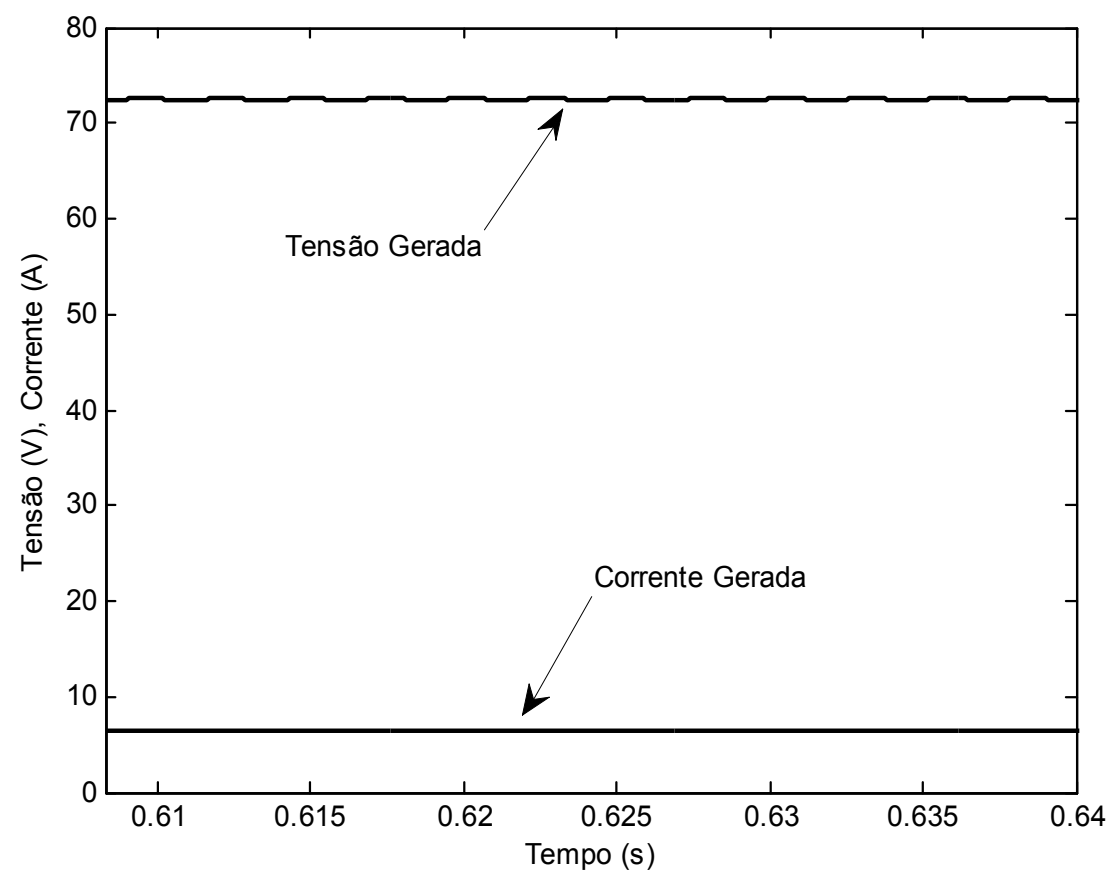

Figura 37 - Tensão e corrente na carga.

\subsubsection{Resultados dinâmicos de simulação em malha fechada}

Com a implementação da malha de controle ao SGRC, algumas mudanças ocorrem na dinâmica de funcionamento da máquina. Agora, com a atuação do controlador, a chave Q0 do CAM não permanece a todo instante fechada, portanto, a etapa de roda livre do conversor torna-se ativa em determinados instantes. Para este ensaio foi mantido fixos todos os parâmetros de entrada da simulação do sistema GRC e inserido o sistema fuzzy de controle para o GRC. Os valores das variáveis permaneceram os mesmos do ensaio realizado em malha aberta e a tensão referência para o controlador foi predeterminada em 50 V. A Figura 38 apresenta a modelagem em Simulink do sistema de controle fuzzy proposto. 


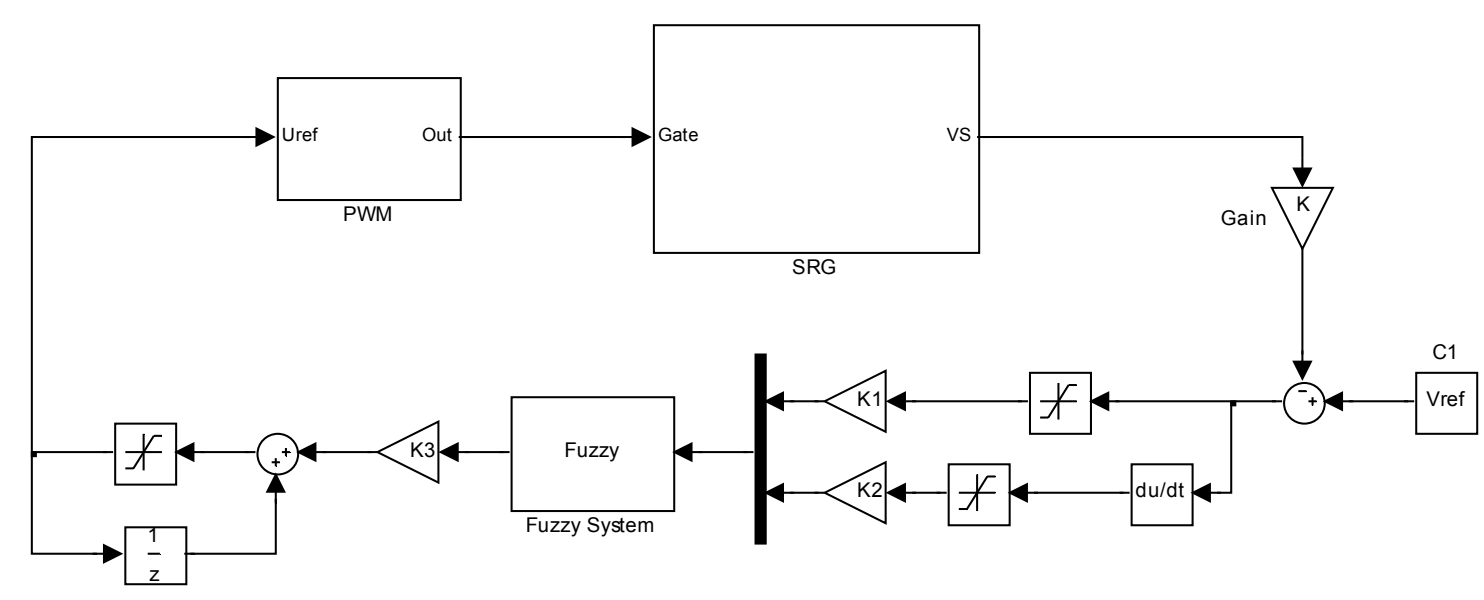

Figura 38 - Diagrama Simulink do sistema de controle fuzzy.

A Figura 39 mostra a dinâmica de funcionamento de uma fase do GRC com a inserção do sistema fuzzy de controle. Em malha aberta, a tensão de excitação é um pulso quadrado e contínuo que percorre toda a janela de excitação da fase. Já com o sistema fuzzy de controle, a atuação da chave Q0 dá origem a um perfil descontínuo de tensão de excitação, onde as descontinuidades respeitam a frequência pré-estabelecida da portadora PWM. É interessante ressaltar que, diferentemente da tensão de excitação, a corrente na fase não apresenta as descontinuidades imposta pela chave Q0, pois a corrente responsável pela excitação da máquina é a soma da corrente que flui pelo diodo D0 e pela corrente fornecida pela fonte de excitação. Assim, com a modulação da chave Q0, conseguese atuar nos níveis médios de corrente de excitação, seguindo a lógica de que quanto menor o D de Q0 menor será os valores médios de corrente de excitação. Esta constatação é apresentada na Figura 40, onde a linha tracejada representa a corrente de excitação de uma fase da máquina simulada com o conversor alternativo (sem inserção de Q0) e a linha sólida é a corrente de excitação de uma fase da máquina simulada com o CAM e D fixado em $80 \%$ de condução. 


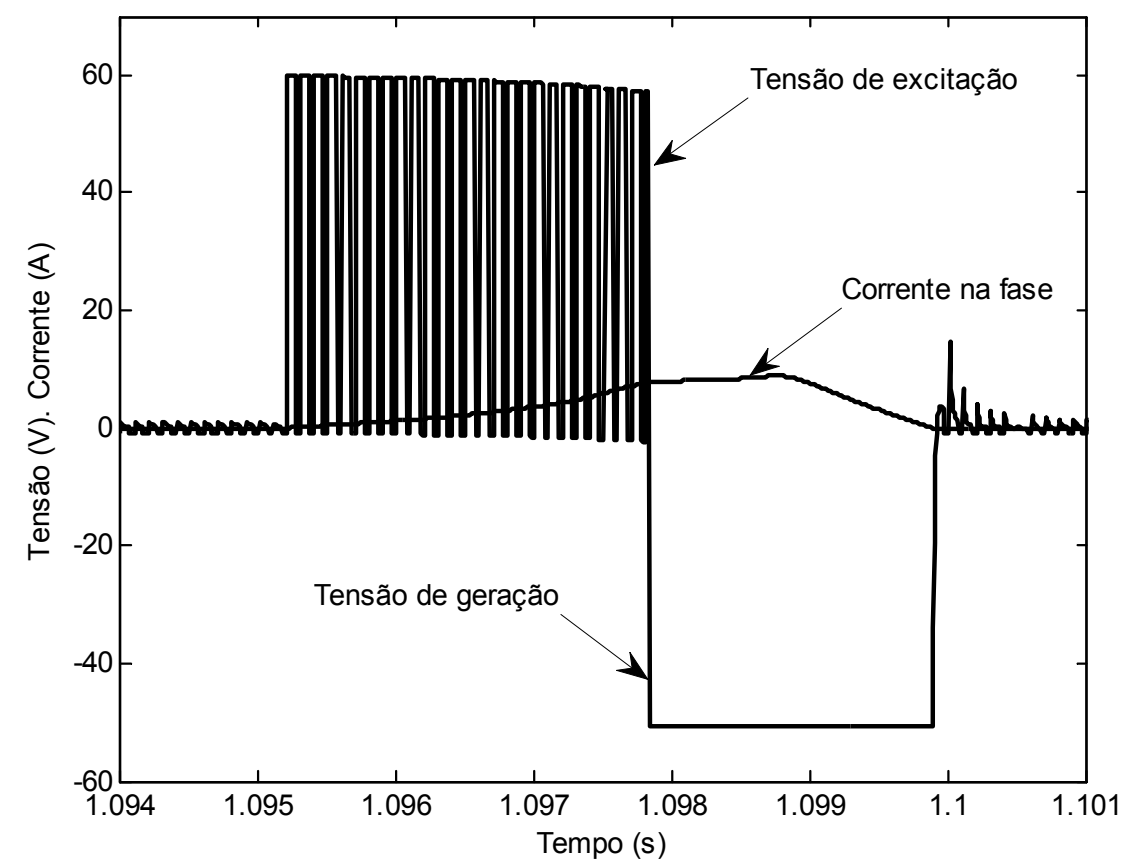

Figura 39 - Dinâmica de funcionamento de uma fase do GRC com malha de controle fuzzy.

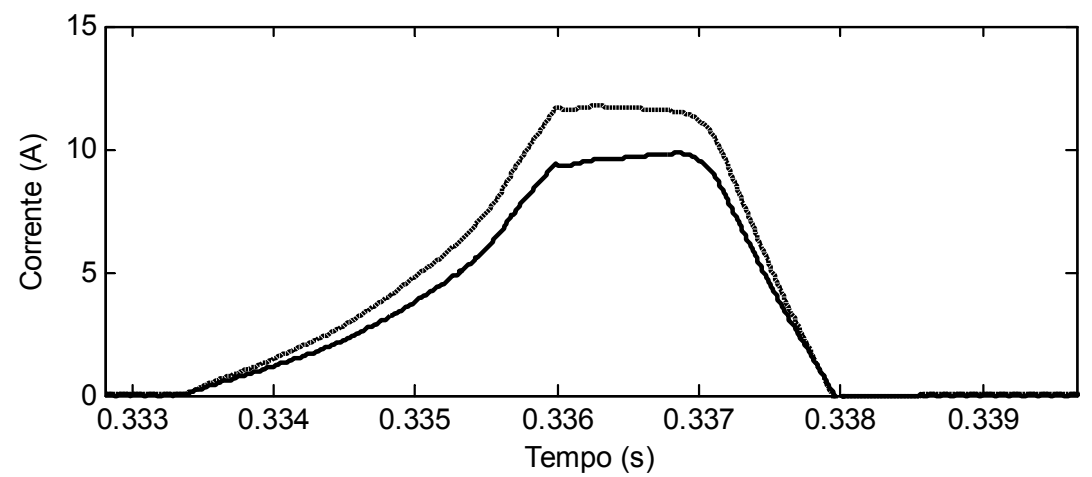

Figura 40 - Comparativo de corrente de excitação com o conversor alternativo e o CAM com D em $80 \%$ de condução.

Analisando a estratégia adotada para o controle do sistema GRC, foi então investigada a ocorrência de períodos ativos do circuito de roda-livre do CAM, ou seja, o intervalo em que flui corrente pelo diodo D0 durante a operação do sistema. A Figura 41 mostra o perfil de corrente encontrado. É possível observar a existência de corrente no diodo $\mathrm{D} 0$, deduzindo que há instantes ativos do circuito de roda livre do CAM, onde o perfil de corrente respeita a operação da chave Q0, além de 
apresentar ascendência durante a janela de operação de uma fase. Nos instantes ativos do diodo de roda livre, a corrente na fonte de excitação é nula, não havendo excitação externa neste período, Assim, a corrente que circula pelo enrolamento das fases auxilia na excitação da máquina.

Com o modo de operação em malha fechada do GRC, a corrente na fonte de excitação passa a ter um aspecto descontinuo, por seu perfil estar atrelado à atuação da chave Q0 e da velocidade rotórica da máquina. A Figura 42 detalha o perfil de corrente da fonte de excitação junto com a tensão de excitação que se manteve idêntica ao ensaio em malha aberta, contínua em $60 \mathrm{~V}$.

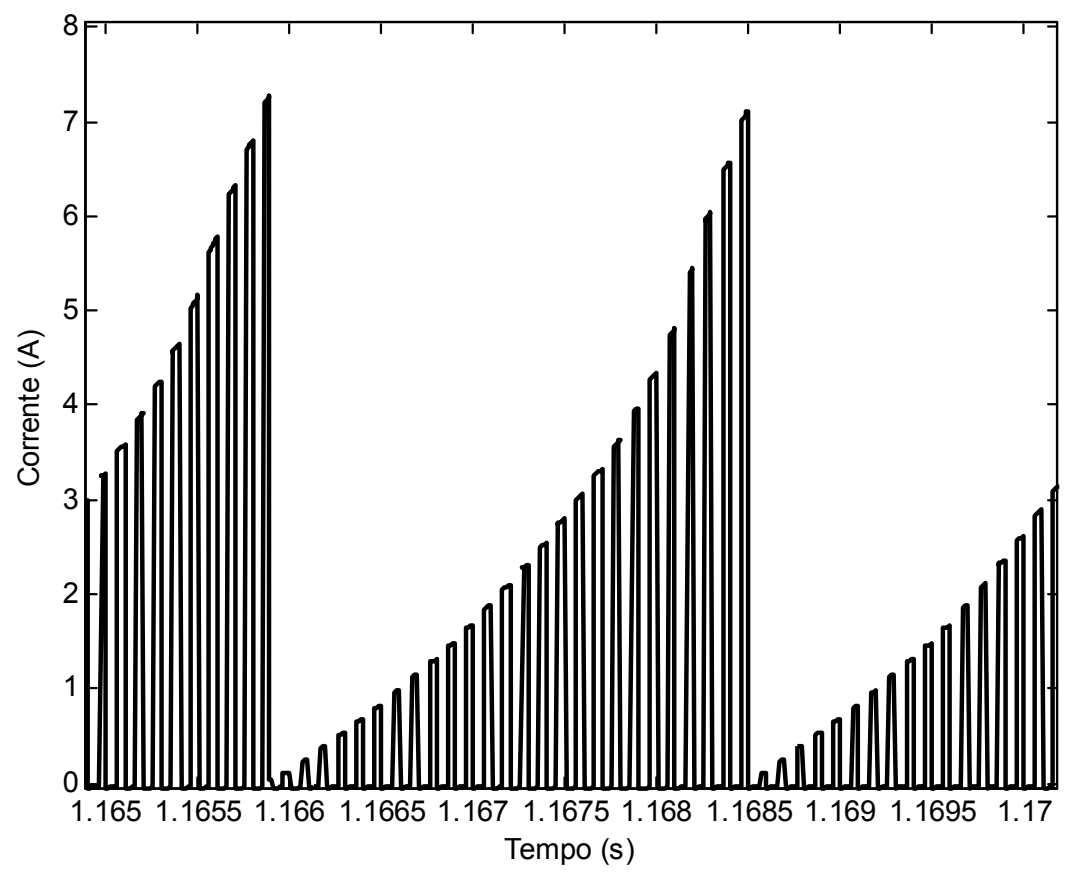

Figura 41 - Corrente circulante no diodo D0.

Como pode ser visto na Figura 39, Figura 41 e Figura 42, o sistema GRC é dependente do funcionamento da chave Q0, sendo ela a responsável por controlar e/ou limitar a energia que excita a máquina. Na ação de Q0, um módulo PWM é responsável por lhe fornecer um sinal de trabalho. O sinal de referência para o 
módulo PWM é justamente o sinal de saída do controlador fuzzy, estando compreendido entre $[-1.0 ;+1.0]$, onde [-1.0] representa ausência de disparo da chave Q0 e [+1.0] representa a total condução da chave Q0.

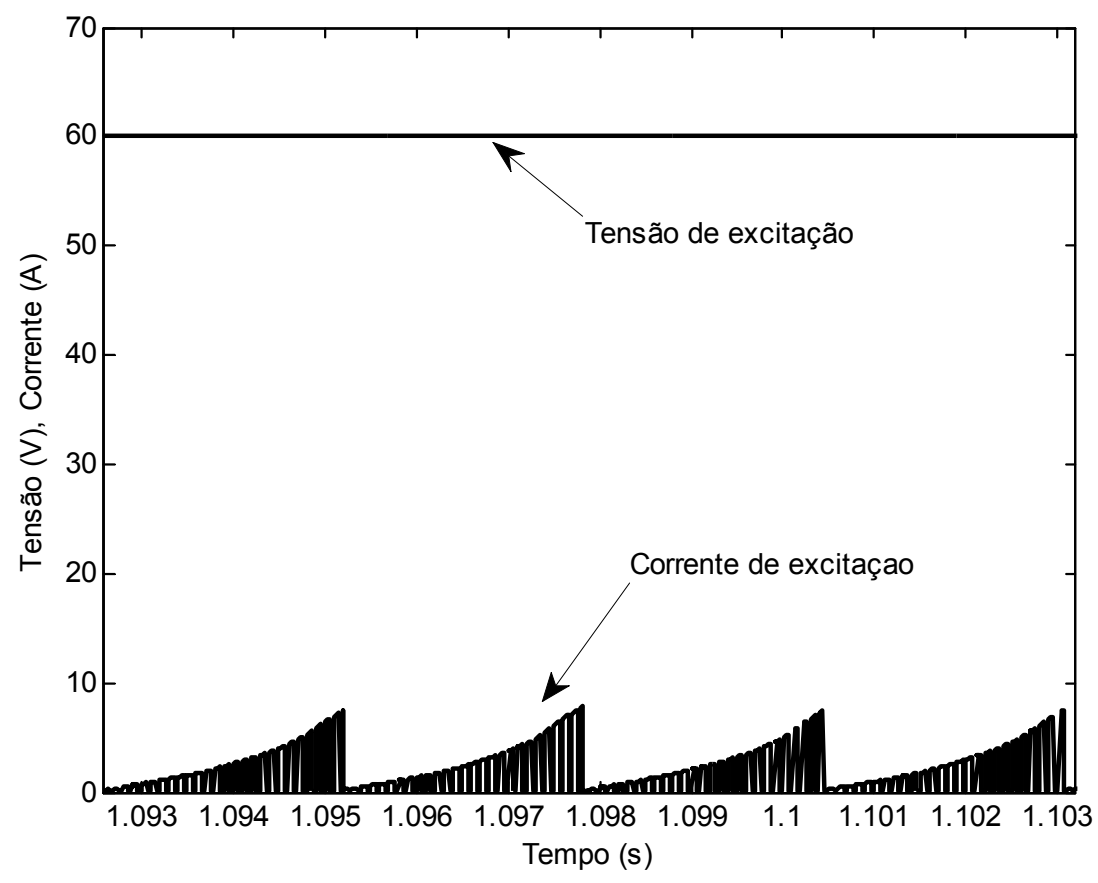

Figura 42 - Tensão e corrente na fonte de excitação do SGRC com controlador fuzzy.

A Figura 43 apresenta a influência do sinal de controle durante a operação da máquina, destacando sua dinâmica de corrente e tensão de fase. Ao se iniciar o ensaio, todas as variáveis dinâmicas (corrente de saída, corrente de fase, etc.) do sistema são inicializadas com zero, com exceção da tensão de referência do controlador que se mantem em $50 \mathrm{~V}$. Assim sendo, nos primeiros passos de simulação, a tensão de saída do SGRC é pequena e o controle necessita atuar de forma brusca para elevar o valor para próximo da tensão de referência, logo o sinal de controle atinge seu valor máximo, i.e., [+1.0].

Quando o controle assume o valor [+1.0] implica em que toda a energia disponível da fonte é usada para a excitação da máquina, produzindo valores mais 
altos de corrente de fase, consequentemente elevando os níveis de geração. Com o decorrer da simulação, a tensão de saída do GRC atinge valores próximos aos valores da tensão de referência, forçando-se a atuação do controle para manter o erro próximo a zero. Assim, o sistema fuzzy gera um sinal de controle diferente para a portadora PWM. Na Figura 43 pode-se observar esta mudança a partir do instante [0.16 s], onde o sistema fuzzy ajusta sua saída até estabilizar o sinal de controle em 0.25. Este sinal de controle é o necessário para manter a tensão de saída estável em 50 V quando a máquina está em regime de operação. Qualquer perturbação no sistema implicará na atuação do sistema fuzzy, para gerar um novo valor de sinal de controle, garantindo estabilidade na tensão de saída.
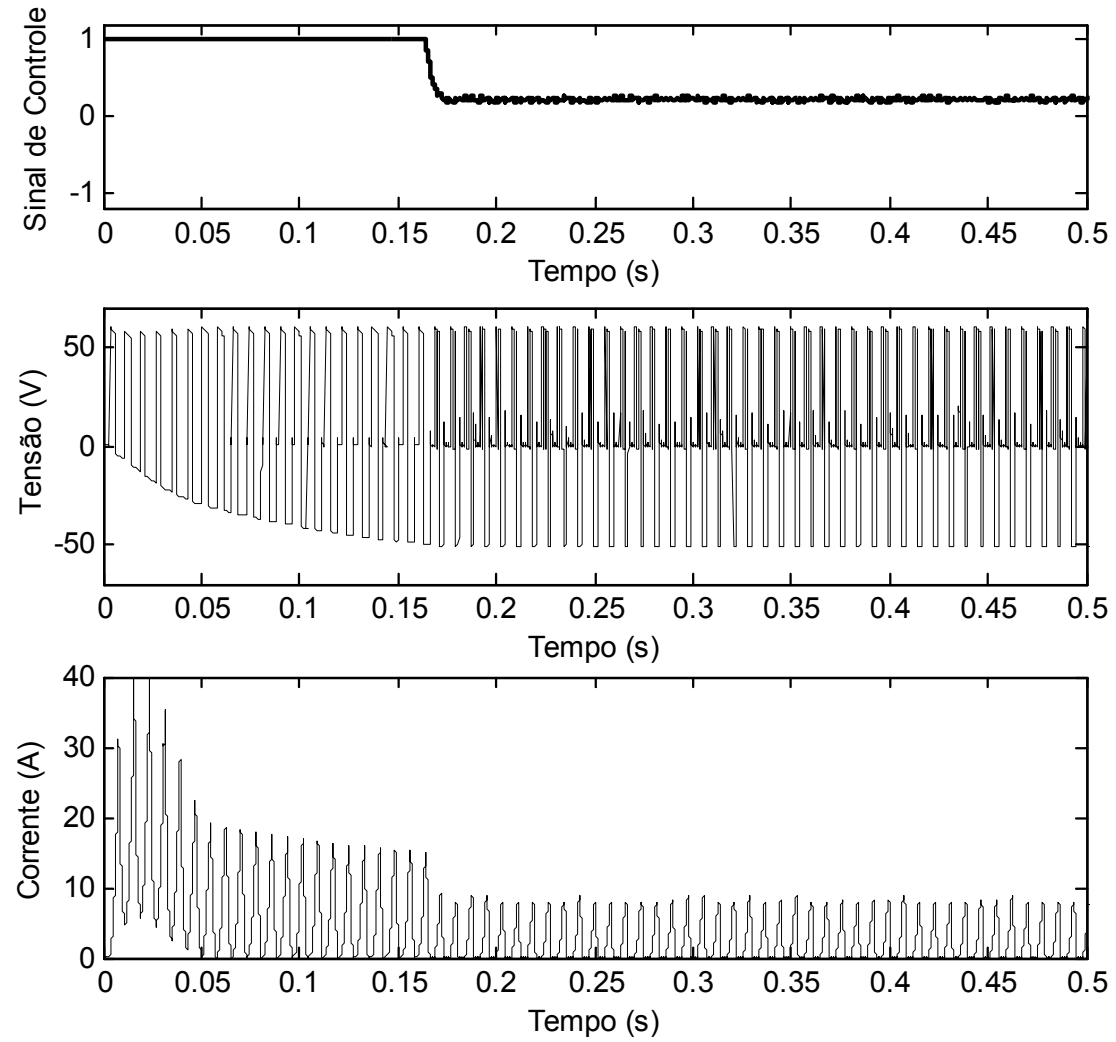

Figura 43 - Influência do sinal de controle na tensão e na corrente de fase. 


\subsubsection{Resultado de simulação do controlador fuzzy com carga e velocidade constante}

Para testar a confiabilidade do sistema, o controlador inteligente foi submetido a dois ensaios. No primeiro ensaio o SGRC foi simulado em malha aberta. Em um segundo ensaio foi adicionado a malha de controle ao SGRC e os resultados de tensão de saída dos ensaios comparados e mostrados na Figura 44. Em ambos os ensaios foram utilizados os mesmos parâmetros de entrada dos ensaios anteriores. A tensão referência do controlador foi mantida em $50 \mathrm{~V}$.

Em malha aberta, a tensão de saída estabilizou em 72 V. Com a malha de controle fuzzy a curva de tensão de saída segue a mesma dinâmica de geração da malha aberta, porém estabiliza antes, limitando a tensão próximo à tensão referência do controlador, i.e., 50 V. É notório que os dois perfis de tensão de saída da Figura 44 apresentam pequenas variações em torno do ponto médio, sendo a dinâmica de carga e descarga do capacitor de saída uma justificativa para as pequenas oscilações nos perfis.

Para verificar a robustez do controlador, e para garantir que sua operação satisfatória não seja apenas em uma única referência, novos ensaios foram realizados alterando o valor de tensão referência do controlador para $40 \mathrm{~V}$ e $60 \mathrm{~V}$. Suas dinâmicas são apresentadas na Figura 45. Como resultado obteve-se a mesma performance do controlador para todas as referências ensaiadas. Fica claro a eficiência do controlador fuzzy em manter constante a tensão de saída em torno de uma referência pré-estabelecida quando operado sem variação de velocidade ou carga. 


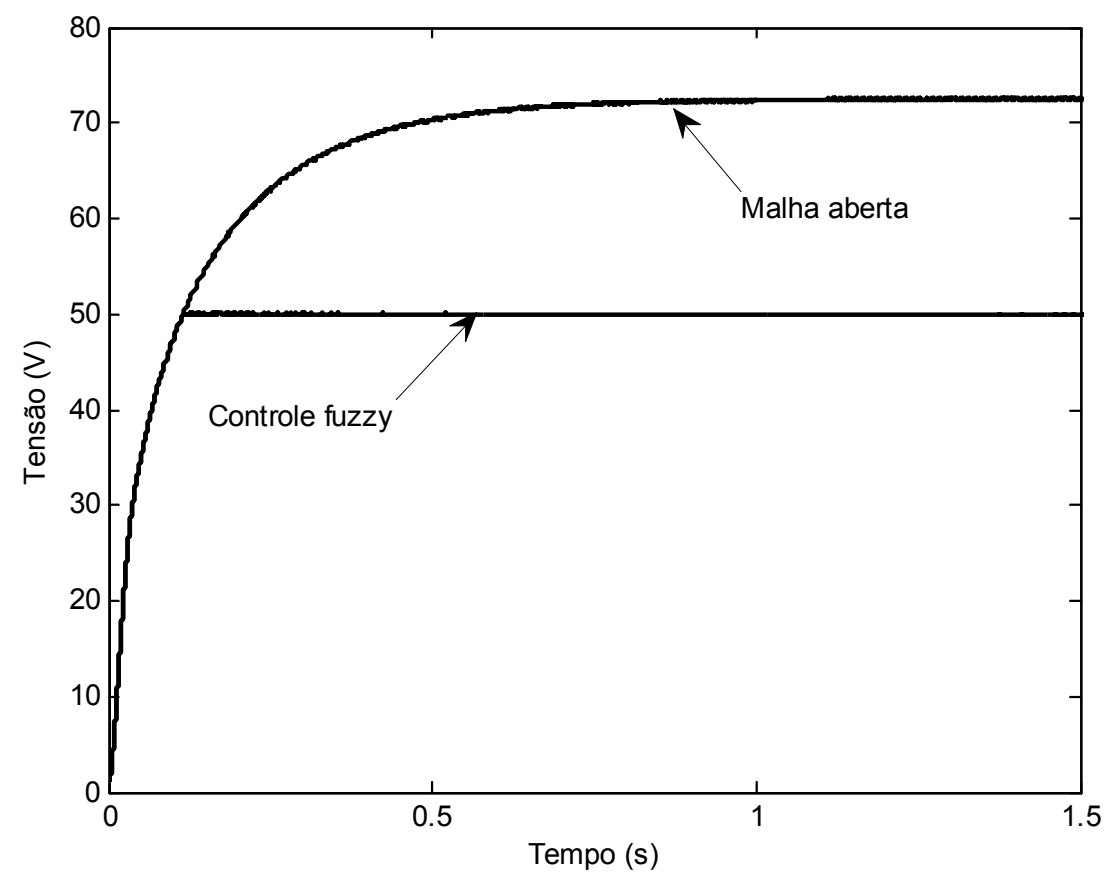

Figura 44 - Perfil de tensão da saída com velocidade de 1800 rpm em malha aberta e com controlador fuzzy.

Outro teste realizado com o controlador fuzzy foi efetuar mudanças na tensão de referência do controlador ao longo de um único ensaio, conforme a Figura 46. Neste ensaio utilizou-se a seguinte estratégia: a tensão de referência para o controlador manteve-se em $50 \mathrm{~V}$ até meio segundo de simulação. A partir deste ponto este valor foi alterado para 40 V. Após um segundo de simulação, o valor de tensão de referência foi mudado para $60 \mathrm{~V}$ e, após um segundo e meio de simulação, o valor de tensão de referência foi trocado para o valor inicial de $50 \mathrm{~V}$, que se manteve até o fim. É possível observar o bom desempenho do controlador fuzzy, onde em todas as mudanças de tensão o controlador conseguiu acompanhar a referência imposta e estabilizar-se em torno dela em um curto espaço de tempo, ficando limitado apenas pela dinâmica de excitação do GRC quando há um acréscimo na mudança da tensão de referência, ou pela descarga da energia 
acumulada no GRC quando há decréscimo na tensão de referência. Isso indica a robustez e versatilidade do controlador fuzzy.

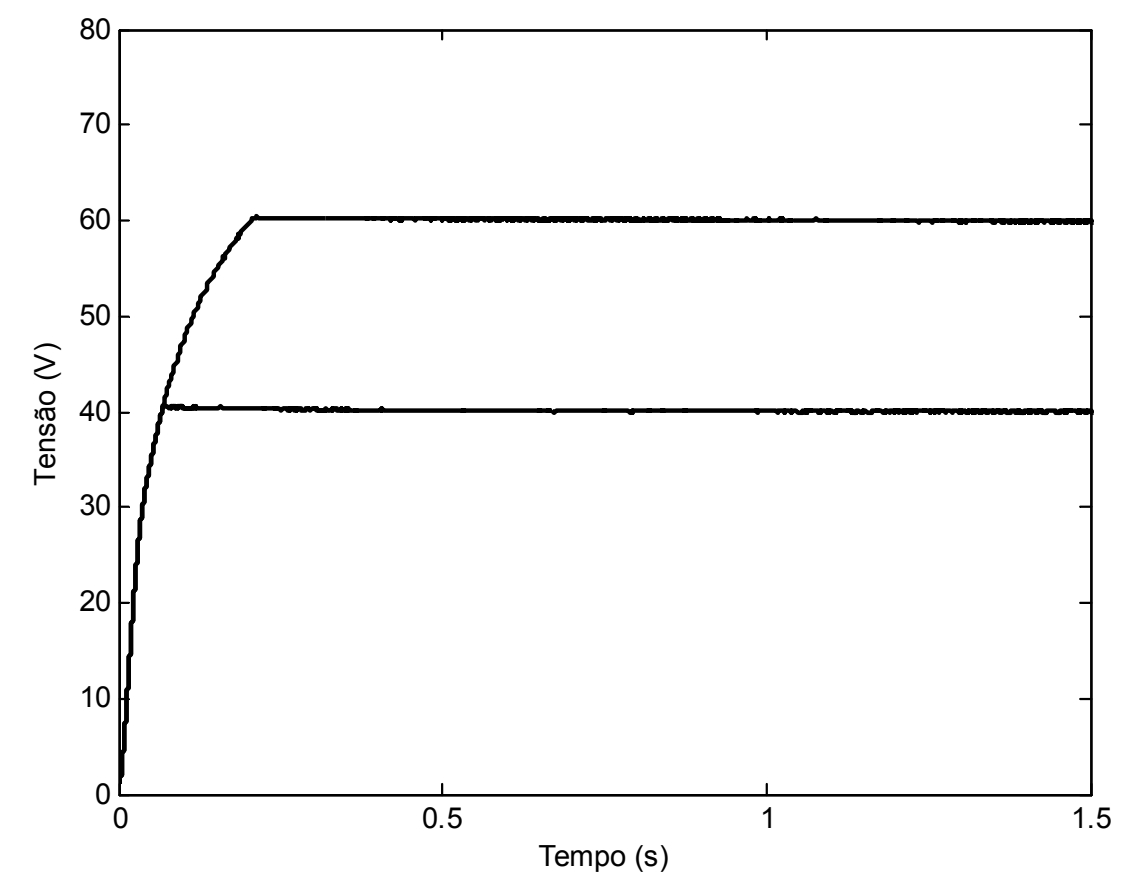

Figura 45 - Perfis de tensão de saída com velocidade de 1800 rpm e controlador fuzzy para referências de $40 \mathrm{~V}$ e $60 \mathrm{~V}$.

Adicionalmente, na Figura 46 é possível observar o comportamento do sinal de controle, ou seja, o sinal de saída do sistema fuzzy. Fica claro que com cada mudança imposta no valor da tensão referência, o controlador fuzzy atua na planta do GRC de modo a encontrar o novo ponto que atenda as exigências impostas pela perturbação. Para cada valor de tensão de referência há um novo ponto diferente de atuação para manter a tensão de saída estável. 

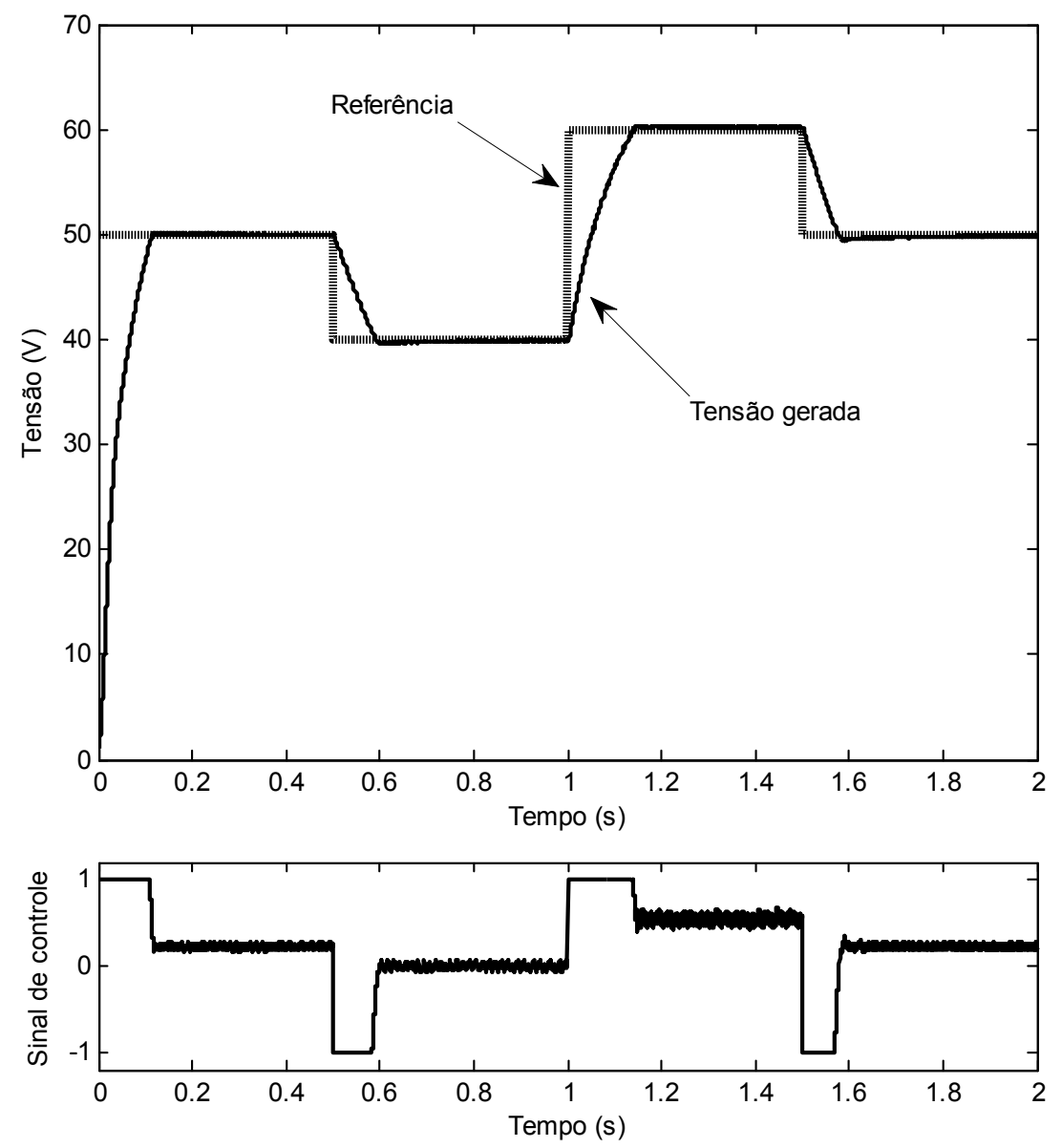

Figura 46 - Tensão de saída do GRC em malha fechada com variação da tensão de referência.

\subsubsection{Resultado de simulação do controlador fuzzy com variação de velocidade}

Ao se pensar em fontes não convencionais de geração de energia, a energia eólica vem ganhando grande interesse da comunidade cientifica. Diante da grande sazonalidade dos ventos inerentes ao sistema, para eficiência na geração de energia em sistemas eólicos são necessários geradores que funcionem adequadamente em uma ampla faixa de velocidade. Nessa vertente, alguns testes foram realizados no SGRC, explicitando sua dinâmica de geração sob diferentes condições de velocidade de operação, onde o alvo principal é a estabilidade de 
tensão gerada durante todos os testes, com a planta GRC sendo realimentada pelo controlador fuzzy.

A Figura 47 mostra a tensão de saída do GRC para as velocidades de 1000 rpm, 2000 rpm, 3000 rpm, 4000 rpm e 5000 rpm após a máquina entrar em regime constante de operação. O SGRC em malha aberta apresenta boa operação quando submetido a diferentes velocidades de operação, mas não garante estabilidade de tensão na saída, ocorrendo o decaimento da tensão com o aumento da velocidade. É visível que em velocidades mais baixas o perfil de tensão da saída apresenta maiores oscilações, causadas pelo efeito de carga e descarga do capacitor. O capacitor de saída, em velocidades mais baixas, recebe maiores pulsos de corrente das fases da máquina.

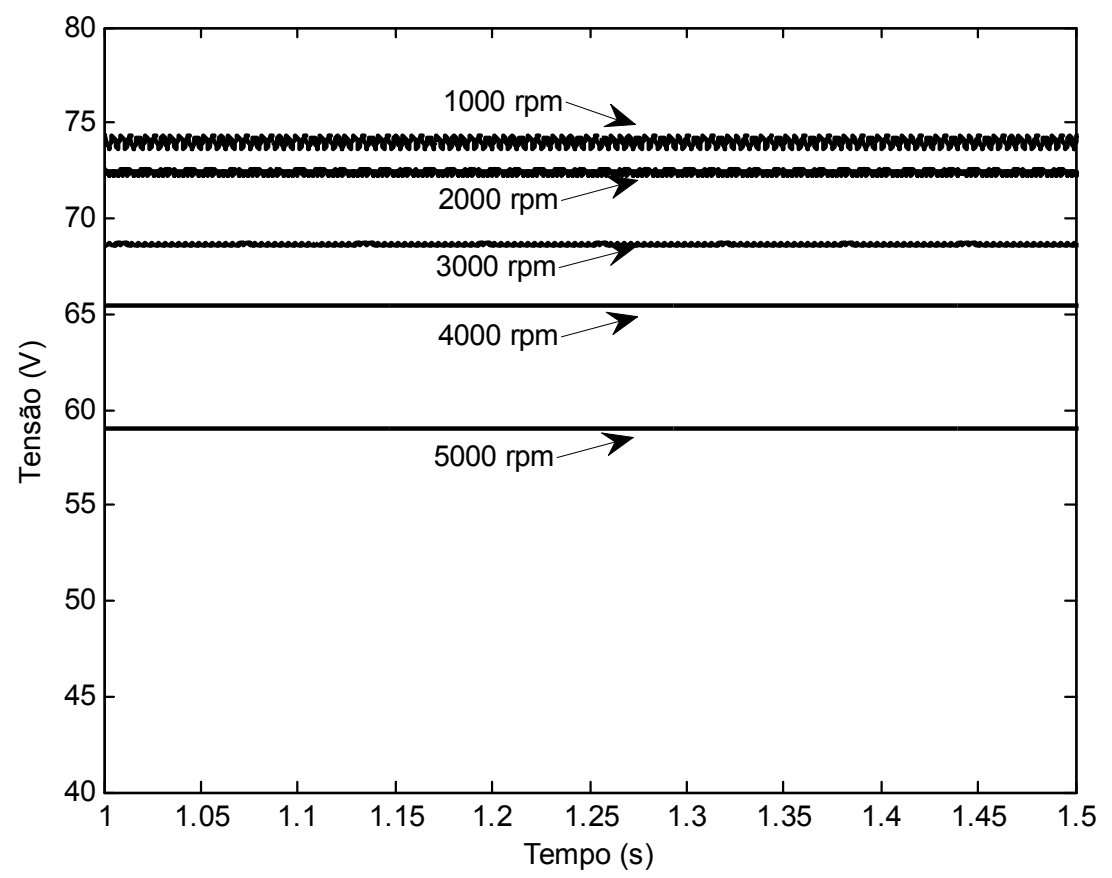

Figura 47 - Perfis de tensão de saída em malha aberta com velocidades de 1000 rpm, 2000 rpm, 3000 rpm, 4000 rpm e 5000 rpm. 
Visto isso, e visando a tensão estável na saída do sistema para este tipo de operação, o SGRC foi realimentado com a malha de controle fuzzy e os mesmos testes repetidos. A tensão referência do controlador manteve-se fixa em $50 \mathrm{~V}$. Como resultado obteve-se estabilidade da tensão gerada junto a referência, com pequenas oscilações, para todas as velocidades testadas. Para os ensaios com o controlador fuzzy não são apresentados todos os resultados gráficos, por se tratar de resultados muito próximos, o que ocasionaria a sobreposição dos sinais. O ensaio para a velocidade de $4000 \mathrm{rpm}$ pode ser visto na Figura 48.

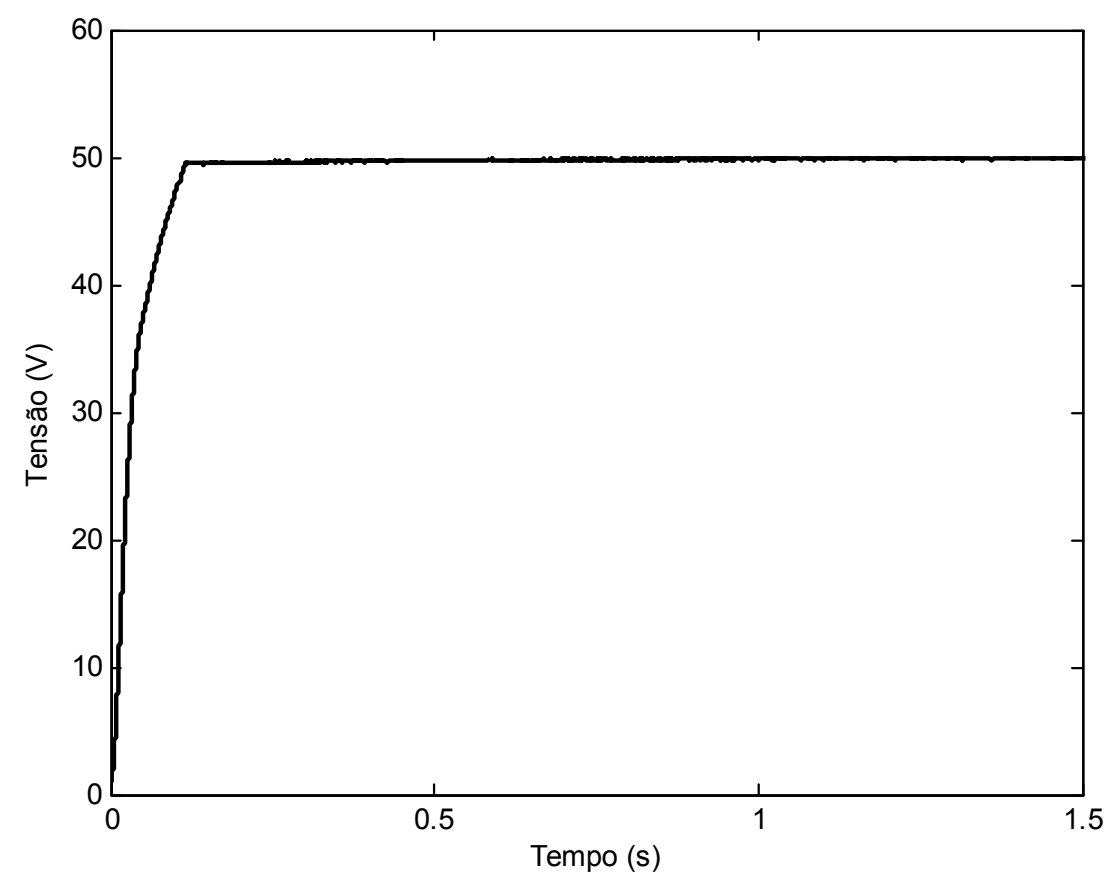

Figura 48 - Perfil de Tensão de saída com controlador fuzzy para velocidade de 3000 rpm.

O SGRC com o controlador fuzzy obteve bom desempenho atuando em um grande leque de velocidades. Contudo, é interessante apresentar o comportamento do SGRC controlado quando há transitórios na velocidade de operação. Para tanto, uma simulação de transitório foi efetuada onde empregou-se variações em degraus da velocidade, conforme mostrado da Figura 49. É fato que não é possível a 
constatação real de variação tão severa de velocidade, mas foi dessa forma modelado para obter a resposta do sistema para o caso mais crítico de variação de velocidade, visto que, se a malha de controle atuar satisfatoriamente neste caso, possivelmente em casos realísticos, cuja a complexidade de controle é menor, ela terá grandes chances de se manter estável.

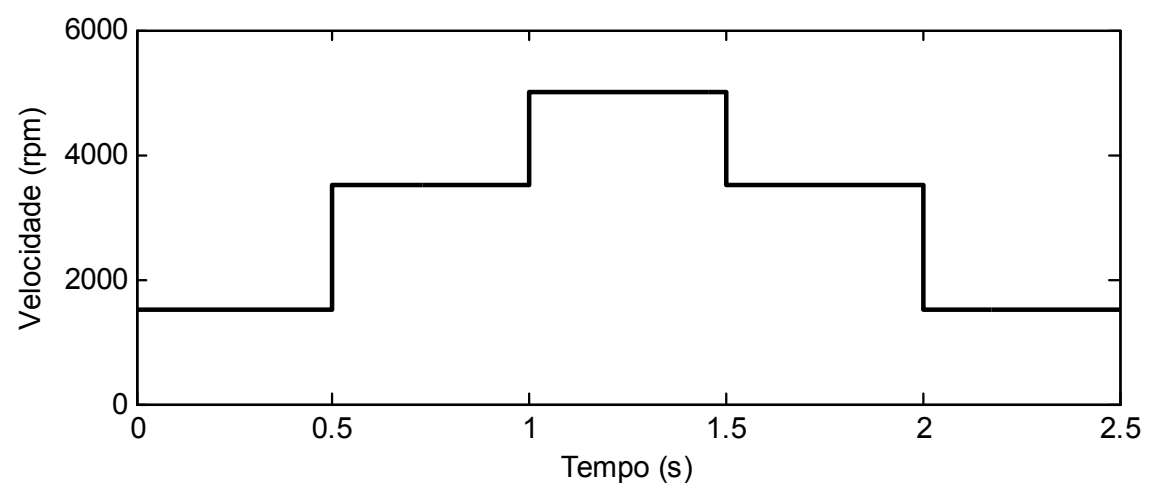

Figura 49 - Variação de velocidade em forma de degrau.

O ensaio de transitório de velocidade se deu da seguinte forma: A simulação teve duração de dois segundos e meio. A cada meio segundo de simulação a velocidade foi alterada em forma de degrau para os valores de $1500 \mathrm{rpm}, 3500 \mathrm{rpm}$, $5000 \mathrm{rpm}, 3500 \mathrm{rpm}, 1500 \mathrm{rpm}$ respectivamente. A estratégia visa verificar o comportamento da planta GRC em acréscimo e decréscimo da velocidade. A tensão de referência do controlador manteve-se $50 \mathrm{~V}$.

A Figura 50 mostra os resultados para o teste de transitório de velocidade, onde pode ser visto a tensão gerada pelo SGRC em malha aberta e a tensão gerada pelo sistema GRC realimentado pelo controlador fuzzy. Em malha aberta, o SGRC apresenta flutuações na tensão de saída, que se agrava com o acréscimo da velocidade. Com a malha de controle, a tensão de saída manteve-se estável nos 50 $\mathrm{V}$, apresentado apenas pequenas perturbações na mudança do degrau de 
velocidade. Portanto o sistema de controle fuzzy mostrou-se confiável e estável quando aplicado a um SGRC com regime de variação de velocidade.
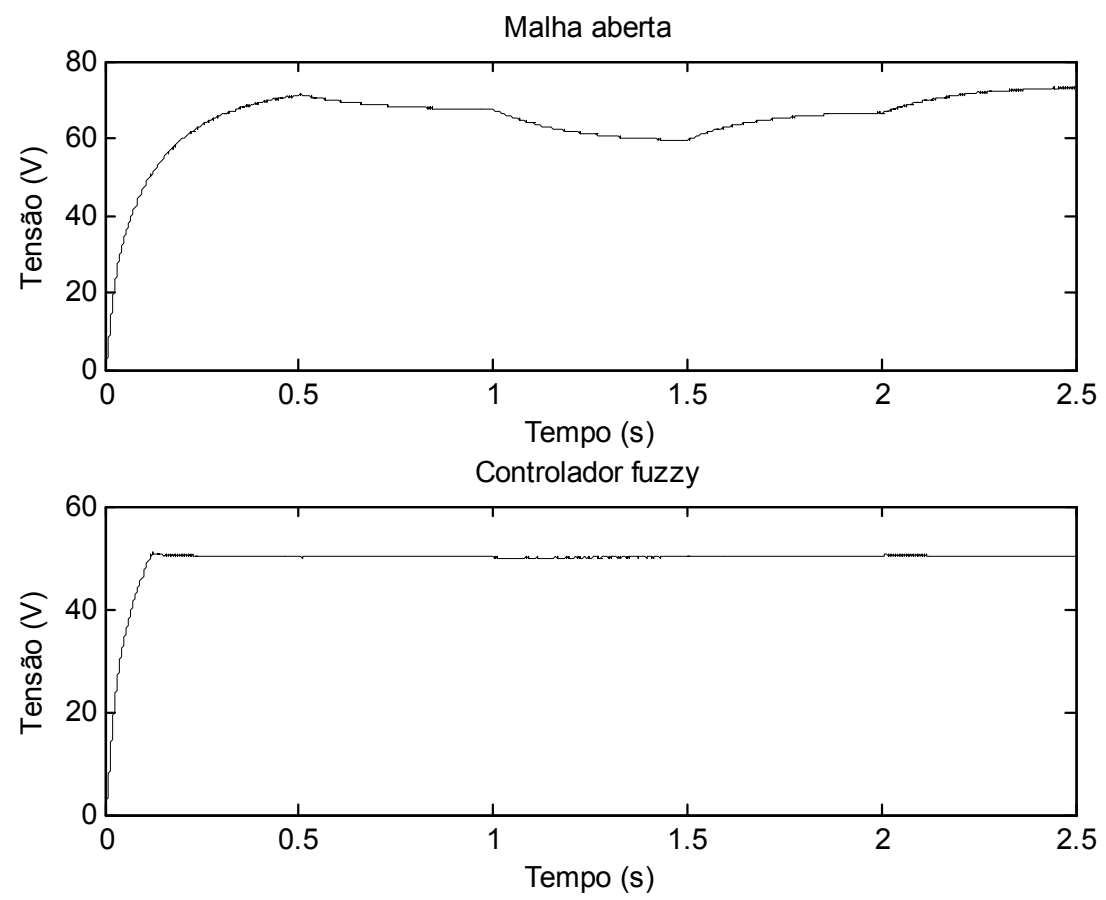

Figura 50 - Tensão de saída em malha aberta e em malha fechada.

\subsubsection{Resultado de simulação do controlador fuzzy com variação de carga}

Pelo perfil dos consumidores e por fatores horo-sazonais, os sistemas de geração de energia elétrica têm a característica de operação sobre mudança de demanda, ou seja, ocorre inserção ou retirada de carga alimentadas pelo sistema ao longo do dia, tornando interessante a investigação do comportamento dos perfis de geração do GRC mediante estas variações.

O sistema GRC foi avaliado para operação com variação de carga, onde em um primeiro ensaio manteve-se constante a velocidade do GRC em 3000 rpm com o sistema operando em malha aberta. A escolha da velocidade foi de forma aleatória e poderia ter sido escolhido qualquer velocidade dentro do leque possível de operação 
do GRC. Três cargas foram testadas, i.e., $11.1 \Omega, 16.1 \Omega$ e $21.1 \Omega$, e suas respectivas tensões de saída do sistema são apresentadas na Figura 51.

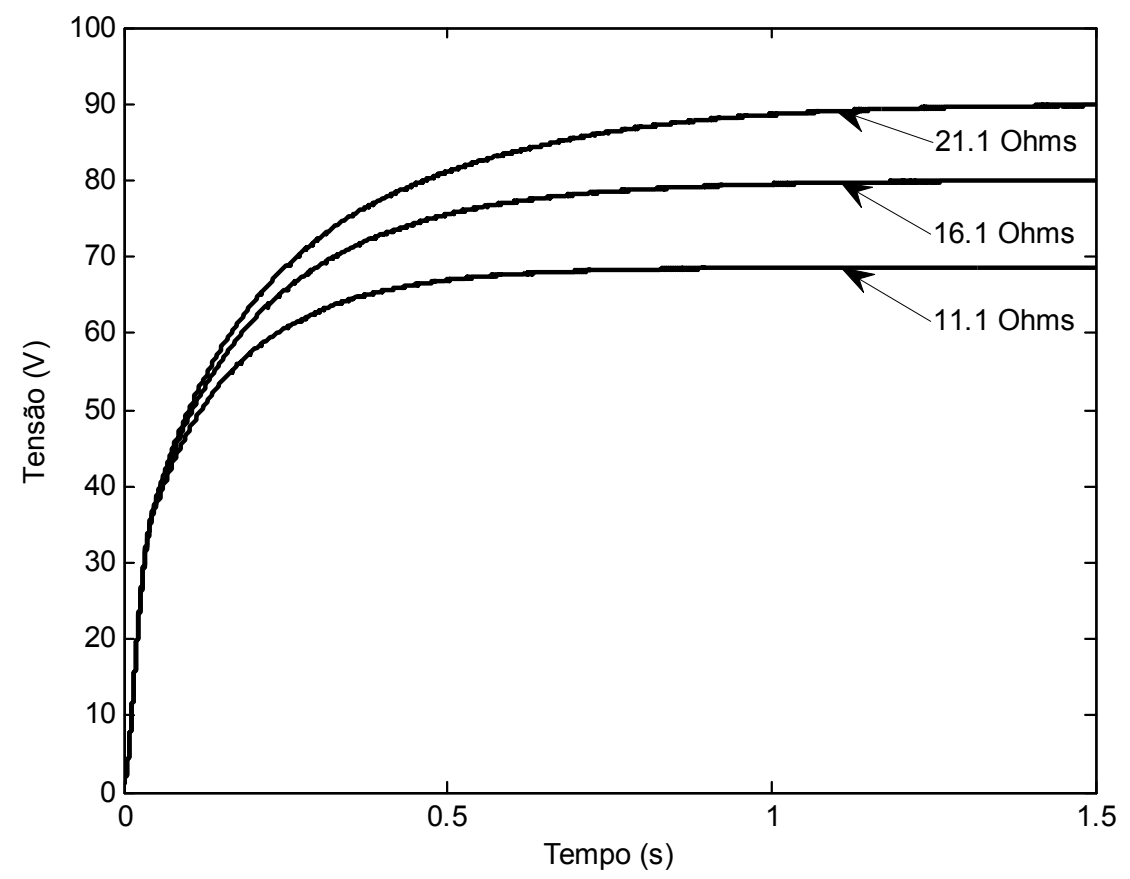

Figura 51 - Tensão de saída para cargas de $11.1 \Omega, 16.1 \Omega$ e $21.1 \Omega$ em malha aberta.

Na Figura 51 é possível observar que a medida que ocorre incremento de carga alimentada pelo sistema ocasiona a elevação dos níveis de tensão de saída, mostrando que apesar de bom funcionamento nas três cargas testadas o SGRC não garante níveis estáveis de tensão na saída. Esta característica motivou a inserção da malha de controle fuzzy para estabilizar a tensão de saída para toda e qualquer carga alimentada. Para tanto, os testes para as cargas de $11.1 \Omega, 16.1 \Omega$ e $21.1 \Omega$ foram repetidos com o SGRC realimentado pela malha de controle fuzzy. A tensão de referência do controlador manteve-se fixa em $50 \mathrm{~V}$ e o resultado apresentado na Figura 52. É observável que para as três cargas testadas a tensão ficou próxima a tensão de referência, o que ocasionou a sobreposição dos sinais, mas para os três casos a malha de controle operou satisfatoriamente. 


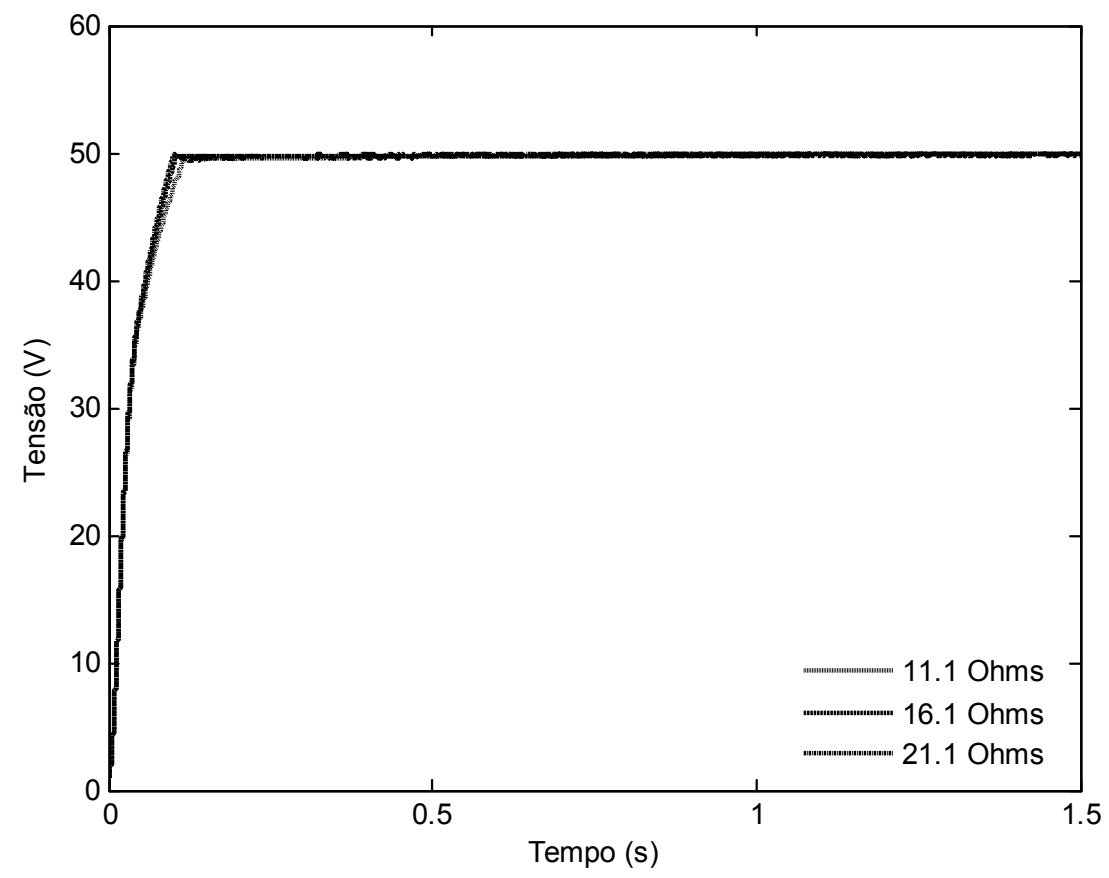

Figura 52- Tensão de saída para cargas de $11.1 \Omega, 16.1 \Omega$ e $21.1 \Omega$ com controlador fuzzy.

Para evidenciar a eficiência do controlador fuzzy, um novo teste foi realizado para verificar sua atuação com a dinâmica de variação de carga, ou seja, em um único ensaio houve variação de carga, onde as cargas de $11.1 \Omega, 16.1 \Omega$ e $21.1 \Omega$ são testadas no sistema com a seguinte estratégia: A simulação inicia-se com o SGRC alimentado a carga de $11.1 \Omega$. A partir de meio segundo é incrementado $5 \Omega$ ao sistema, suprindo agora uma carga de $16.1 \Omega$. Por fim, no instante [1.0 s] é inserido mais $5 \Omega$ e o sistema passa a ter uma carga de $21.1 \Omega$ em sua saída. Este valor se manteve até o fim da simulação. Neste teste a velocidade de operação manteve-se fixa em 1800 rpm e a tensão de referência fixa em $50 \mathrm{~V}$.

A Figura 53 mostra que a tensão de saída do SGRC quando controlado pelo sistema fuzzy manteve-se estável próxima a referência para as três cargas testadas. É interessante ressaltar que a dinâmica de mudança de carga utilizada neste teste foi em forma de degrau, o que não condiz com a realidade de sistemas de geração 
de energia que tem um perfil mais suave de variação. Porém, ao se obter boa resposta para o teste em degrau, espera-se boa atuação para casos realísticos de menor complexidade.
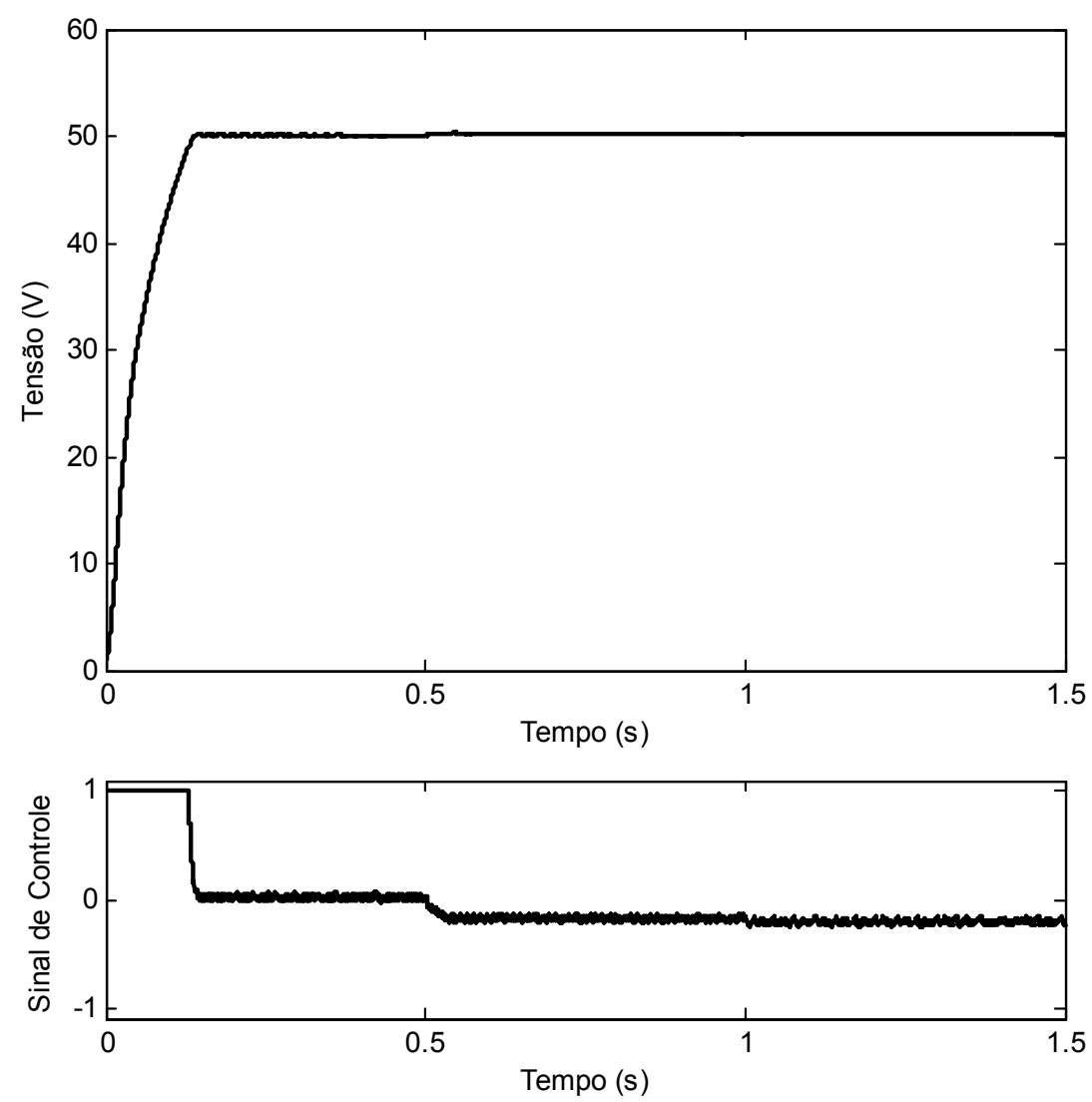

Figura 53 - Tensão de saída com variação de carga e atuação do controlador fuzzy.

Como informação adicional é apresentado na Figura 53 o comportamento do sinal de controle que serve de referência para a portadora PWM, sendo visível que apesar constância em $50 \mathrm{~V}$ da tensão de saída, ocorrem variações no sinal de controle. Inicialmente por ainda não haver tensão na saída do SGRC o sinal de controle assume o valor máximo, ou seja, $[+1,0]$. No decorrer da simulação a tensão de saída assume valores próximos a tensão referência e o sistema de controle fuzzy atua para manter a tensão em $50 \mathrm{~V}$, alterando o sinal de controle que se estabiliza 
em torno de [0,0]. Quando ocorre a primeira perturbação de carga no sistema GRC, no instante $[0,5 \mathrm{~s}]$, novamente o controlador fuzzy atua para manter a tensão estável em $50 \mathrm{~V}$, alterando o sinal de controle para $[-0,16]$. Ao ocorrer a segunda perturbação de carga, no instante $[1,0$ s], novamente o controlador fuzzy se ajusta produzindo um sinal de controle de [-0.24]. As alterações dos valores do sinal de controle são as responsáveis por garantir níveis estáveis de geração do SGRC. 



\section{Avaliações experimentais}

Todo o trabalho desenvolvido para o gerador a relutância está vinculado a modelos computacionais, onde as técnicas apresentadas mostraram-se bastante satisfatórias. Porém, é interessante verificar se todo o material apresentado e se a técnica adotada realmente apresentará bom resultado em plataforma real, ou seja, torna-se necessária a apresentação de dados experimentais para que se possa realizar as devidas comparações e validações de todo o sistema montado de forma virtual. O intuito é realizar o estudo prático, em bancadas experimentais, de todo o sistema montado em simulações computacionais, respeitando fielmente todos os parâmetros, modelos e dados já utilizados. Este processo foi realizado em etapas, e toda a sua evolução é tema deste capitulo.

\subsection{Investigações experimentais do SGRC em malha aberta}

Com a conclusão do trabalho de mestrado de OLIVEIRA (2011b) e COELHO (2011b) ficaram-se à disposição da Escola de Engenharia de São Carlos (EESC USP) duas máquinas a relutância chaveadas, as quais foram projetadas, construídas e implementadas. A medida inicial para obtenção de uma bancada experimental de testes para o SGRC proposto foi utilizar o material já existente e disponível na EESC - USP. Assim, para os ensaios de malha aberta utilizou-se a bancada experimental apresentada na Figura 54. Nesta bancada, um inversor de frequência ligado a um motor de indução trifásico são responsáveis por fornecer conjugado mecânico para o GRC. Na entrada elétrica do GRC uma fonte trifásica de tensão variável associada a 
uma ponte retificadora em paralelo com um banco de capacitores fazem a excitação da máquina. Em sua saída, o GRC supre uma carga em paralelo com um segundo banco de capacitores. A Figura 54 também apresenta o CAM utilizado, alguns equipamentos de medições, os drivers do CAM com suas fontes de alimentação.

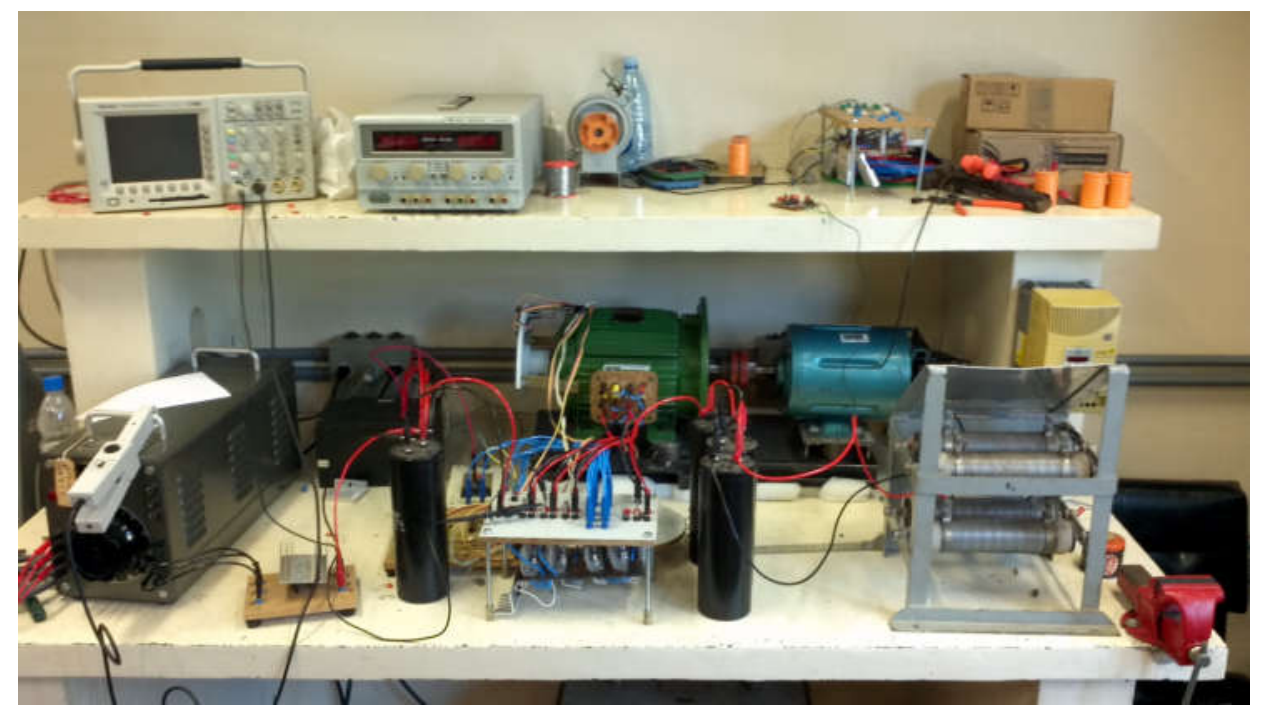

Figura 54 - Bancada experimental de testes em malha aberta.

Como a bancada de testes já estava parcialmente montada, pouco esforço foi necessário para a implementação em malha aberta do SGRC. A maior dificuldade foi a montagem do conversor CAM, que por ter sido concebido para este trabalho, a EESC - USP ainda não dispunha de sua montagem e nem de seu circuito de drives. Detalhes da montagem do CAM é mostrado na Figura 55.

Com a bancada experimental de testes montada, e apresentando os mesmos parâmetros de componentes já citados no modelo computacional, o SGRC em malha aberta está apto a realizar-se testes experimentais. Para tanto, por se tratar de ensaio em malha aberta, a chave Q0 do CAM recebeu sempre sinal alto em seu gate, ou seja, para todos os testes em malha aberta Q0 comportou-se como curto-circuito. 

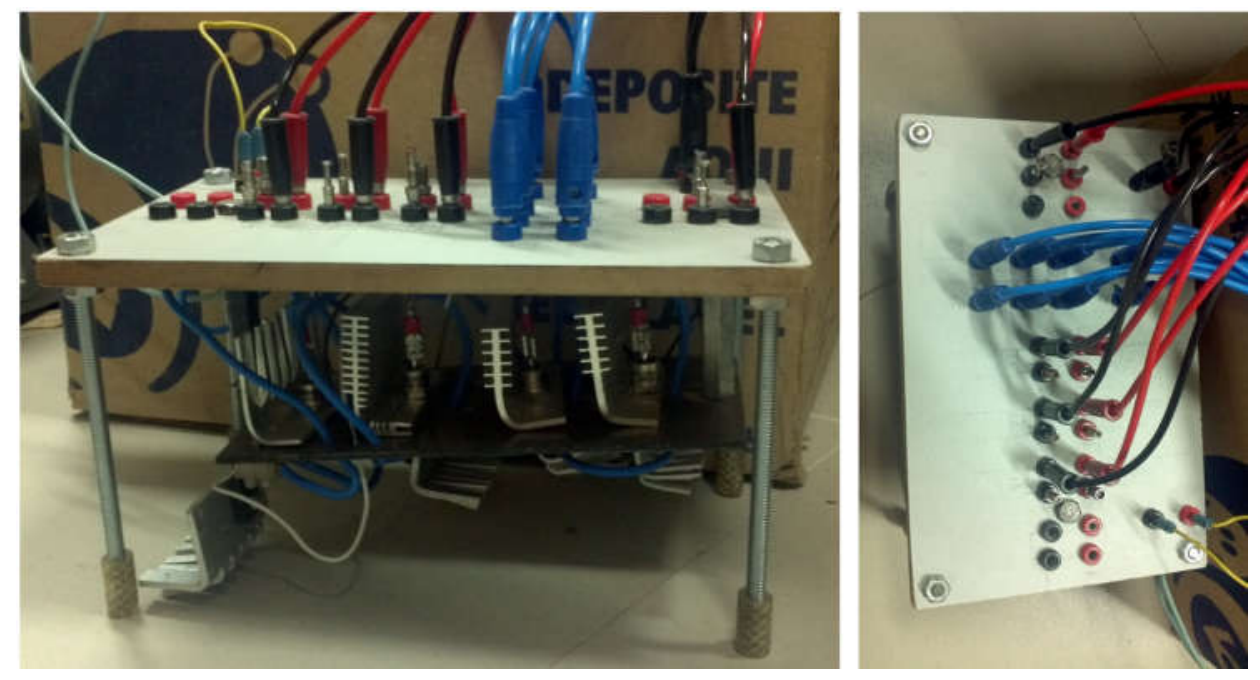

Figura 55 - Montagem experimental do CAM.

No ensaio experimental em malha aberta, o SGRC foi excitado com tensão de $80 \mathrm{~V}$ estabilizada por um capacitor de $6 \mathrm{mF}$. A velocidade de operação foi mantida constante em 3000 rpm e o GRC alimentava uma carga resistiva de $11.1 \Omega$ associada em paralelo a um banco de capacitor de $18 \mathrm{mF}$. A Figura 56 apresenta a tensão e corrente responsáveis pela excitação do GRC. Como já citado, a tensão de excitação se manteve constante em $80 \mathrm{~V}$ e a corrente de excitação tem o perfil pulsado, o que é uma característica da máquina. Por o GRC ser uma máquina de acionamento sequencial, cada uma das três fases proporciona o aparecimento de um pulso de tensão, que se repetem em toda operação da máquina. Uma particularidade interessante que a Figura 56 ilustra é a diferença de amplitude dos pulsos de corrente das fases, mesmo todas as fases apresentado características idênticas de resistência e indutância. Na montagem experimental, os cabos de ligação das fases da máquina com o conversor necessitou-se de diferentes comprimentos, o que aparentemente alterou a simetria dos parâmetros das fases, ocasionando pequenas diferenciações nos perfis de correntes, o que não atrapalha a funcionalidade do sistema. 


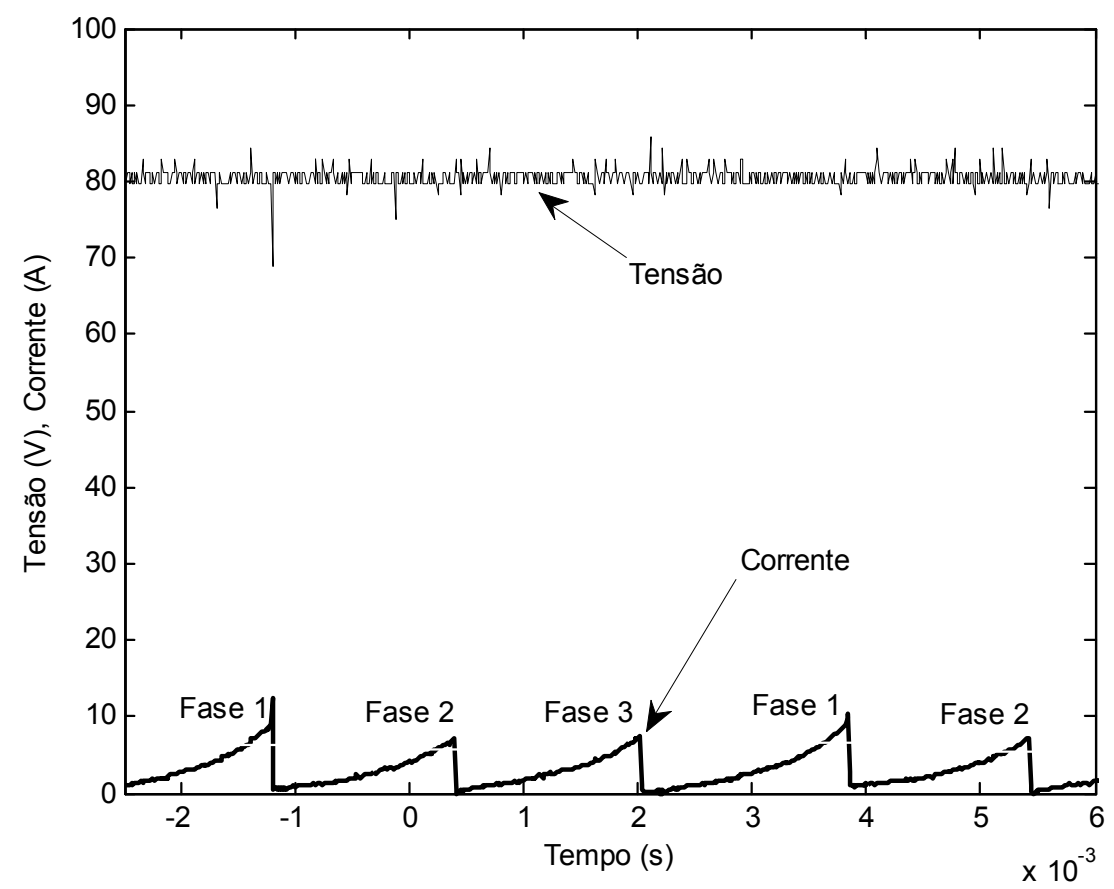

Figura 56 - Tensão e corrente na entrada do GRC em malha aberta.

A Figura 57 mostra a dinâmica de funcionamento para uma fase do GRC. É notório a presença de um pulso quadrado de excitação com o valor de $80 \mathrm{~V}$, que é o mesmo valor da tensão pré-determinada para a excitação. Durante a excitação há o surgimento de corrente na fase do GRC, que se eleva até o fim desse período. Com o fim da excitação a energia armazenada na fase e a FCEM produzida é enviada para a carga, encerrando o ciclo de operação da máquina. Nota-se que a Figura 57 cotem a mesma dinâmica e contornos das curvas apresentadas na simulação da Figura 34, com o diferencial de que no ensaio experimental o perfil de corrente na fase recebeu um fator multiplicativo $(k=5)$ para melhor evidenciar seu comportamento.

Na Figura 57 o sinal de tensão apresentado no período compreendido antes da tensão de excitação e após a tensão de geração deveria ser nulo, assim como é mostrado na simulação da Figura 34, mas o equipamento utilizado para realizar a 
medida de tensão utiliza uma ponteira diferencial de tensão, e como neste período o circuito da fase está aberto, o equipamento perde o sinal de referência, mostrando um resíduo de medida no período citado, o que ocasiona o aparecimento de ruídos indesejados.

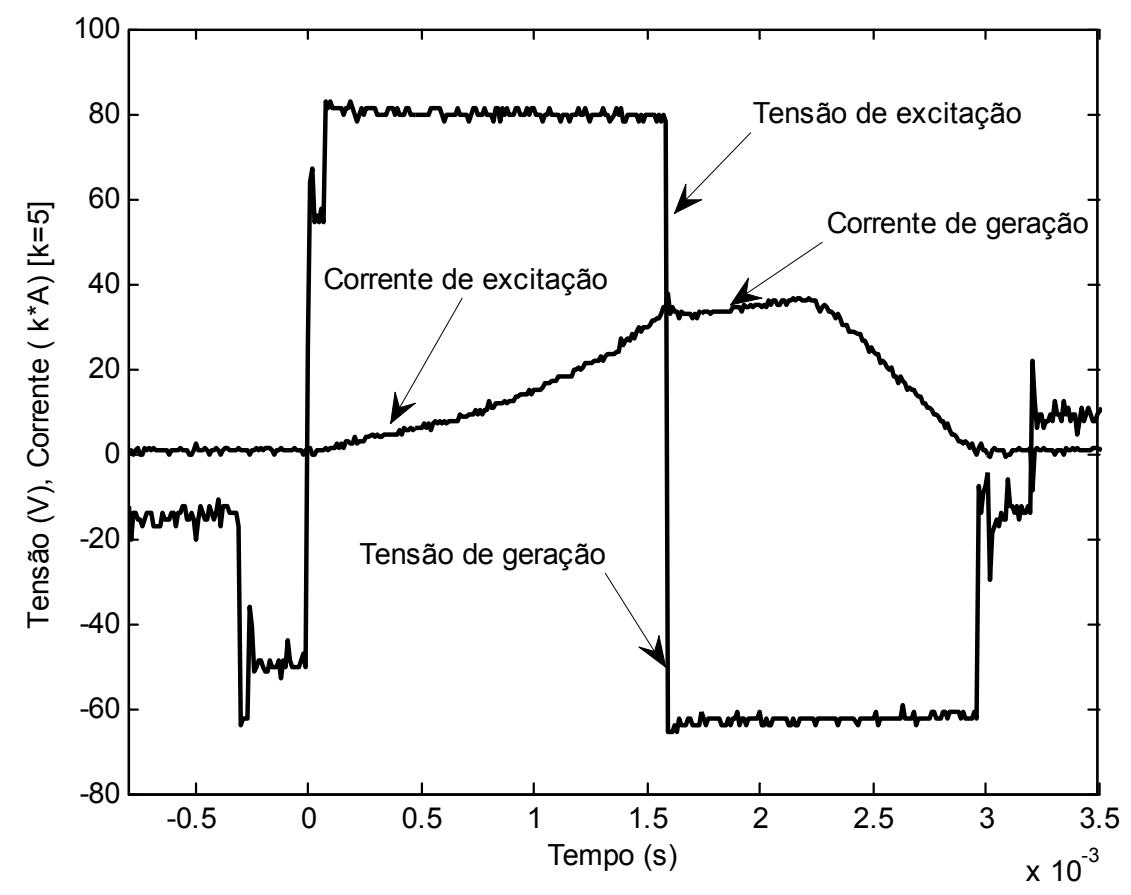

Figura 57 - Dinâmica de funcionamento de uma fase do GRC em malha aberta.

A Figura 58 apresenta as curvas de tensão e corrente do barramento de saída do GRC. A tensão e corrente apresentam valores contínuos e constantes o que se deve a atuação dos capacitores adicionados na saída. Com isso, tem-se que o SGRC apresentou bom funcionamento, em bancada de testes, ao ser experimentado em malha aberta, onde a dinâmica e perfis mostrados na Figura 56, Figura 57 e Figura 58 apresentam adequadamente o funcionamento da máquina e são semelhantes a Figura 36, Figura 34 e Figura 37 respectivamente, o que valida a o modelo computacional em malha aberto apresentado. 


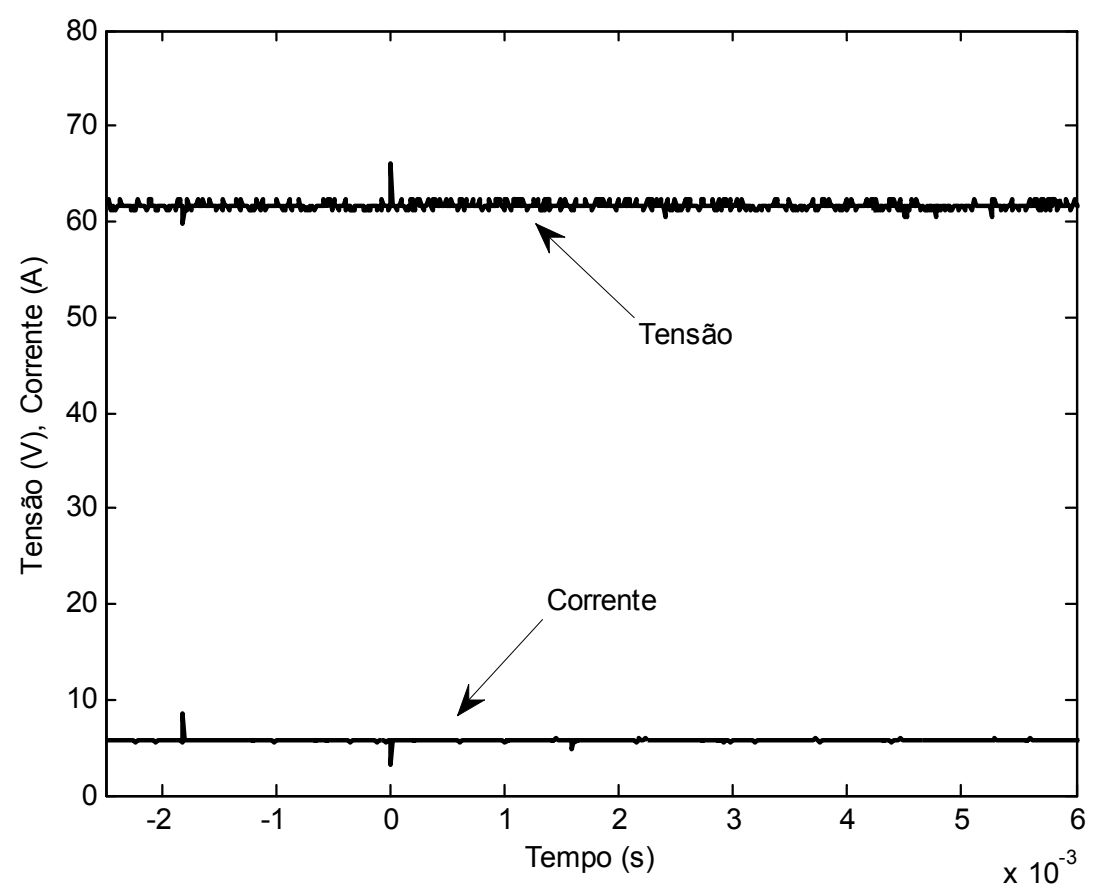

Figura 58 - Tensão e corrente na saída do GRC em malha aberta.

\subsection{Análise experimental em malha aberta da estratégia de controle adotada}

Diferentemente da proposta em malha aberta, uma análise experimental foi realizada com objetivo de verificar se a estratégia de controle adotada seria capaz de controlar e/ou estabilizar a tensão de saída tendo como base a tensão de excitação e sua devida modulação. Para tanto, foi necessário a concepção de um circuito PWM analógico capaz de realizar a modulação da chave Q0 do CAM, durante a operação da máquina.

A Figura 59 mostra o módulo PWM analógico implementado. Ele opera com frequência de chaveamento de $10 \mathrm{kHz}$ (a mesma adotada para a simulação do sistema de controle fuzzy), e é capaz de variação de $0 \%$ a $100 \%$ do $D$, ou seja, 
pode-se realizar testes para inúmeras configurações de $D$ e verificar o comportamento do sistema para cada uma delas.
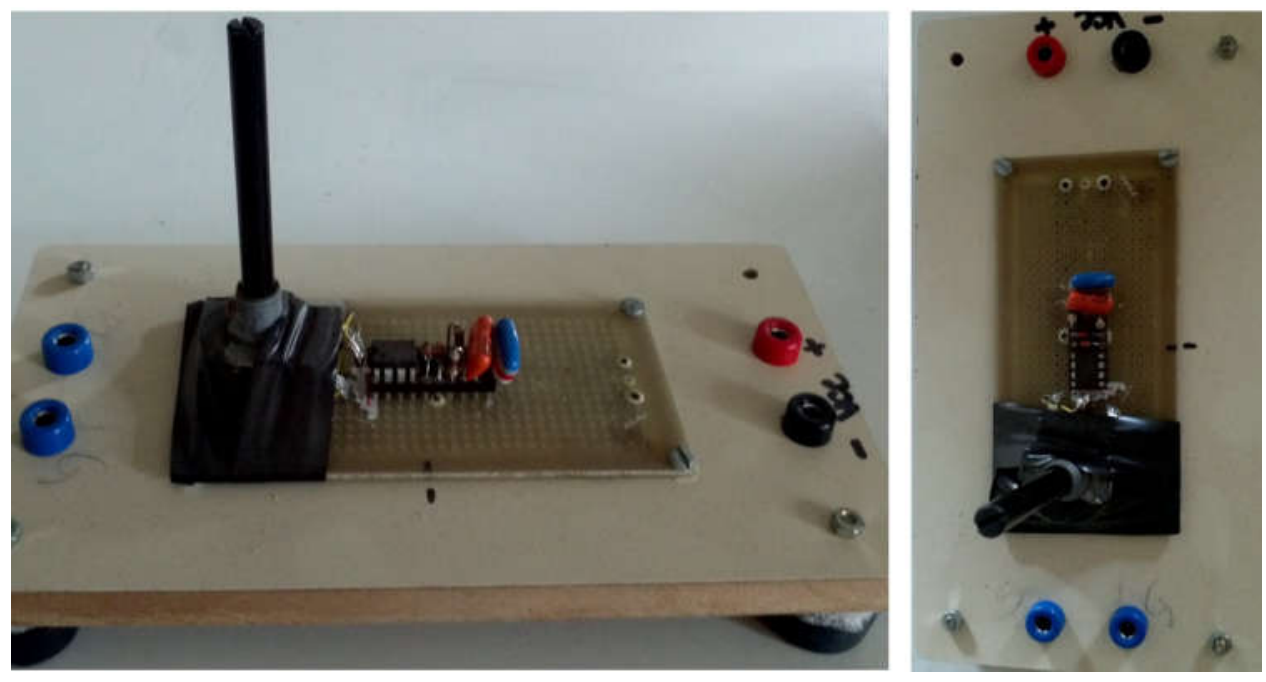

Figura 59 - Módulo PWM analógico implementado.

Primeiramente, um ensaio experimental da dinâmica de funcionamento do GRC foi realizado com D de Q0 mantida fixo em $50 \%$. Este ponto de operação é o ideal para o funcionamento do GRC em regime, permitindo a maior variação para o incremento ou decaimento de carga no barramento CC de saída e/ou velocidade de operação. Para este ensaio a velocidade de rotação adotada foi 1800 rpm e $60 \mathrm{~V}$ de tensão de excitação.

A Figura 60 mostra a tensão e corrente de uma fase do GRC experimentado, onde é notório a presença de várias oscilações no perfil da tensão de excitação provenientes da modulação de Q0. Assim, pode-se observar que é possível a limitação da tensão dentro da etapa de excitação com a modulação de Q0. Sem a modulação de Q0 a tensão de excitação seria um pulso quadrado com amplitude igual a tensão de excitação. Para a Figura 60 a corrente da fase recebeu o fator multiplicativo $(k=5)$ para melhor visualização de sua dinâmica. 


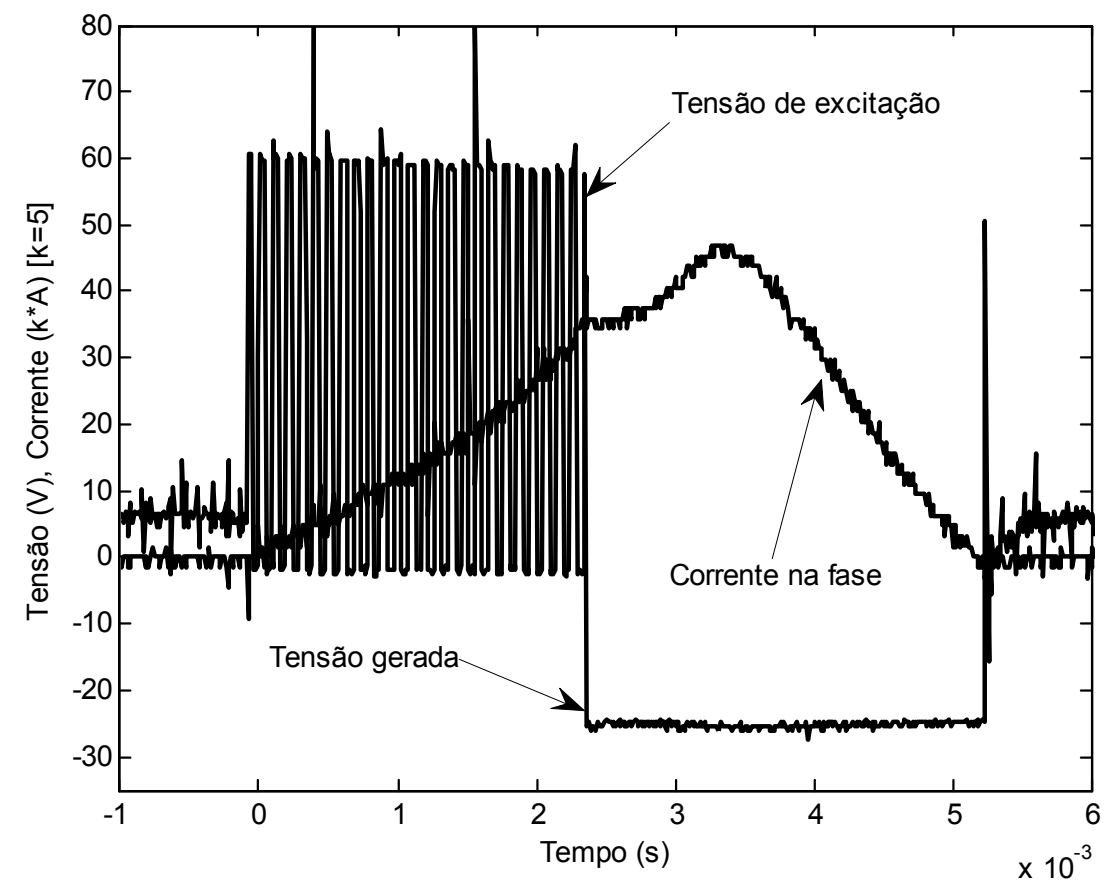

Figura 60 - Tensão e corrente na fase do GRC com modulação de Q0 em 50\%.

Na Figura 61 é exibido a corrente da fonte de excitação e a corrente que passa pelo diodo de roda-livre D0. Quando a fase 1 do GRC encontra-se na etapa de excitação, Q1 está conduzindo e a chave Q0 pode estar conduzindo ou não. Caso Q0 esteja conduzindo, fecha-se o caminho da fonte de excitação com a bobina da fase, ocasionando o surgimento de uma corrente no circuito. Quando Q0 deixa de conduzir, há energia armazenada na bobina da fase, que passa a recircular por meio de D0. A junção dos dois perfis de corrente é responsável por excitar a máquina. $\mathrm{Na}$ Figura 61 a corrente no D0 foi deslocada em amplitude propositalmente para facilitar a visualização dos perfis de correntes. Originalmente, os perfis estariam entrelaçados.

Em um segundo ensaio experimental verificou-se o comportamento do GRC na ocorrência de mudanças na D. Variou-se a D de $0 \%$ a $100 \%$, em passo de $20 \%$. A Figura 62 mostra as curvas de correntes para uma fase do GRC, onde percebe-se 
que para uma janela de $100 \%$, a corrente na fase obteve pico de $11 \mathrm{~A}$, ao passo que, quando essa janela é de $20 \%$, o pico de corrente na fase não ultrapassa $3 \mathrm{~A}$, ou seja, quanto maior a $D$, maior é também a corrente na fase. Essa constatação é importante pois indica que realmente é possível controlar e/ou limitar a energia gerada pelo GRC por meio da energia utilizada para a excitação da máquina.

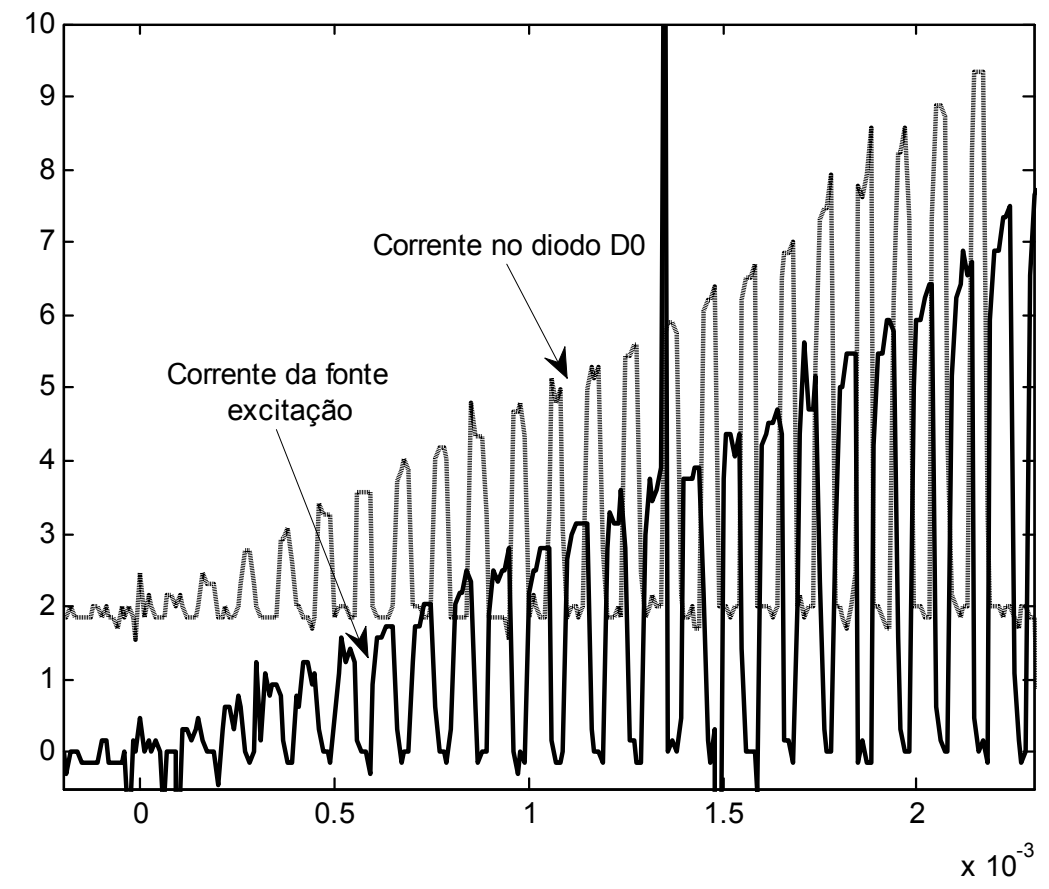

Figura 61 - Corrente na fonte de excitação e corrente no diodo D0.

Extensas análises foram realizadas, com o objetivo de se conhecer o comportamento do sistema GRC para variação de D e da carga. Ensaios foram realizados onde a carga foi alterada entre $4.2 \Omega$ e $41.2 \Omega$. A cada nova carga, a razão D foi variada entre $0 \%$ e $100 \%$, em etapas. Coletando-se os pontos relativos a cada razão cíclica, nível de carga e tensão de saída é possível representação destes dados na superfície indicada na Figura 63. 


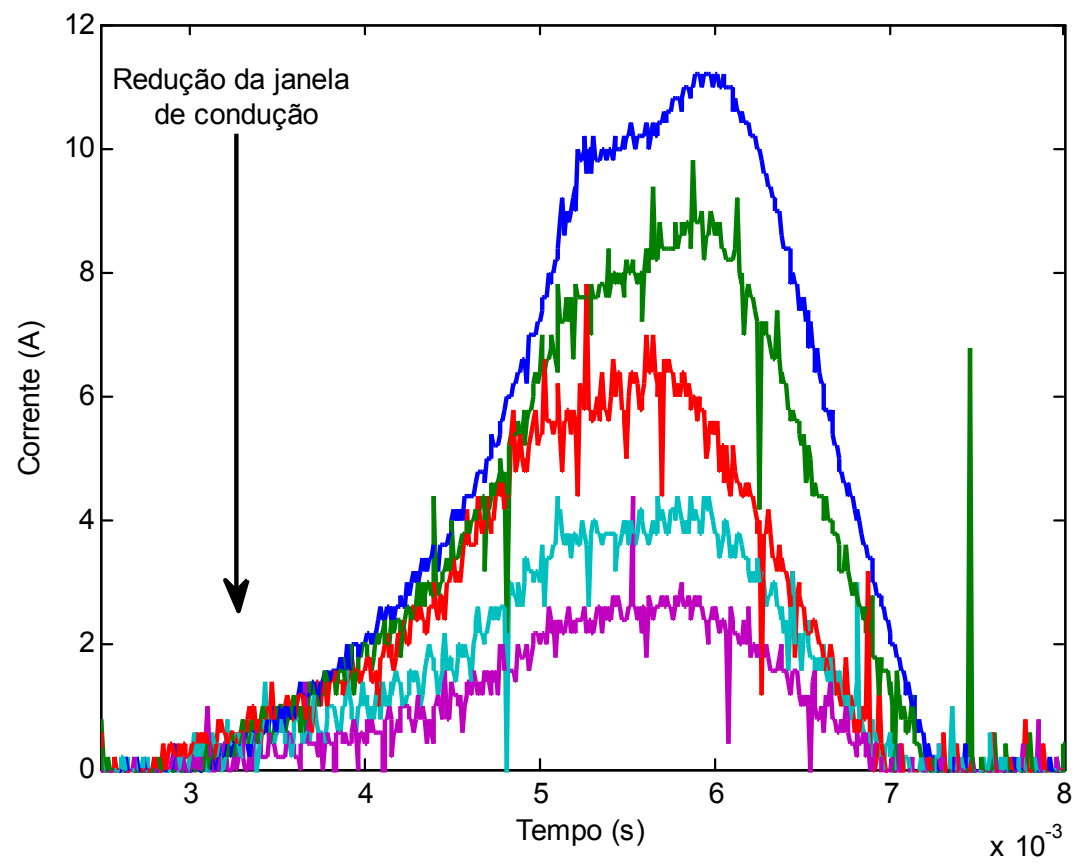

Figura 62 - Corrente em uma fase do GRC com variação da janela de condução de Q0.

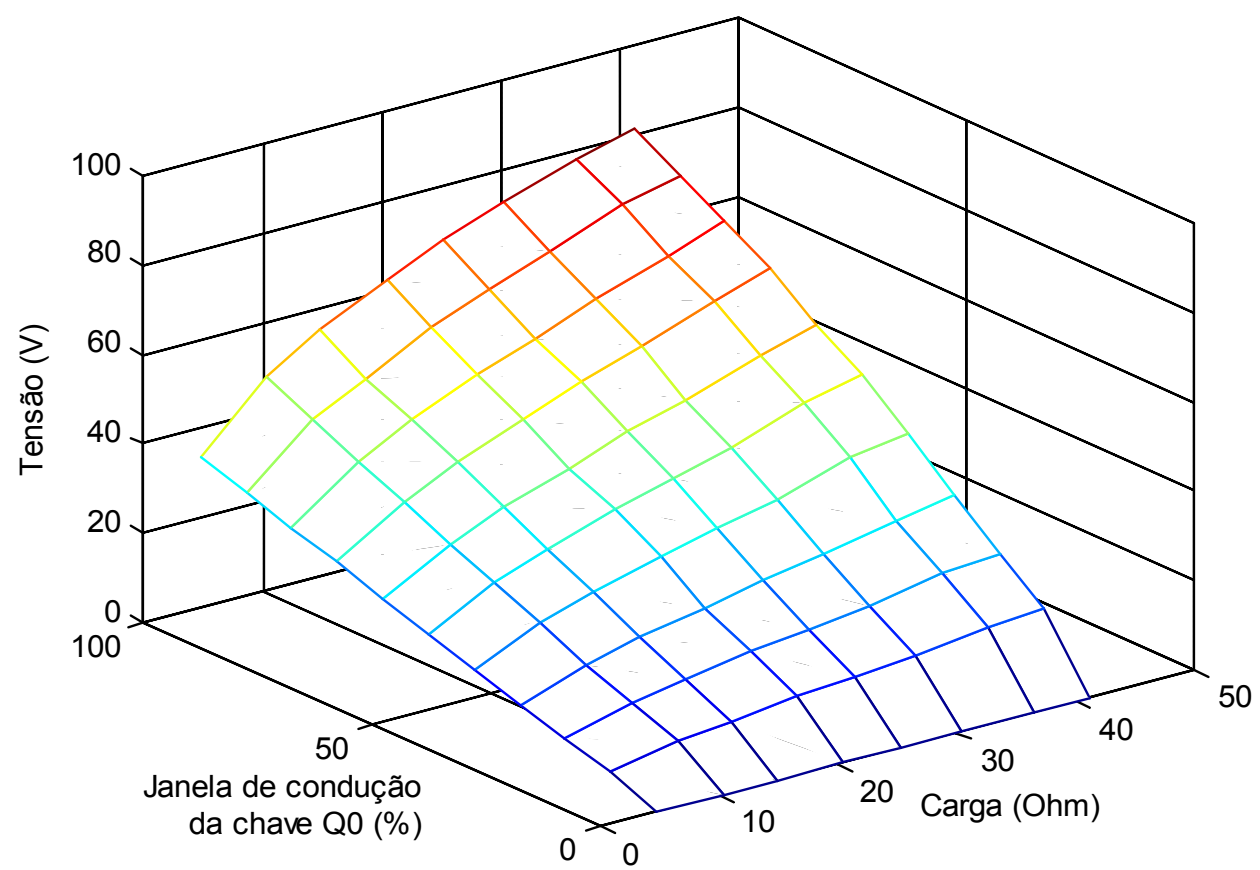

Figura 63 - Resultados relacionando tensão de saída, razão cíclica (D), e a carga.

Os resultados obtidos na Figura 63 mostra que para cada carga experimentada, a tensão gerada sobe rapidamente com o aumento de $D$, atingindo 
seu valor máximo quando D atinge 100\%. A Figura 63 também aponta que, para cada carga aplicada, a tensão de saída pode ser estabilizada por meio do ajuste $D$, indicando que a metodologia de controle fuzzy empregada em simulações computacionais, fundamentada apenas na tensão de excitação pode vir a ser implementada com sucesso para controlar o sistema GRC de acordo com as necessidades da carga.

De forma semelhante, outras análises foram realizadas com objetivo de se conhecer o comportamento do SGRC para variação de D e da velocidade. A velocidade foi variada entre $900 \mathrm{rpm}$ e $4000 \mathrm{rpm}$. A cada nova velocidade, a razão D foi alterada entre $0 \%$ e $100 \%$, em etapas. Com a junção de cada um dos pontos que relacionam a velocidade, razão cíclica e a tensão de saída foi possível formar a superfície mostrada na Figura 64.

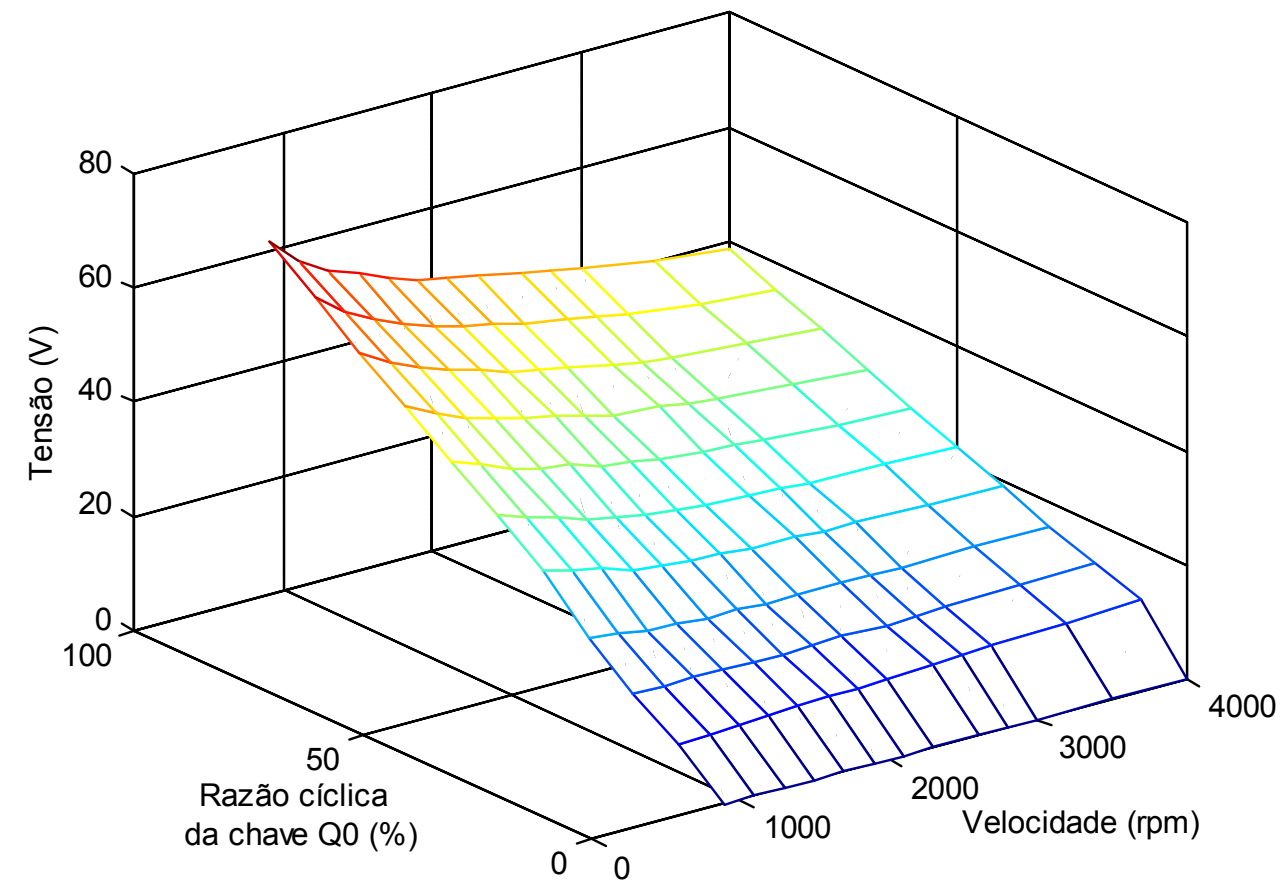

Figura 64 - Resultados relacionando tensão de saída, razão cíclica (D) e a velocidade. 
A análise da Figura 64 mostra que para cada velocidade experimentada, a tensão sobe rapidamente com o aumento de $D$, atingindo seu máximo valor quando D está em 100\%. Adicionalmente a Figura 64 indica que para cada velocidade aplicada, a tensão de saída pode ser estabilizada com o ajuste de $\mathrm{D}$, indicando novamente que a metodologia de controle fuzzy pode vir a ser empregada para o sistema GRC quando há necessidade de operação em velocidade variável.

\subsection{Análise experimental do SGRC com controlador fuzzy}

Para a montagem experimental do sistema GRC, a última etapa foi a implementação da malha de controle de tensão a ser utilizada no SGRC. A estratégia escolhida foi utilizar microprocessadores por serem equipamentos capazes de realizar multitarefas seguindo a lógica pré-estabelecida e armazenada

em seu núcleo. O controlador fuzzy proposto foi aplicado ao SGRC utilizando o kit de desenvolvimento de baixo custo Tiva ${ }^{\text {TM }}$ C Series TM4C1294, o qual apresenta um microprocessador ARM Cortex M4 de ponto flutuante com $120 \mathrm{MHz}$ de velocidade de processamento, um conversor analógico digital (ADC) de 12 bits, e um modulo PWM digital.

No Capitulo 5 foi apresentada toda a fundamentação necessária para o entendimento do sistema fuzzy proposto neste trabalho. No entanto, ao se embarcar o sistema fuzzy, algumas etapas adicionais foram implementadas, e essas etapas, juntamente com montagens e resultados, são alvos de discussão deste tópico.

\subsubsection{Controlador fuzzy embarcado em microprocessador}

O sistema fuzzy embarcado proposto neste trabalho foi concebido com a intenção de reduzir os esforços computacionais para sua aplicação em tempo real, 
sendo possível graças a metodologia proposta por SUETAKE (2011). O trabalho de SUETAKE (2011) mostra o processo de criação de um sistema fuzzy para ser embarcado em microprocessadores, e já adequando para o sistema fuzzy proposto procede da seguinte forma: a superfície fuzzy e discretizada e tabelada. A tabela das respostas fuzzy é armazenada no núcleo do microprocessador. Com a fuzzyficação dos valores lidos no módulo ADC é possível percorrer a tabela armazenada (inferência fuzzy), extraindo a resposta fuzzy desejada. Com a defuzificação, o valor encontrado é enviado a um modulo PWM digital. A saída do PWM é enviada para o SGRC, controlando a operação da chave Q0 do CAM. As outras chaves controladas do CAM são comandadas por fotosensores de posição, possuindo razão cíclica constantes para todo tempo de funcionamento da máquina. Um diagrama de blocos do processo é apresentado na Figura 65.

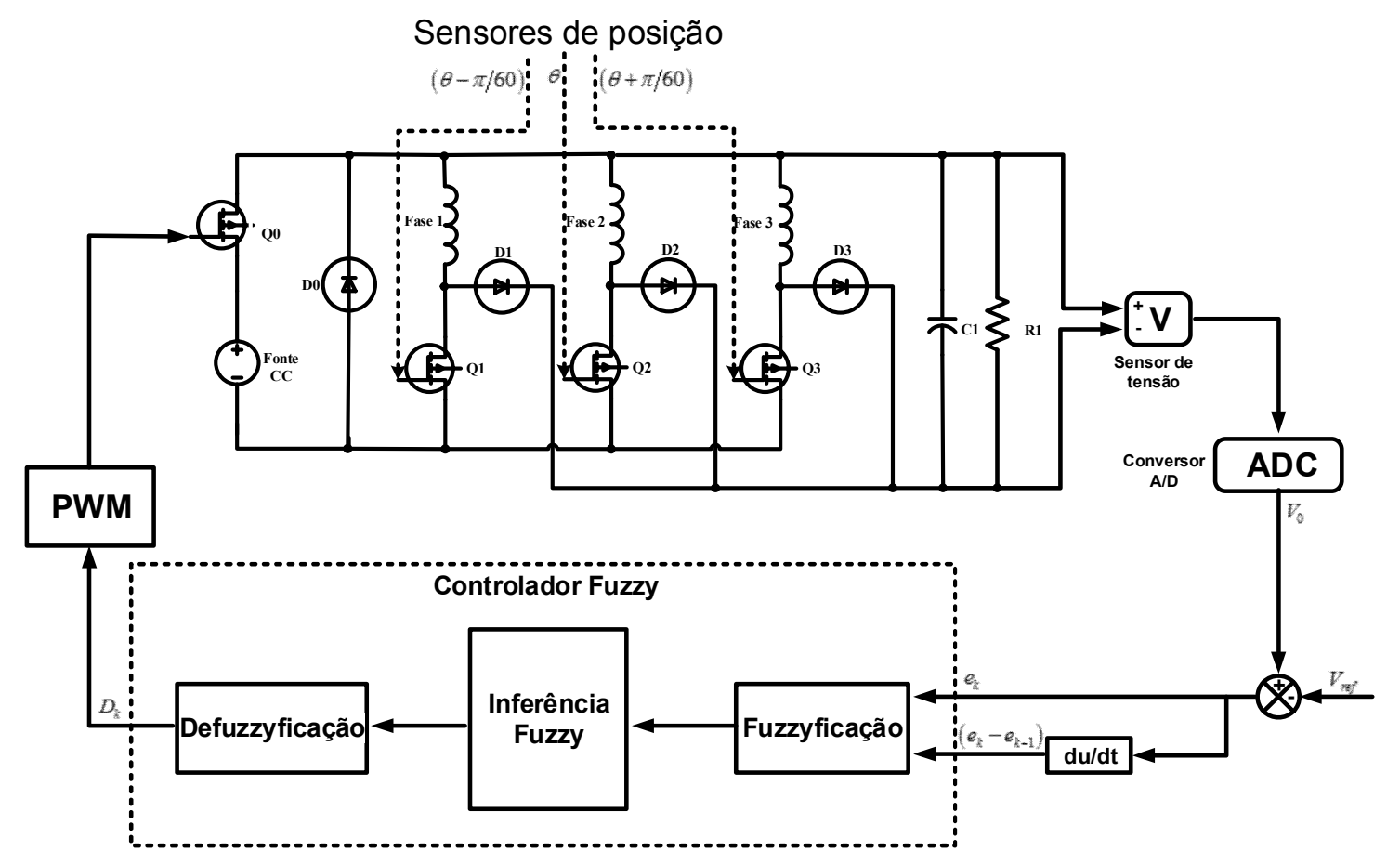

Figura 65 - Diagrama de blocos do controlador fuzzy de tensão para o sistema GRC. 
A Figura 66 apresenta a superfície de controle fuzzy. Nota-se que o sinal de controle fuzzy apresenta o universo de discurso $[-0.1 ; 0.1]$ e está correlacionada aos universos de discurso $[-0.1 ; 0.1]$ e $[-10.0 ; 10.0]$ das variáveis fuzzy, erro e derivada do erro, respectivamente. Para embarcar a superfície fuzzy no microprocessador, discretizou-se os universos de discursos das variáveis fuzzy em cinquenta pontos cada. Por meio da correlação dos graus de pertinência das funções obteve-se a superfície fuzzy discreta de controle. Os pontos da superfície fuzzy discreta forma uma matriz quadrada de dois mil e quinhentos elementos dispostos em cinquenta linhas e cinquenta colunas. Esta superfície fuzzy discreta foi a utilizada na implementação.

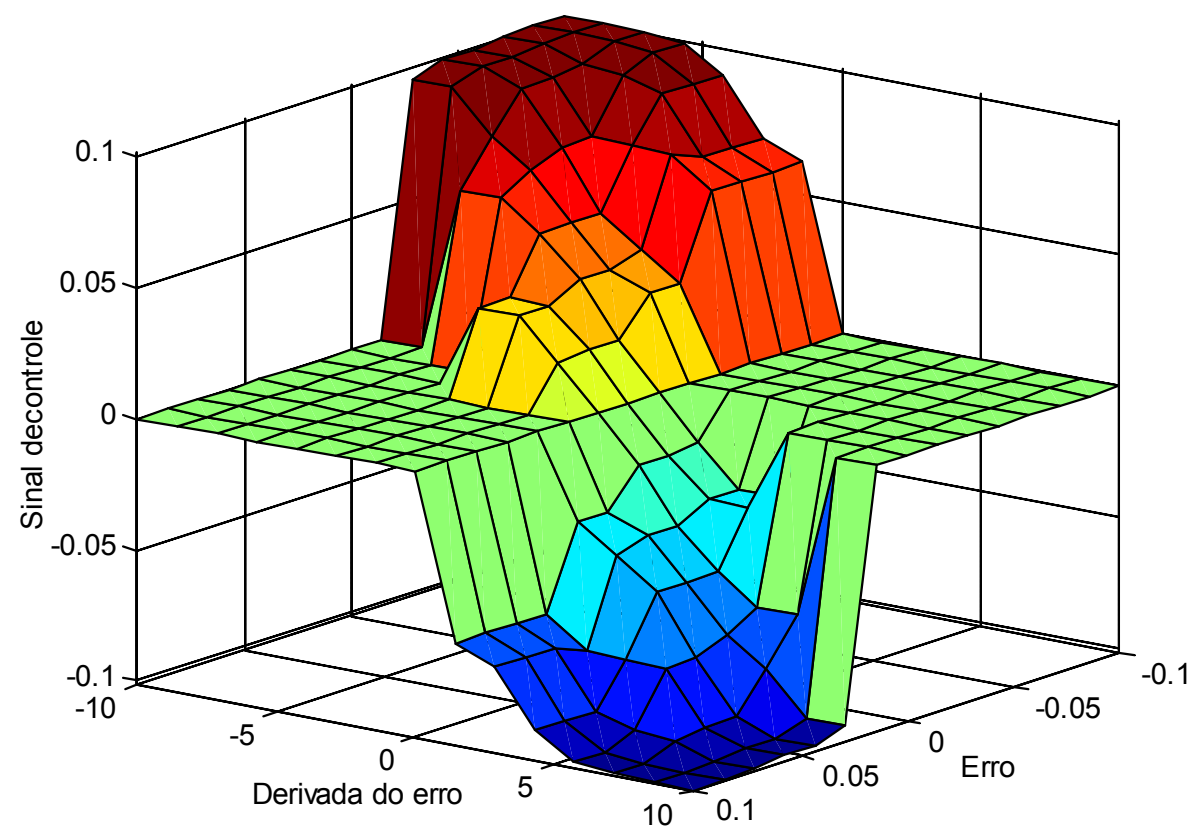

Figura 66 - Superfície fuzzy de controle. 


\subsubsection{Bancada de testes}

Nos testes preliminares, com o SGRC em malha aberta, utilizou-se a bancada de testes da Figura 54, que encontrava-se parcialmente montada. Foi necessário pequenos ajustes e somente a construção do CAM para seu funcionamento. Porém, a bancada da Figura 54 foi construída de maneira totalmente manual, arcaicamente, com longos cabos e layout desprivilegiado ocupando grande espaço físico. Essas características são desvantajosas e contribuem para o aparecimento de ruídos nos sinais, mudança de parâmetros de elementos, mau contato, curto-circuito, e ainda, risco de choques elétricos.

Diante das dificuldades encontradas, somadas com a anseio de embarcar o controlador fuzzy em um microprocessador, houve a necessidade de elaboração e montagem de uma nova bancada experimental de teste. A nova bancada de teste foi criada com layout simples, compacto, afim de privilegiar o funcionamento do microprocessador. Os circuitos dos drivers das chaves controladas e o sensoriamento foram montados em placas de circuito impresso, com trilhas isoladas dificultando a propagação de ruídos. O CAM, que apresenta circuito de potência, foi feito em circuito impresso e suas trilhas reforçadas com estanho, garantindo a operação com valores de correntes elevadas. Ao fim, obteve-se um painel com todos os circuitos, componentes e drivers necessários para o funcionamento do GRC. A Figura 67 e a Figura 68 mostram a nova bancada experimental implementada.

A Figura 69 apresenta um diagrama de blocos com todas as etapas existentes na bancada experimental. O diagrama é dividido em dois circuitos: circuito de potência e circuito de sensoriamento, condicionamento e drivers de acionamento. 


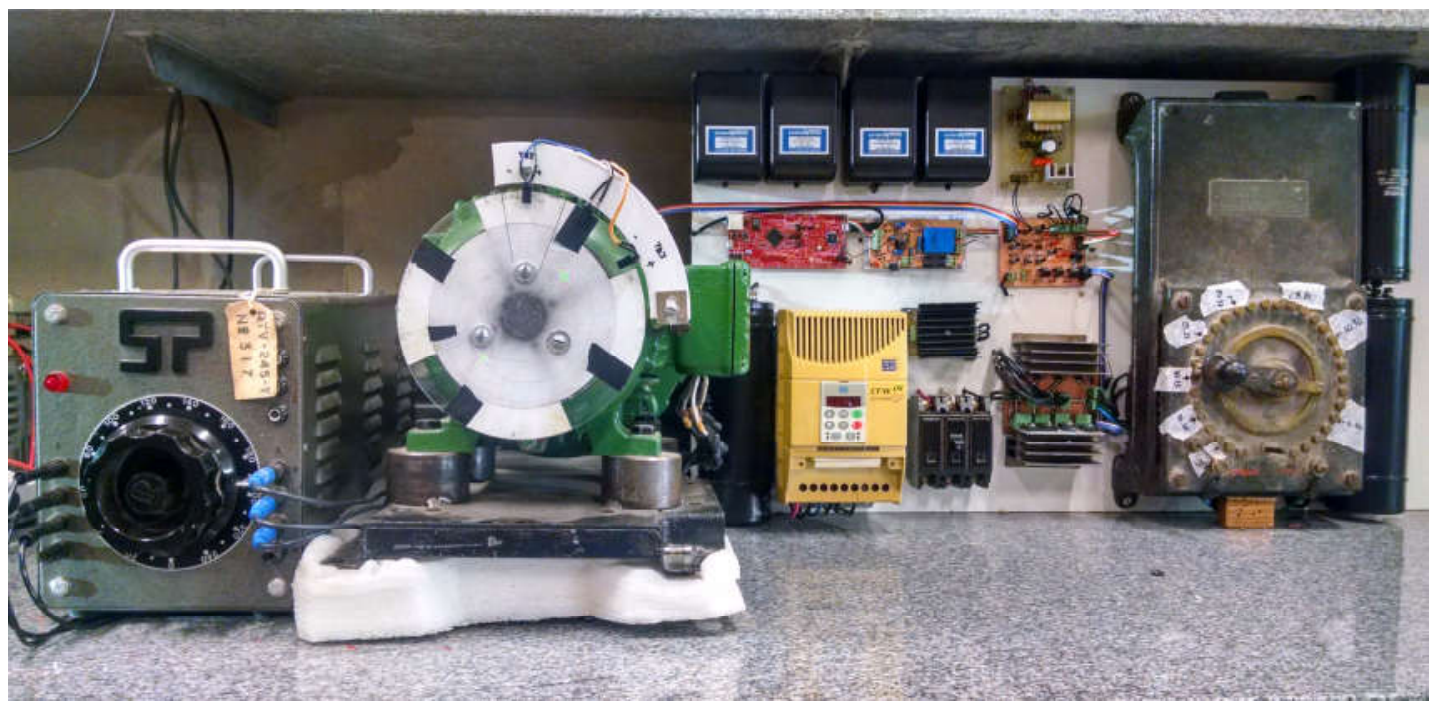

Figura 67 - Vista frontal da bancada experimental.

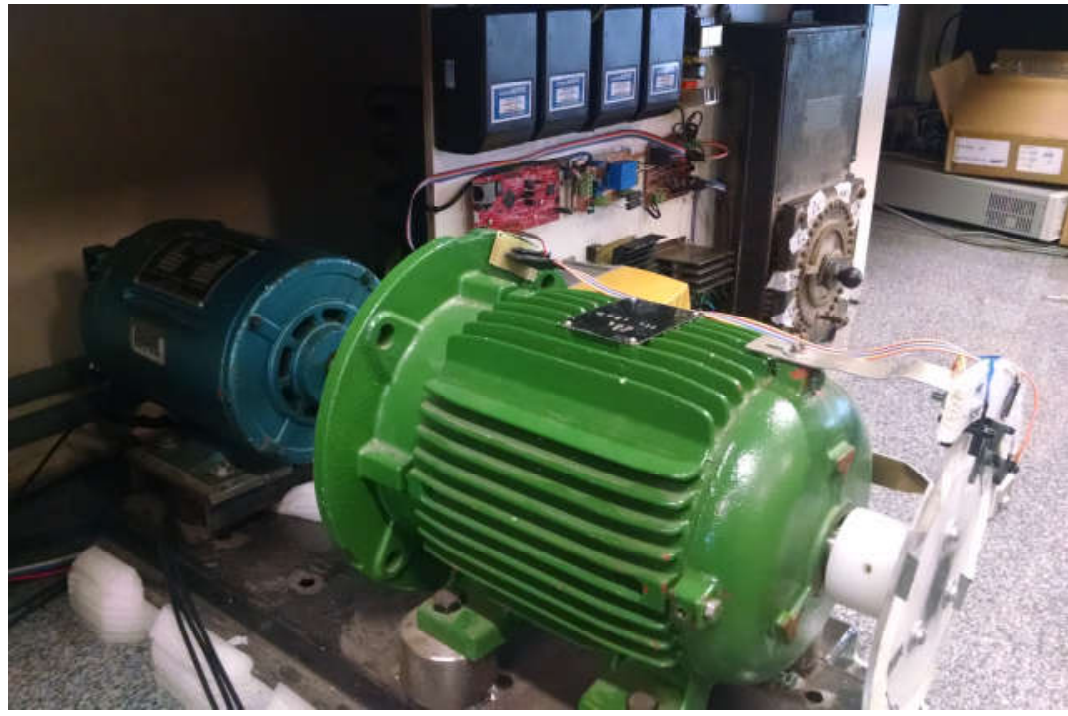

Figura 68 - Vista lateral da bancada experimental.

O circuito de potência apresenta: um motor de indução trifásico (MIT) acionado por um inversor de frequência comercial na entrada mecânica do GRC. O inversor de frequência tem tensão nominal de $380 \mathrm{~V}$ fase-fase e a rede de distribuição é de 220 V fase-fase, fazendo-se necessário a inserção de um transformador elevador no sistema. O transformador é responsável pela alimentação de todo SGRC. Para a proteção da rede foi inserido um disjuntor na saída do transformador. Uma fonte variável de tensão associada a uma ponte retificadora em 
paralelo com um capacitor são responsável pela excitação da máquina. A interação do GRC, tensão de excitação e o CAM gera uma saída que supre a carga do sistema.

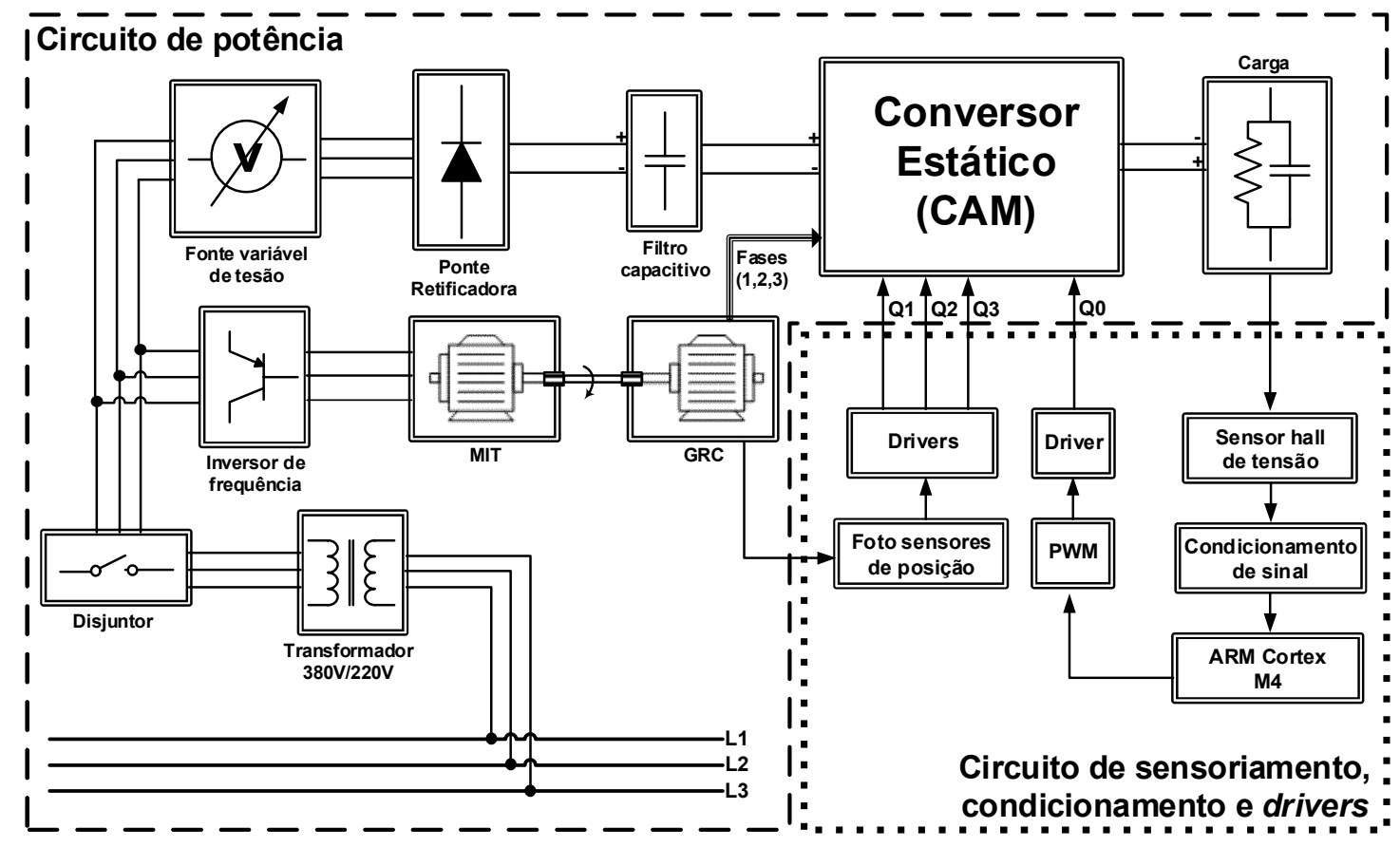

Figura 69 - Diagrama de blocos da banca experimental do sistema GRC com controlador fuzzy.

No circuito de sensoriamento, condicionamento e drivers de acionamento tem-se: Foto sensores de posição acoplados ao GRC enviando informações para os drivers de acionamento das chaves Q1, Q2 e Q3. Um sensor hall de tensão com seu condicionamento de sinal coletando e enviando para o microprocessador informações de tensão na carga. Um microprocessador realizando as etapas necessárias para o controle. Por fim, tem-se um PWM acionando o driver responsável pelo chaveamento de Q0.

Todas as etapas do circuitos de potência e circuito de sensoriamento, condicionamento e drivers de acionamento acontecem simultaneamente e seu sincronismo garante o correto funcionamento do SGRC com controlador fuzzy. Após 
montagens, ajustes e testes, pode-se operar experimentalmente o SGRC e obter dados de seu funcionamento.

\subsubsection{Resultados}

Os resultados a serem apresentados nesse tópico foram obtidos por meio de ensaios experimentais realizados na bancada de teste mostrada na Figura 67. As especificações dos componentes utilizados na montagem são os mesmos utilizados para as simulações computacionais e foram apresentados na Seção 5.3.

A primeira atitude tomada após a montagem da bancada experimental de teste foi verificar o correto funcionamento do sistema fuzzy de controle. Para a fonte de excitação ajustada na tensão de 80V, a velocidade constante de 3000 rpm, mudou-se o valor de tensão de referência do controlador fuzzy. No primeiro ensaio a tensão referência manteve-se fixa em $50 \mathrm{~V}$ e alterada para $30 \mathrm{~V}$ no segundo ensaio. A Figura 70 mostra a tensão na saída do GRC para os ensaios. Em ambos os ensaios houve a correta atuação do controlador, estabilizando a tensão no valor referência pré-estabelecido. Ambos perfis de tensão apresentam baixa oscilação, o que representa o bom funcionamento do controlador para valores distintos de referência.

Em ambos ensaios manteve-se inalterada as variáveis do sistema. Logo, para tensão de saída do sistema seguir diferentes valores de referência é necessário que aconteça mudanças no sinal de controle, ou seja, torna-se necessário a variação de D da chave Q0. Ao comparar os dois ensaios, a chave Q0 necessitou de maior período de condução com $50 \mathrm{~V}$ de tensão referência do controlador, conforme indica a Figura 71. Isto informa que é necessário maior energia de excitação para alcançar maiores valores de tensão na carga. 


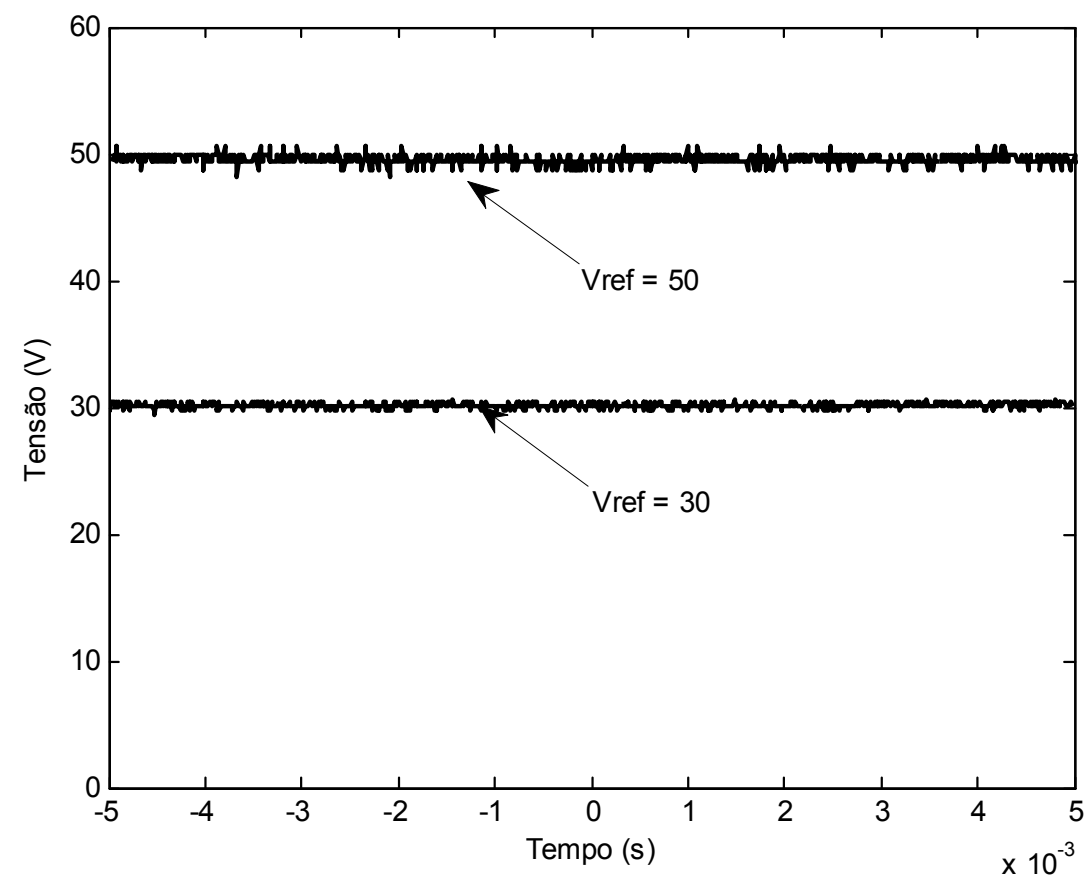

Figura 70 - Tensões de saída do SGRC para $30 \mathrm{~V}$ e $50 \mathrm{~V}$ de tensões referência.
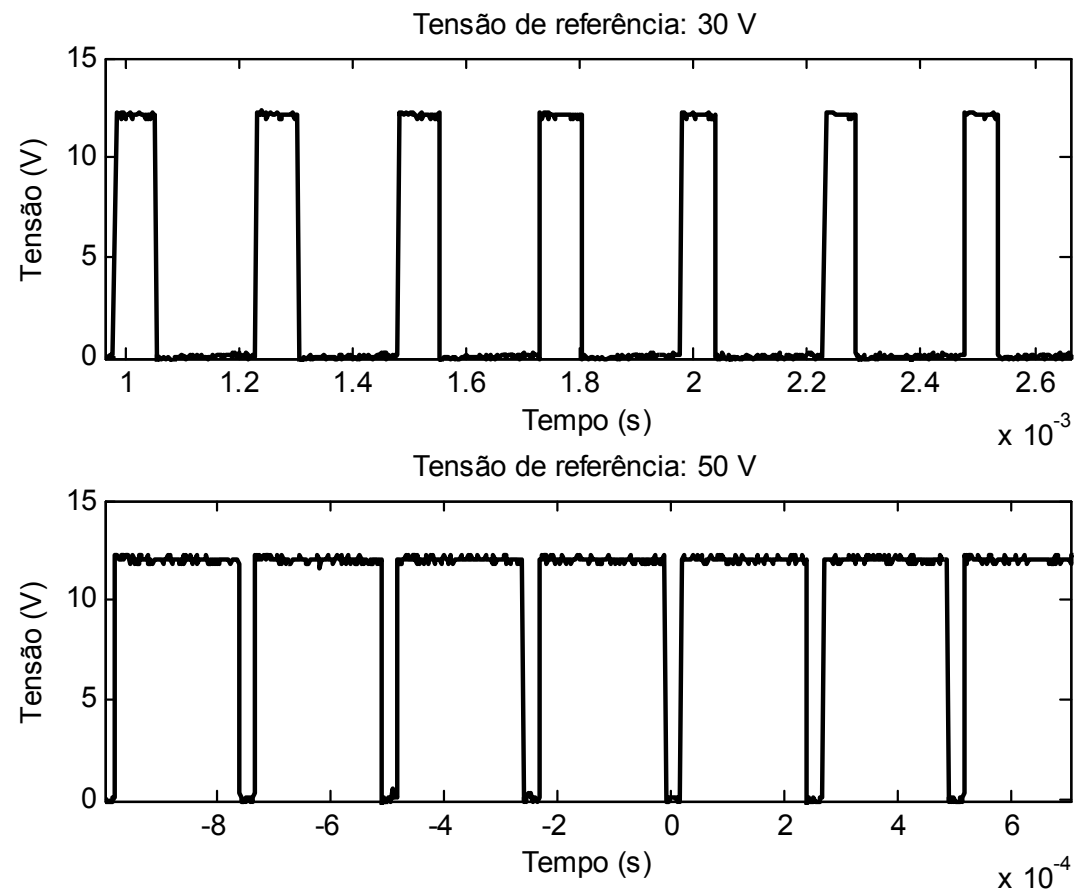

Figura 71 - Razão Cíclica da chave Q0 para tensões referência de $30 \mathrm{~V}$ e $50 \mathrm{~V}$. 
Durante a realização dos testes experimentais foi observado que a fonte de tensão de excitação frequentemente apresentava oscilações. Foi investigado e chegou-se à conclusão que as oscilações eram provenientes da rede elétrica que alimentava o sistema. Por os sistemas de distribuição comumente apresentarem oscilações em seus perfis de tensão, teve-se a ideia de verificar o comportamento do controlador fuzzy quando submetidos a alterações no valor da tensão fornecida pela fonte de excitação do GRC. Dois ensaios foram realizados. No primeiro, a tensão da fonte de excitação foi fixada em $80 \mathrm{~V}$ e no segundo em $100 \mathrm{~V}$. Em ambos os ensaios, a tensão referência do controlador foi $50 \mathrm{~V}$. Com o resultado ilustrado na Figura 72, pode-se então observar a eficiência controlador em manter a tensão de saída em $50 \mathrm{~V}$ em amos os casos. Os valores de tensão e corrente na saída do GRC ficaram muito próximas nos dois ensaios indicando que a mesma energia de excitação foi empregada para os dois casos.

Analisando a Figura 73 fica evidente que para obter a mesma energia de excitação nos ensaios, o tempo de condução da chave Q0 sofreu alteração, onde o período de condução da chave Q0 é maior para a tensão de $80 \mathrm{~V}$, já que seu valor de pico e menor. Com a variação da $\mathrm{D}$ de $\mathrm{Q} 0$ consegue-se equilíbrio de energia de excitação em ambos os casos, indicando que o controlador fuzzy mantem boa operação mesmo com oscilação da fonte de excitação.

Uma das aplicações ressaltadas para um GRC é a sua utilização em geração eólica. O GRC experimentado foi testado para operação em velocidade variável e verificou-se bom funcionamento, ilustrado na superfície da Figura 64. A Figura 64 também mostra que a tensão de saída do GRC sofre variações com a mudança da velocidade de operação. Nesse aspecto, testes foram realizados com controlador fuzzy verificando seu desempenho com velocidade variável de operação. 
Tensão de entrada: $80 \mathrm{~V}$

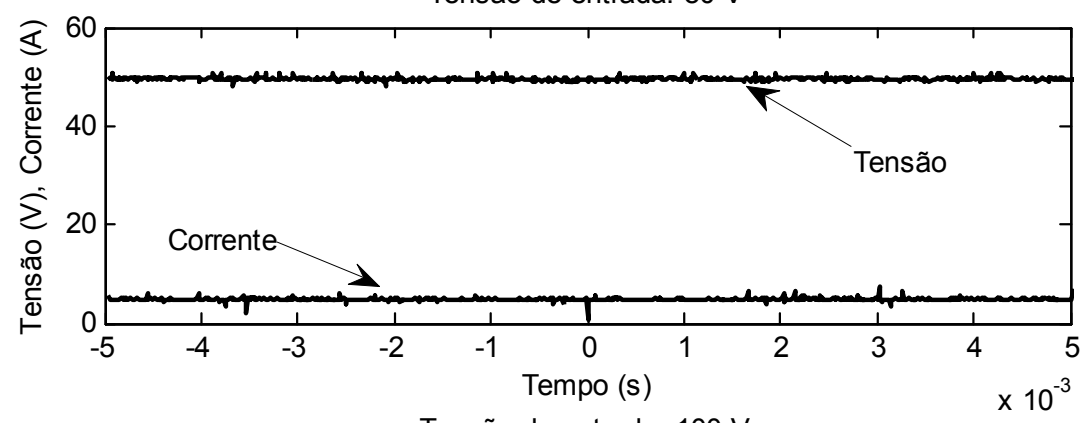

Tensão de entrada: $100 \mathrm{~V}$

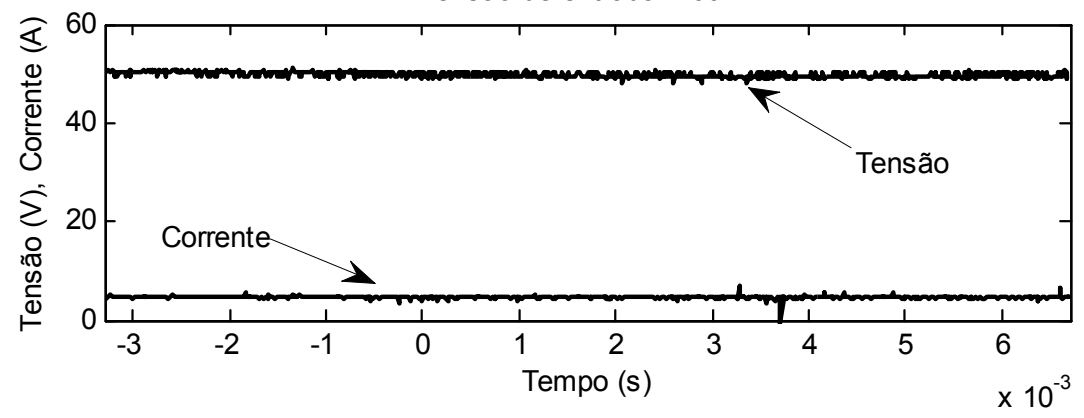

Figura 72 - Tensões e corretes de saída do GRC para tensões de excitação $80 \mathrm{~V}$ e $100 \mathrm{~V}$.

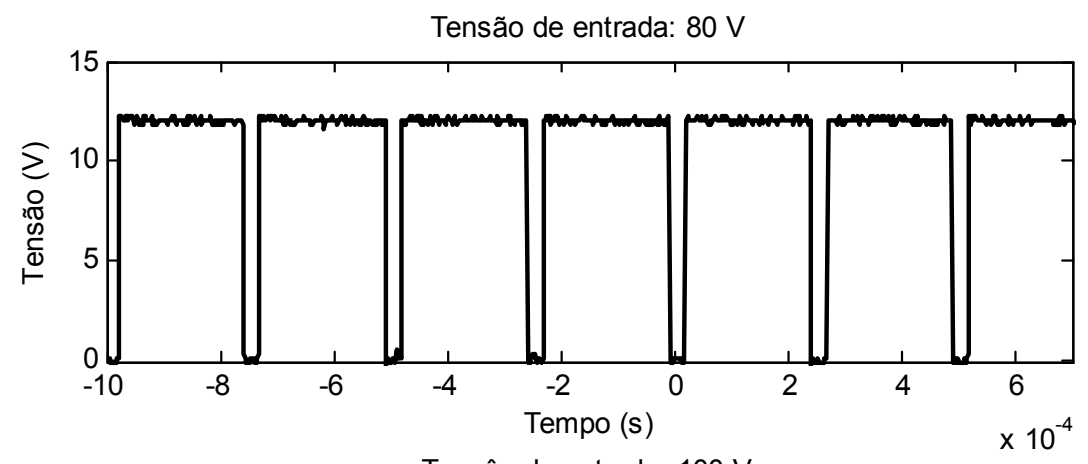

Tensâo de entrada: $100 \mathrm{~V}$

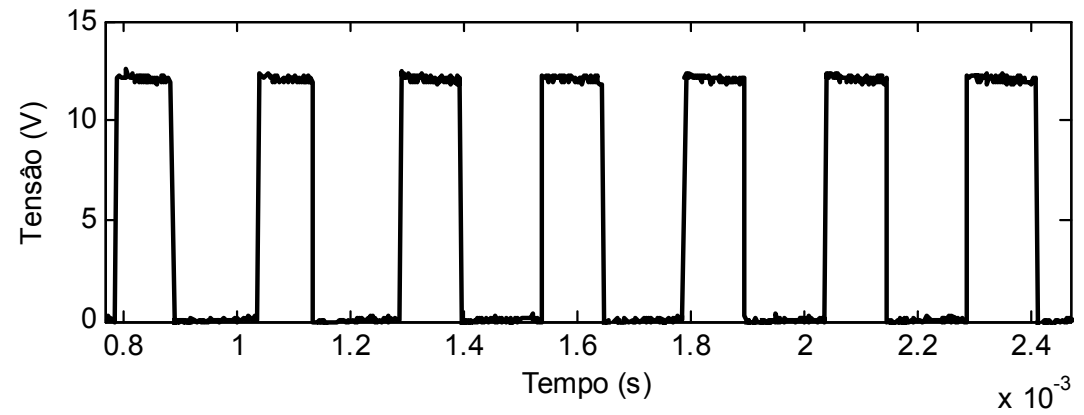

Figura 73 - Razão cíclica da chave Q0 para tensões de excitação de $80 \mathrm{~V}$ e $100 \mathrm{~V}$. 
As velocidades de 1800 rpm e 3000 rpm foram ensaiadas na atuação do controlador fuzzy. $50 \mathrm{~V}$ foi a tensão referência do controlador e $80 \mathrm{~V}$ a tensão da fonte de excitação. Como resultado, as tensões de saída, para as duas velocidades de operação, mantiveram-se constantes em 50 V, conforme ilustrado na Figura 74. Para garantir a tensão de $50 \mathrm{~V}$ nas duas velocidades experimentadas o controlador fuzzy agiu alterando a D da chave Q0, conforme mostra a Figura 75.
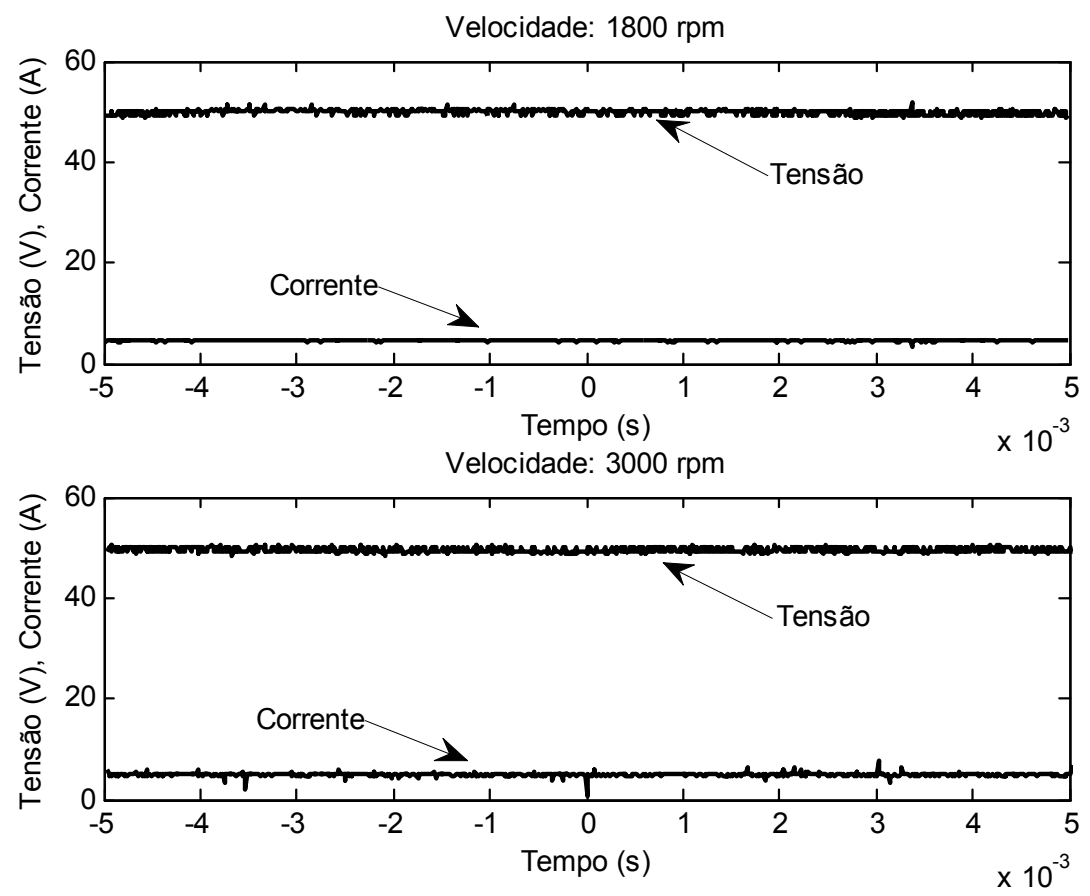

Figura 74 - Tensões e correntes na saída do GRC para 1800 rpm e 3000 rpm de velocidade.

A superfície mostrada na Figura 64 indica que nas velocidades mais elevadas ocorre queda da tensão na saída do GRC. Para manter a tensão constante o sistema fuzzy de controle atuou aumentando o período de condução da chave Q0, conforme mostra Figura 75. Essa atuação garante a mesma dinâmica de geração para as duas velocidades experimentadas.

A operação sobre variação de carga é uma propriedade dos sistemas de geração de energia. Para o SGRC, foi mostrado na Figura 63 que a tensão da saída 
do sistema é altamente dependente da carga que ele alimenta, sofrendo acentuadas perturbações com a mudança de carga. Sabendo disso, e visto que a estabilidade da tensão de saída do GRC é o alvo deste trabalho, o controlador fuzzy foi testado sobre condições de varga variável.
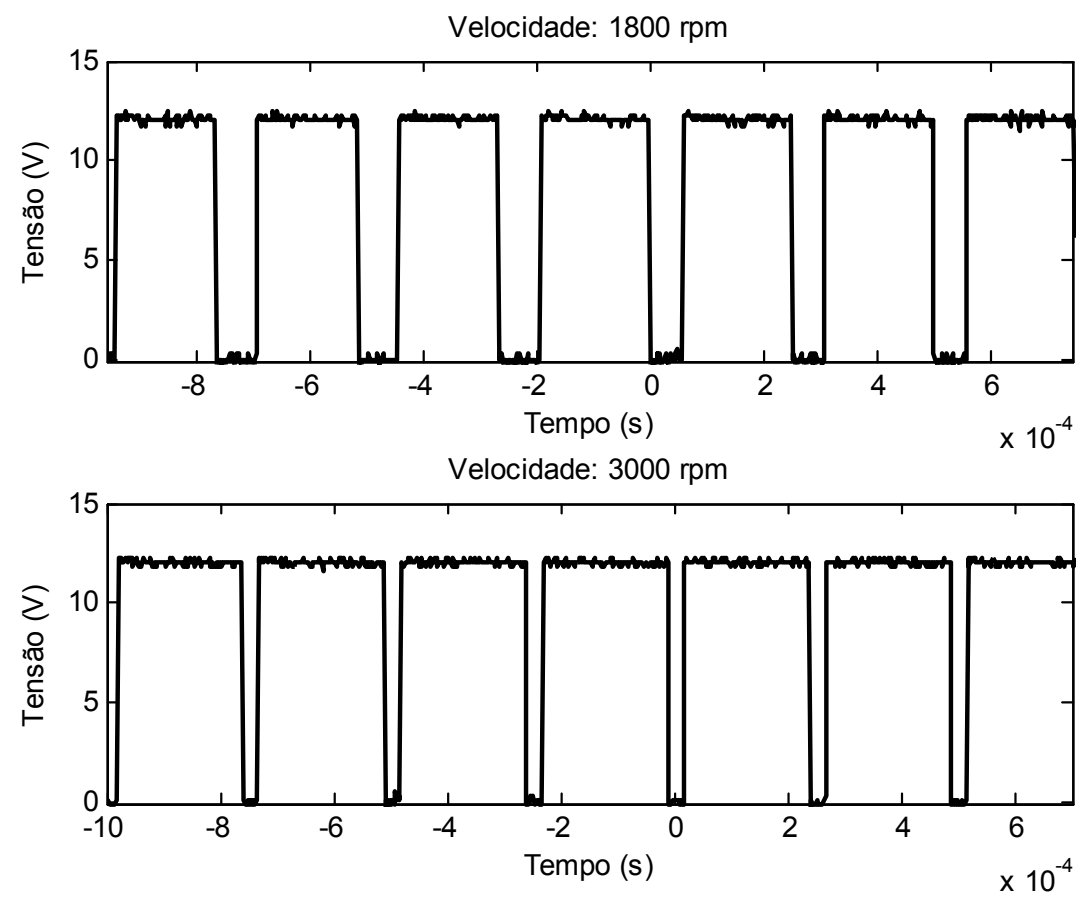

Figura 75 - Razão cíclica de Q0 para 1800 rpm e 3000 rpm de velocidade.

Para o GRC operando em malha aberta fez-se um ensaio de variação de carga, com resultados mostrados na Figura 76. A tensão da fonte de excitação foi definida em $80 \mathrm{~V}$ e a velocidade em 3000 rpm. O teste inicia-se com o GRC suprindo $11.1 \Omega$ de carga. Tensão e corrente estão estáveis em $7.3 \quad \mathrm{~V}$ e $7.0 \quad \mathrm{~A}$ respectivamente. No instante $[-0.20 \mathrm{~s}]$ adiciona-se paralelamente outra carga de $11.1 \Omega$, resultando em uma carga equivalente de $5.55 \Omega$. Como consequência, ocorre afundamentos na tensão e elevação na corrente, que após suas dinâmicas estabilizam-se em $54.9 \mathrm{~V}$ e $10.0 \mathrm{~A}$, respectivamente. No instante [0.60 s] a carga de $11.1 \Omega$ adicionada paralelamente é retirada do sistema, causando nova perturbação. 
Após suas dinâmicas, tensão e corrente voltam a apresentar valores idênticos ao do início do teste. Na Figura 76 a corrente recebeu um fator multiplicativo $(k=5)$ para possibilitar a análise de tensão e corrente em um único gráfico, e destaca a dependência existente da tensão de saída pela carga alimentada pelo GRC.

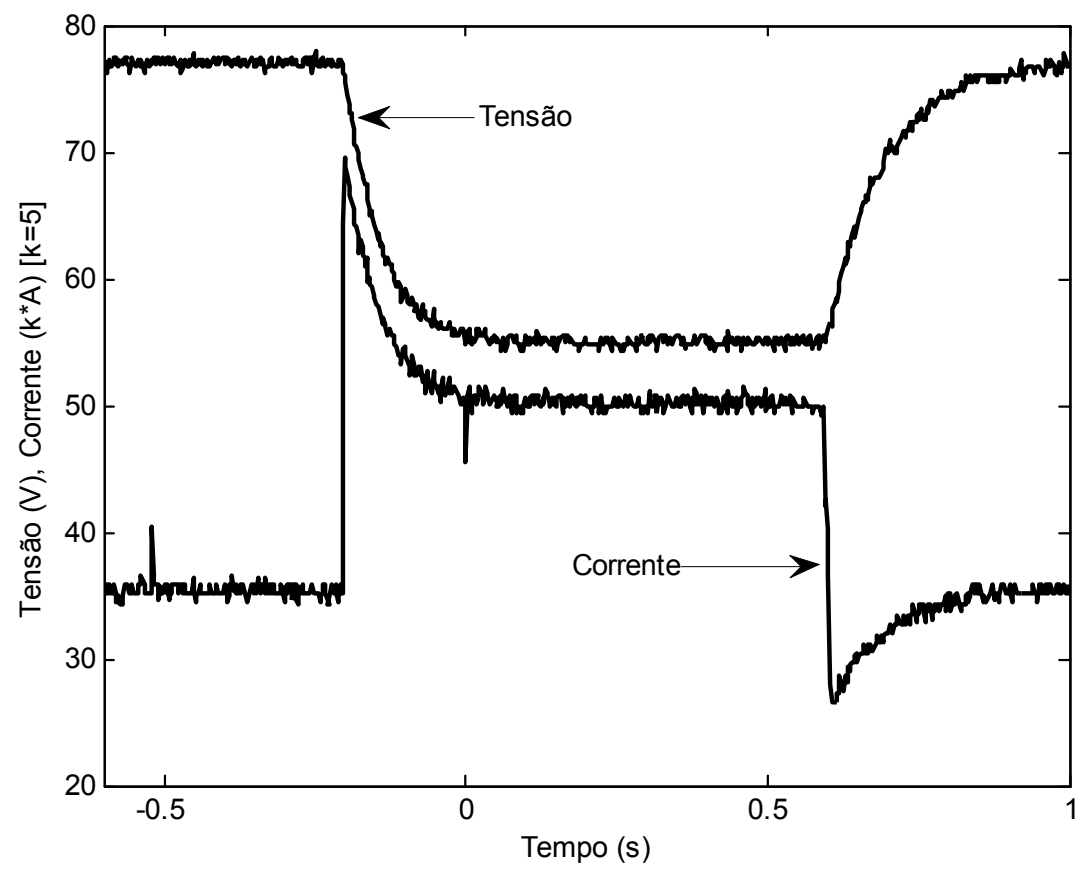

Figura 76 - Dinâmica de tensão e corrente sobre variação de carga em malha aberta.

Com a malha de controle anexada ao GRC repetiu-se o ensaio de variação de carga mantendo a tensão referência em $50 \mathrm{~V}$. Como resposta obteve-se o gráfico da Figura 77. Os parâmetros do ensaio são os mesmos apresentados para o ensaio em malha aberta, Figura 76. Os instante de inserção e retirada da segunda carga em paralelo são [-0.49 s] e [0.55 s] respectivamente. Nota-se na Figura 77 que a tensão de saída manteve-se fixa em $50 \mathrm{~V}$ para todo o ensaio, não sofrendo oscilações com a inserção ou retirada de carga do sistema. Por sua vez, a corrente na saída mudou de 4.6 A para 9.0 A ao variar a carga de $11.1 \Omega$ para $5.6 \Omega$. A dinâmica de transição do perfil de corrente ocorre de forma rápida e estável, não apresentando transitórios 
ou oscilações consideráveis. De forma semelhante, ao efetuar a mudança de cara de $5.6 \Omega$ para $11.1 \Omega$, com rápida dinâmica a corrente volta a assumir o valor inicial de ensaio, 4.6 A. Na Figura 77 o perfil de corrente recebeu um fator multiplicativo $(\mathrm{k}=5)$ possibilitando a análise dos perfis de tensão e corrente em uma mesma imagem.

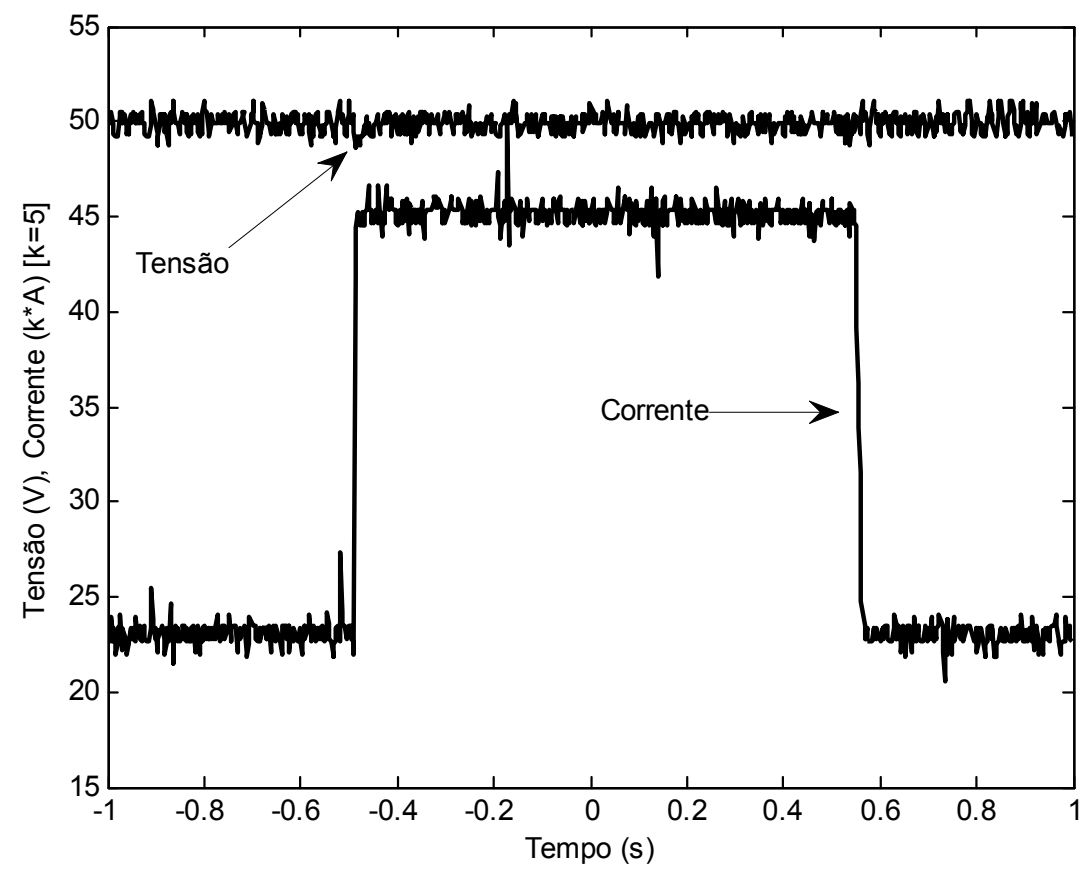

Figura 77 - Dinâmica de tensão e corrente sobre variação de carga com atuação do controlador fuzzy de tensão.

Os ensaios de variação de carga são considerados importantes por ser uma condição trivial dos sistemas de geração de energia. Com os resultados obtidos na Figura 76 e na Figura 77 foi possível observar a diferença da dinâmica de operação do sistema GRC em malha aberta e com controlador fuzzy, quando operado em condição de velocidade variável. Ficou destacado a eficiência do controlador fuzzy de tensão, que foi capaz de estabilizar de forma satisfatória a tensão na saída, para degraus crescentes e decrescentes de carga. 
Ao fim dos ensaios experimentais, e de porte dos resultados apresentados neste capitulo foi possível destacar a estratégia de controle utilizada, que por meio exclusivo da limitação e/ou controle da tensão de excitação foi possível manter estável a tensão de saída para diferentes tipos de operação do GRC. O sistema fuzzy de controle de tensão obteve bom desempenho com a estratégia empregada, conseguindo bons resultados com o SGRC operando em: velocidade variável, carga variável e fonte de excitação variável. Portanto, mediante os resultados apresentados, pode-se afirmar que o controlador fuzzy de tensão, baseado na tensão de excitação foi concebido, simulado, implementado e testado satisfatoriamente em várias condições de operação do sistema GRC, sendo o sistema de controle versátil, estável, robusto e apto para ser empregado em sistemas de geração de energia elétrica que utilizam o GRC. 


\section{Discussões e conclusões}

Nesta tese de doutorado foi apresentada uma nova proposta para o controle de tensão para um sistema de geração de energia com a utilização de um gerador a relutância chaveado, por meio de um controlador inteligente baseado em lógica fuzzy. Com o desenvolvimento do trabalho pode-se destacar as seguintes contribuições:

- Uma nova técnica inteligente foi apresentada para a inserção do perfil de indutância na simulação do sistema GRC. A técnica que utiliza uma rede neural PMC para realizar a aproximação do perfil de indutância a partir de dados experimentais teve bom desempenho e foi inserida ao modelo computacional do SGRC. A vantagem de se utilizar a técnica inteligente é por esta propiciar menor custo computacional, sendo este um benefício ao se pensar em sistemas de simulação em tempo real ou em se embarcar a técnica em hardware.

- Uma nova topologia de conversor estático, denominado conversor alternativo modificado, foi concebida com a função principal de tornar possível o controle da tensão de saída do sistema GRC por meio de limitações na tensão de excitação da máquina. Este novo conversor foi testado e simulado com o software Matlab Simulink, ficando constatado seu bom funcionamento desse tipo de operação, além de 
apresentar menor quantidade de componentes semicondutores quando comparado à topologias tradicionais.

- Uma modelagem computacional de um sistema de geração de energia com um gerador a relutância chaveado trifásico $6 \times 4$ foi apresentada. Toda a modelagem foi realizada em Matlab Simulink pela facilidade de integração das várias partes complexas do sistema. Resultados simulados dos perfis de tensão e corrente de excitação, tensão e corrente nas fases, tensão e corrente gerada, foram apresentados demonstrando a dinâmica de funcionamento desse tipo de máquina especial.

- Uma abordagem inteligente para um controlador fuzzy de tensão gerada foi apresentada. Foi detalhada sua concepção e sua forma de atuação. Assim, uma simulação foi desenvolvida em Matlab Simulink para confirmar as características e eficiência do controlador fuzzy em questão. Foram apresentados resultados do controlador atuando em velocidade constante, velocidade variável e com variação de carga. Em todas as situações o controlador fuzzy de tensão teve bom desempenho, apresentando pequenas flutuações próximas ao valor de referência. Trata-se de um controlador robusto e versátil que se adapta a mais de um tipo de perturbação do sistema.

- Uma bancada de testes pré-existente adaptada ao sistema GRC proposto foi implementada e junto com a montagem do CAM foi realizado ensaios experimentais em malha aberta. Resultados experimentais mostram a dinâmica de funcionamento do GRC quando 
operado pelo CAM, esclarecendo o funcionamento do novo conversor.

- Com a criação de um módulo PWM analógico a metodologia de controle foi testada. Ainda com a operação em malha aberta do GRC pode-se inspecionar a nova dinâmica de funcionamento do GRC. Adicionalmente, com exaustivos testes experimentais pode-se obter uma coleção de dados que, por meio de análises numéricas e gráficas pode-se observar o comportamento do GRC para diferentes razoes cíclicas de operação do módulo PWM. Os resultados apresentados apontaram que a estratégia de controle adotada poderia ser implementada com êxito.

- Uma nova bancada de testes foi desenvolvida, tornando possível a junção do sistema GRC com o controlador fuzzy de tensão embarcado em um microprocessador. Resultados experimentais do sistema GRC controlado pelo sistema fuzzy operando em diferentes condições foram apresentadas, destacando a estabilidade e versatilidade do controlador proposto.

Com a utilização do controlador fuzzy destacado neste texto, a tensão de saída apresenta estabilidade para diferentes perturbações impostas ao sistema GRC. Ensaios experimentais realizados destacaram o comportamento do GRC para operação em velocidade variável, carga variável e tensão de excitação variável com atuação eficiente do controlador fuzzy para todos os ensaios. Portanto, ao se controlar a tensão de saída do GRC, os conversores CC/CA a serem ligados no barramento CC de saída do gerador pode ser projetado para um ponto fixo de operação. Assim, não necessitando de operação com tensão variável, os projetos de 
conversores CC/CA são simplificados, e consequentemente com melhor eficiência e mais baratos.

Por se tratar de uma máquina com estudos recentes, pouco ainda se sabe a respeito dos GRC. O sistema de controle apresentado funcionou bem, e aparece como candidato a ser utilizado em sistemas de geração de energia elétrica. Estudos específicos e aprofundados devem ser realizados para confirmar sua eficiência e aplicabilidade, mas o GRC com a malha de controle fuzzy proposta, mostrou-se bastante promissor.

Para continuidade deste trabalho sugere-se explorar a bancada de testes desenvolvida. Assim, frentes de pesquisas voltadas para conexão do sistema proposto com a rede elétrica tornam-se bastante interessantes, pois, ao se ter um barramento CC estável, uma série de investigações podem ser lançadas para simplificação de conversores de potência, abrangendo desde o tradicional inversor PWM, conversores Multiníveis, ou até a concepção de uma nova topologia especifica para este objetivo. 


\section{Referências bibliográficas}

ABBASIAN, M.; FAHIMI, B.; MOALLEM, M., "High torque double-stator switched reluctance machine for electric vehicle propulsion," Vehicle Power and Propulsion Conference (VPPC), 2010 IEEE, vol., no., pp.1,5, 1-3 Sept. 2010

ANDRADE, D.A.; GOMES, L.C.; DIAS, R.J.; CABRAL, L.G.; SILVEIRA, A.W.F.V.; FLEURY, A.; BISSOCHI, C.A., "Comparative study between a Single-phase and a

Three-phase switched reluctance machine," Electric Machines \& Drives Conference (IEMDC), 2011 IEEE International, vol., no., pp.1391,1396, 15-18 May 2011

ANTHONY M., BARLETT P. L.(2009). Neural Network Learning - Theoretical Foundations, Cambridge University Press,

BALATHANDAYUTHAPANI, S.; FLEMING, F.; EDRINGTON, C.; EL-KHARASHI, E., "Impact of modifying the stator tooth tip on electromagnetic torque production for an 8/6 switched reluctance machine," Electric Machines \& Drives Conference (IEMDC), 2011 IEEE International, vol., no., pp.1386,1390, 15-18 May 2011

BERNARDELI, V. R., ANDRADE, D. A., SILVEIRA, A. W. F. V., GOMES L. C.,

VIAJANTE G. P., "Gerador a Relutância Variável no Modo Auto Excitado", Eletrônica de Potência - SOBRAEP, vol. 16, no. 4, pp 357-366, 2011.

BERNARDELI, V. R. "Controle de Conjugado em motores à Relutância Variável Multifásicos", Dissertação, Universidade Federal de Uberlândia, 2008, 84pp. 
BRAUER, H.J.; De DONCKER, R.W., "Thermal modeling of a high-speed switched reluctance machine with axial air-gap flow for vacuum cleaners," Power Electronics and Applications (EPE 2011), Proceedings of the 2011-14th European Conference on , vol., no., pp.1,10, Aug. 30 2011-Sept. 12011.

BILGIN, B.; RMADI, A.; KRISHNAMURTHY, M., " Design Considerations for Switched Reluctance Machines With a Higher number of Rotor Poles", IEEE Transactions on Industrial Electronics, vol. 59, no. 10, pp. 3745-3756, 2012.

CARDENAS, R., PEÑA, R., PEREZ, M., ASHER, G., CLARE, J., WHEELER, P. (2004), "Control system for grid generation of a switched reluctance generator driven by a variable speed wind turbine", Industrial Electronic Society, 2004, 30th Annual Conference of IEEE, Vol. 2, 2-6 nov. 2004, pp. 1879-1884.

CARDENAS, R.; PENA, R.; PEREZ, M.; CLARE, J.; ASHER, G.; WHEELER, P., "Control of a switched reluctance generator for variable-speed wind energy applications," Energy Conversion, IEEE Transactions on, vol.20, no.4, pp.781,791, Dec. 2005

COELHO, A., "Simulação, Projeto e Teste de um Gerador a Relutância Chaveado Trifásico 6 x 4", 2011. 148 f. Dissertação - Escola de Engenharia de São Carlos, Universidade de São Paulo, São Paulo.

COELHO, A.; OLIVEIRA, E. S L; SUETAKE, M.; AGUIAR, M.L., "Experimental performance comparison between singlephase and three-phase Swiched Reluctance Generator," Power Electronics Conference (COBEP), 2011 Brazilian , vol., no., pp.479,485, 11-15 Sept. 2011a

COSTA, R. S. "Análise, projeto e construção do motor monofásico a relutância chaveado: uma solução inteligente para cargas de potência fracionaria", Dissertação, Universidade Federal de Uberlandia - UFU, 2004, 154pp. 
CHEN, X.; ZHIQUAN, D.; PENG, J., "Fault tolerant switched reluctance machine for fuel pump drive in aircraft," Industrial Electronics and Applications, 2009. ICIEA 2009. 4th IEEE Conference on , vol., no., pp.2340,2344, 25-27 May 2009

DA SILVA, I. N., SPATTI D. H., FLAUZINO R. A. "Redes Neurais artificiais para engenharia e ciências aplicadas curso prático", Ed. Artliber, 2010.

DE ARAUJO PORTO HENRIQUES, L.O.; BARBOSA ROLIM, L.G.; ISSAMU SUEMITSU, W.; DENTE, J.A.; COSTA BRANCO, P.J., "Development and Experimental Tests of a Simple Neurofuzzy Learning Sensorless Approach for Switched Reluctance Motors," Power Electronics, IEEE Transactions on , vol.26, no.11, pp.3330,3344, Nov. 2011

FITZGERALD, A. E., KINGSLEY, JR. C., UMANS, S.D., "Electric machinery", McGraw-Hill Series in Electrical Engineering, 1990, 585 pp.

FLEMING, F.; AKAR, F.; EDRINGTON, C.S., "An optimal maximum torque per ampere strategy for switched reluctance machines," Transportation Electrification Conference and Expo (ITEC), 2012 IEEE , vol., no., pp.1,6, 18-20 June 2012

FLEURY,A., "Modelagem, Construção, Testes e Análise de Desempenho de um Gerador a Relutância Chaveado", Tese, Universidade Federal de Uberlândia, 2008, 205pp..

FLEURY, A., ANDRADE, D., SILVEIRA, A. W. F. V., RIBEIRO, F. S. L., COELHO, A., CABRAL, L. G., "Dependence of the switched reluctance generator output on the speed and the excitation voltage", 34th Annual Conference of IEEE Industrial Electronics - IECON 2008, 2008a.

FLEURY, A. ; ANDRADE, D. A. ; OliveiRA, E. S. L. ; FLEURY-NETO, G. A. C. ; OLIVEIRA, T. F. ; DIAS, R. J. ; SILVEIRA, A. W. F. V., "Study on an Alternative Converter Performance for Switched Reluctance Generator", The 34th Annual 
Conference of the IEEE Industrial Electronics Society - IECON'08, 2008b, Orlando.

FLEURY, A., DIAS, R. J., COELHO, A., OliveiRA, E. S. L., ANDRADE, D. A., SILVEIRA, A. W. F. V., "Gerador a Relutância Chaveado Para Energia Eólica" Conferência Internacional de Aplicações Industriais (INDUSCON), 2008b, Poços de Caldas.

FUJISHIRO, S., ISHIKAWA, K., KIKUCHI, S., "Design of outer-rotor-type multipolar switched reluctance motor for electric vehicle", Journal of Applied Physics, Volume 99, Apr 2006, pp. 08R324 - 08R324-3.

GREENHOUGH, P., "Switched Reluctance Variable Speed Drives - A Focus on Applications", Technology Mining - Papers and articles, pp. 107-110, Abr. 1996

HENRIQUES, L. O. A. P., "Implementação de Estratégia de Minimização de Oscilações e Remoção do Sensor de Posição Para Um Acionamento de Relutância Variável Usando Técnica Neuro-Fuzzy". Tese, Universidade Federal do Rio de Janeiro, 2004, 156pp..

JEBASEELI, E.A.E.; SUSITRA, D., "Performance analysis of various configurations of Switched Reluctance Machine for wind energy applications," Recent Advances in Space Technology Services and Climate Change (RSTSCC), 2010 , vol., no., pp.419,423, 13-15 Nov. 2010

JIANBO SUN; ZHE KUANG; HUANGYUAN WU; SHUANGHONG WANG; GUOYUN NING, "Implementation of a high-speed switched reluctance starter/generator system," Electrical Machines and Systems (ICEMS), 2011 International Conference on , vol., no., pp.1,5, 20-23 Aug. 2011

KOREBOINA, V.B.; VENKATESHA, L., "Modelling and simulation of Switched Reluctance generator control for Variable Speed Wind Energy Conversion 
Systems," Power Electronics, Drives and Energy Systems (PEDES), 2012 IEEE International Conference on , vol., no., pp.1,6, 16-19 Dec. 2012

KRISHNAN, R., "Switched reluctance motor drives", Industrial Electronic Series, 393 pp. 2001.

LECOINTE, J.P.; ROMARY, R.; BRUDNY, J. F; MCCLELLAND, M., "Analysis and active reduction of vibration and acoustic noise in the switched reluctance motor," Electric Power Applications, IEE Proceedings -, vol.151, no.6, pp. $725,733,7$ Nov. 2004

LIU XIANG; YI LINGZHI, "Optimization Output Voltage of SRG Wind Power Generation System," Power and Energy Engineering Conference (APPEEC), 2011 Asia-Pacific , vol., no., pp.1,4, 25-28 March 2011

MACMINN, S. R., JONES, W. D., A very high-speed switched-reluctance startergenerator for aircraft engine applications, Proceedings of the IEEE National Aerospace and Electronics Conference - NAECON, Volume 4, 1989, pp. 17581764.

MARTINS, W. F., "Controle fuzzy em tempo real aplicado ao sistema plataformaesfera". Dissertação, Instituto Militar de Engenharia, 2007, 112 pp.

MIKAIL, R.; SOZER, Y.; HUSAIN, I.; ISLAM, M.; SEBASTIAN, T., "Torque ripple minimization of switched reluctance machines through current profiling," Energy Conversion Congress and Exposition (ECCE), 2011 IEEE, vol., no., pp.3568,3574, 17-22 Sept. 2011

MILLER, T.J.E., "Electronic Control of Switched Reluctance Machines", Edited by T J E Miller, Newness Power Engineering Series, 2001, 272 pp.. 
MILLER, T.J.E., "Switched reluctance motors and their control", Magna Physics Publishing and Clarendon Press, 1993, 200 pp..

OLIVEIRA, E. S. L., “Projeto, Construção, Simulação, Implementação e Testes de um Gerador a Relutância Chaveado Monofásico", 2011, 139pp.. Mestrado Escola de Engenharia de São Carlos, Universidade de São Paulo, São Paulo.

OLIVEIRA, E. S L; COELHO, A.; SUETAKE, M.; AGUIAR, M.L., "Investigations on single-phase switched reluctance generator under variable speed operation," Power Electronics Conference (COBEP), 2011 Brazilian, vol., no., pp.300,305, 11-15 Sept. 2011a

OLIVEIRA, E. S. L., AGUIAR, M. L., COELHO, A., "Simulação de Um Sistema Completo de Gerador a Relutância Chaveado Monofásico em Ambiente Matlab", XVIII Congresso Brasileiro de Automática - CBA 2010, 2010.

OLIVEIRA, E. S. L., COELHO, A., AGUIAR, M. L., Gerador a relutância chaveado monofásico aplicado em sistema híbrido eólico-fotovoltaico descentralizado, 2010 IEEE/PES Transmission \& Distribution Latin America, São Paulo - SP, Brasil, 2010b.

OLIVEIRA, V. S., "Aplicação do método dos elementos finitos 3D na caracterização eletromagnética estática de motores de relutância variável com validação experimental', Tese, Universidade Federal do Ceará, 2013, 124pp.

POWELL, D.J.; JEWELL, G.W.; HOWE, D.; ATALLAH, K., "Rotor topologies for a switched-reluctance machine for the 'more-electric' aircraft engine," Electric Power Applications, IEE Proceedings - , vol.150, no.3, pp.311,318, May 2003

RUBA, M.; SZABO, L.; FODOREAN, D., "Design and analysis of low voltage high current SRM for small automotive applications," Power Electronics, Electrical 
Drives, Automation and Motion (SPEEDAM), 2012 International Symposium on , vol., no., pp.341,346, 20-22 June 2012

SILVEIRA, A. W. F. V, ANDRADE, D. A., GOMES, L. C., BISSOCHI JR., C. A., FLEURY, A., "Estratégia de Controle para o GRV Baseada na Variação do Ângulo de Magnetização" Conferência Internacional de Aplicações Industriais (INDUSCON), 2010, São Paulo.

SILVEIRA, A. W F V; ANDRADE, D.A.; FLEURY, A.; GOMES, L. C.; BISSOCHI, C.A.; Dias, R. J., "Voltage control in starter/generator SRM based systems," Energy Conversion Congress and Exposition, 2009. ECCE 2009. IEEE , vol., no., pp.2460,2465, 20-24 Sept. 2009

SKVARENINA, T. L., PEKAREK, S., WASYNCZUK, O., KRAUSE, P. C., THIBODEAUX, R. J., WEIMER, J., Simulation of a switched reluctance, more electric air craft power system using a graphical user interface, Proceedings of the $32^{\text {nd }}$ Intersociety Energy Conversion Engineering Conference, IECE, Volume 1, 27 de Julho - 1 Agosto, 1997, pp. 580-584.

SUETAKE, M.; DA SILVA, I.N.; GOEDTEL, A., "Embedded DSP-Based Compact Fuzzy System and Its Application for Induction-Mot $v / f$ Speed Control," Industrial Electronics, IEEE Transactions on , vol.58, no.3, pp.750,760, March 2011

TEIXEIRA, V. S. C. "Projeto de motores a relutância variável e ferramenta computacional para determinação das estáticas da máquina", Universidade Federal do Ceará - UFC, 2008, 165pp.

TORREY, D.A., "Switched reluctance generators and their control," Industrial Electronics, IEEE Transactions on , vol.49, no.1, pp.3,14, Feb 2002 
VAN TREEK, D.; MATUSCHEK, P.; BRAUER, H.J.; SCHOENEN, T.; De DONCKER, R.W., "An automatic identification of phase inductance for operation of switched reluctance machines without position sensor," Electric Machines and Drives Conference, 2009. IEMDC '09. IEEE International , vol., no., pp.1005,1009, 3-6 May 2009

VIAJANTE, G.P.; ANDRADE, D.A.; GOMES, L.C.; FREITAS, M.A.A.; BERNADELI, V.R.; SILVEIRA, A.W.F.V., "A voltage control strategy for Switched Reluctance Generator," Electric Machines \& Drives Conference (IEMDC), 2013 IEEE International , vol., no., pp.421,426, 12-15 May 2013

XIAOSHU ZAN; FANGNAN XIE, "Switched reluctance generator system based on single neuron adaptive PID controller," Advanced Mechatronic Systems (ICAMechS), 2011 International Conference on , vol., no., pp.123,127, 11-13 Aug. 